\title{
The Secret World of Women Bloggers: A Feminist Exploration of the Internet Diary Writing Practices of Canadian Women
}

\author{
by \\ Elvira M. Prior, B. A. \\ A thesis submitted to the Faculty of \\ Graduate Studies and Research in partial fulfillment \\ of the requirements for the degree of \\ Master of Arts \\ in Canadian Studies
}

The School of Canadian Studies

Carleton University

OTTAWA, Ontario

(c) 2005, Elvira M. Prior 


$\begin{array}{ll}\begin{array}{l}\text { Library and } \\ \text { Archives Canada }\end{array} & \begin{array}{l}\text { Bibliothèque et } \\ \text { Archives Canada }\end{array} \\ \begin{array}{l}\text { Published Heritage } \\ \text { Branch }\end{array} & \begin{array}{l}\text { Direction du } \\ \text { Patrimoine de l'édition }\end{array} \\ \begin{array}{l}\text { 395 Wellington Street } \\ \text { Ottawa ON K1A ON4 }\end{array} & \begin{array}{l}\text { 395, rue Wellington } \\ \text { Ottawa ON K1A ON4 } \\ \text { Canada }\end{array}\end{array}$

Your file Votre référence

ISBN: 0-494-00725-7

Our file Notre référence

ISBN: 0-494-00725-7

NOTICE:

The author has granted a nonexclusive license allowing Library and Archives Canada to reproduce, publish, archive, preserve, conserve, communicate to the public by telecommunication or on the Internet, loan, distribute and sell theses worldwide, for commercial or noncommercial purposes, in microform, paper, electronic and/or any other formats.

The author retains copyright ownership and moral rights in this thesis. Neither the thesis nor substantial extracts from it may be printed or otherwise reproduced without the author's permission.
AVIS:

L'auteur a accordé une licence non exclusive permettant à la Bibliothèque et Archives Canada de reproduire, publier, archiver, sauvegarder, conserver, transmettre au public par télécommunication ou par l'Internet, prêter, distribuer et vendre des thèses partout dans le monde, à des fins commerciales ou autres, sur support microforme, papier, électronique et/ou autres formats.

L'auteur conserve la propriété du droit d'auteur et des droits moraux qui protège cette thèse. $\mathrm{Ni}$ la thèse ni des extraits substantiels de celle-ci ne doivent être imprimés ou autrement reproduits sans son autorisation.
In compliance with the Canadian

Privacy Act some supporting forms may have been removed from this thesis.

While these forms may be included in the document page count, their removal does not represent any loss of content from the thesis.
Conformément à la loi canadienne sur la protection de la vie privée, quelques formulaires secondaires ont été enlevés de cette thèse.

Bien que ces formulaires aient inclus dans la pagination, il n'y aura aucun contenu manquant.

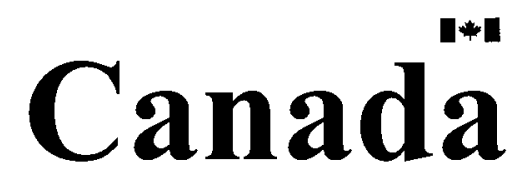




\begin{abstract}
This thesis presents a third wave feminist, interdisciplinary exploration of the secret world of Anglophone, Canadian women bloggers. The central question addressed herein is: what happens to key feminist constructs of activism, identity and community when they are transposed via the blog to an interactive, online space that is produced both for and by women? In order to answer this question, a general sample of sixty-two Canadian women bloggers was drawn from the online blog registry service, www.blogscanada.ca and examined. A case study on a smaller subset of this sample was also investigated. The findings of this study suggest that the blog represents a complex and often contradictory medium that enables some Canadian women to become active producers of their own social and cultural worlds. Although what they do in blog space may not always look 'feminist enough', their activities nonetheless represent a legitimate, creative and noteworthy form of feminist resistance and transformation.
\end{abstract}


Table of Contents

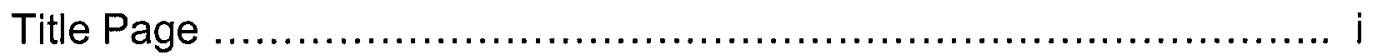

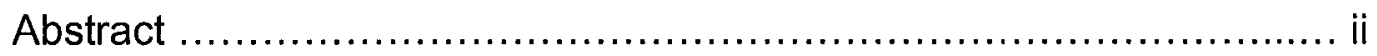

Table of Contents ... ....................................................... ii

Chapter One: Overview of the Issues.................................. 1

Chapter Two: Theoretical Considerations ….......................... 25

Chapter Three: Research Methodology and Observations ............... 49

Chapter Four: Analysis and Discussion: Understanding the Secret World of Canadian Women Bloggers.............................. 67

Chapter Five: Conclusions and Future Research....................129

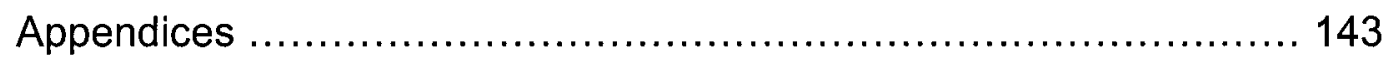

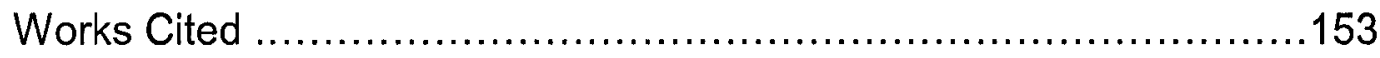




\section{Chapter One: Overview of the Issues}

And where the words of women are crying to be heard, we must each of us recognize our responsibility to seek those words out, to read them and share them and examine them in their pertinence to our lives.

\section{Introduction}

- Audre Lorde

Traditionally, the diary has been considered to be a private place-often guarded by a miniature lock and key-to which female persons retreat in order to record the secret details of their lives. Here, women write daily entries about excursions with bosom friends, confess their innermost feelings and tell tales of torrid love affairs. Every now and again, the diary of an important woman is unearthed and published. When this happens, the author's seemingly 'trivial' daily musings are reframed as being noteworthy historical artifact-a rich source of information just waiting to be mined by eager scholars. Whether written by ordinary or famous women, all of these words are important since it is here, within the diary, that complex patterns of social, cultural and historical articulations are woven and are just waiting to be read.

In the latter half of the twentieth century, feminist scholars have come to recognize the diary as being an important form of autobiographical life-writing (Bunkers and Huff, 1996; Culley 1985; Jelinek, 1986; Lejeune, 1996; Long, 1999; Smith, 1987; and Wylie, 1995). Apart from being a vital source of historical information, the diary has been viewed as "a therapeutic instrument for psychologists, a repository of information about social structures and 
relationships for sociologists, and a form of literature and composition for rhetoricians and literary scholars" (Bunkers and Huff 1).

The most recent development in the evolution of the diary comes not just because of the ways in which it is understood but also due to how, where and by whom it is produced. With the advent of new communication and information technologies (ICTs), a novel form of the diary has emerged on the digital horizon-known as the "blog."1 Similar to the traditional diary, the blog contains chronologically ordered accounts of everyday life. There are, however, three primary features that distinguish these two autobiographical forms. First, the blog is a public document broadcast over the Internet as opposed to a private journal written out in longhand and housed in a personal notebook. Second, the blog is an interactive communication forum through which participants can converse with one another rather than a private site of personal expression. Third, the blog is a hypertextual medium made up of a dynamic array of communication components (e.g., clickable links, interactive animations and instant messenger services) which break down linear narrative and facilitate new ways of engaging with the text and with one another. In this way, the boundaries of the blog blur as individual participants experience the text differently based on the particular paths they choose to follow and where they opt to post, as they navigate their way through the "blogosphere."

In this thesis, rather than frame the blog as being merely an online version of the traditional diary, I argue that the above differences fundamentally alter the diary form. As a result, I approach this investigation of the blog as a new, 
interactive medium through which a host of seemingly natural boundaries are disrupted. From public/private, mind/body, producer/consumer and author/reader, the deconstruction of these oppositional binaries ${ }^{3}$ opens up a multidimensional and overlapping array of discursive fields through which Canadian women can articulate and share their own unique, lived experiences. While my reading of the blog medium is very much centred around the notion of disruption, it should be noted that the vehicle through I have opted to explore this medium—namely a formal academic thesis—also functions to replicate and reinforce hierarchical pairings. For example, I occupy the privileged position of academic researcher which can be juxtaposed to that of the subject. This is power relationship in which I am able to construct meaning regarding the work these women do, that is both a product of and affected by my own personal experiences and biases. Since my presence as a researcher is not known to the women that I am studying, I also occupy the position of voyeur while they are relegated to that of the viewed. What all of this suggests, is that the blog is in fact a complex and contradictory space. It disrupts, destabilizes and can even reinforce categories of meaning. It also facilitates women's cultural production, and in the process of its production, facilitates the development of supportive, online female-centred communities. It enables participants to transcend place, overcome temporal constraints, register difference and experiment with identity construction. My interest here is to explore not only the blog's ability to facilitate the creation of new discursive fields, but also to assess how its authors are bound by or transgress normative cultural constraints associated with gender. 
The purpose of this thesis, therefore, is to explore and thus render visible the secret world of Anglophone, Canadian women bloggers. The use of the secrecy allusion in the title of this thesis is intentional and ironic in that women often write their blogs using pseudonyms that function to obscure their identities while at the same time render their thoughts, feelings, and experiences visible. The central question addressed herein is: what happens to key feminist constructs of activism, identity, and community when they are transposed via the blog to an interactive, online space that is produced both for and by women? In the undertaking of this study, I construct a theoretical framework for my research drawing from a number of disciplinary locations including women's studies, cultural studies, sociology, communication and technology.

Moreover, in exploring issues of activism, identity and community, I examine the blog by employing a third wave feminist lens. This perspective is useful in that it places emphasis on alternative, Do-It-Yourself (DIY) activist practices such as blogging, in which diversity, contradiction and disruption figure prominently. While the contemporary Canadian women's movement is grounded predominately in second wave feminist ideology, third wave feminism is an emerging feminist movement that represents contested terrain. As such, I am also interested in exploring generational tension as it pertains to women and blogging. Although second and third wave feminism are frequently defined as being distinct and in some instances oppositional entities, I argue that this division is not only inaccurate but is also counterproductive to the feminist project. In general, the main difference between second and third wave feminism 
are the ways in which each group engage in activist practices. By constructing impermeable or irresolvable barriers between generations, it obscures the fact that many key issues ${ }^{4}$ addressed by each group are similar and it conveys the misleading notion that fragmentation has occurred within the contemporary women's movement. In order to illustrate some of the continuities that exists across the waves, in Chapter Two I examine the blog medium in relation to the second wave consciousness-raising (CR) groups of the late 1960s and 1970s. In doing so, what becomes visible is that the blog not only provides women with an alternative, interactive space in which to engage in life writing and resistance activities but also functions as an important and necessary bridge between feminist waves.

\section{Women, Diary Writing and the Blog}

Before elaborating on the blog, a brief introduction to the traditional diary is in order since the two are connected. Although the diary was once marginalized and overlooked site of expression for women, a substantial body of literature has emerged over the past thirty years which places value on the study of women's diaries and their life-writing practices (Anderson, 1997; Brodzkie and Schenck, 1988; Broughton and Anderson, 1997; Bunkers, 2001; Bunkers and Huff, 1996; Buss, 1993; Carter, 2002; Culley 1985; Hogan 1991; Jelinek, 1986; Lejeune, 1996; Long, 1999; Smith,1987; Stanton, 1987; and Wylie, 1995). What all of these scholars have in common is that they consider the diary to be an important source of information about the lives of individual authors, as well as a rich source of social, historical and cultural information associated with the time 
period in which an author lived. Unfortunately, prior to the nineteenth century, only a small number of upper-class Caucasian women in Western culture could read and write, which meant that only a limited number of female authored diaries were produced by a predominantly homogeneous group of privileged women. Furthermore, even when a woman did maintain a diary, there was no guarantee that it would survive or that she had any interest in having her private life writing later made public.

The paucity of literate women in that era is connected directly to the fact that society "has attempted to order itself around a gendered division into private and public spheres, privileging the voices of the public male and, in turn, silencing, or at best limiting to the private, the female voice" (Coleman 1). By reinforcing cultural norms, values and mores, as well as creating laws that either prohibited or discouraged women from obtaining an education, financial independence, reproductive autonomy or general rights as persons, it ensured that women's experiences went unnoticed, unappreciated and for the most part, unrecorded. In the late eighteenth and into the nineteenth century, Lisa DiCaprio and Merry Wiesner contend that more female authors emerged due to an increase in literacy among women brought about by "political revolutions, industrialization, feminist movements, and the expansion of education [which] created unprecedented opportunities for women to shape and record their lives"(8). ${ }^{5}$ By the end of the twentieth century, women's life writing was now understood as being an important site of expression. According to Trev Lynn Broughton and Linda Anderson, feminist scholars of autobiography "carved out a 
space for critical discussion of women's self representation by celebrating the non-autonomous, other-directed, and communal female selves they encountered in a range of ignominiously neglected works" (97).

Although locating and rendering visible female-authored texts represents part of the equation, understanding women's life writing also requires being able to read the 'gender code' associated with the particular culture from which a text emanates. Judy Long asserts that:

[W]hen women think and write reflexively, societal images and stereotypes of women are present in their minds. Women are surrounded by thirdperson definitions of who they are, cultural prescriptions that are transmitted in oral tradition and private writing as well as written and published work. (Long 8).

While I do not disagree with this statement, framing women's life writing exclusively in terms of being the end result or product of prescriptive gender norms does not leave room for theorizing the diary as an active site of cultural production through which resistance and transformation is possible. I contend that there is more of a reciprocal relationship present, particularly with regard to diaries that enter the public sphere. Here, cultural norms are not only reflected in women's life writing but when the diary becomes public, as is the case with the blog, authors are able to alter the cultural landscape through their own individual acts of cultural production.

Diary writing is also very much about understanding 'the daily'. Judy Long suggests that women's life writing: 
reflects the episodic experiences of work and relationships, the lack of closure, and the nonlinear experience of time that characterize women's daily life. It records the interruptions, the 'emotional work' that women do, the psychological and emotional insights that animate their practices of 'relationship work.' Above all, it records and asserts the value of the repetitive work that women do" (Long 4).

Women's autobiographical narrative, therefore, takes on new significance when thought of in terms of women's life rhythms, that both blend into and echo the segmentation of their lives. It may well be, therefore, that blogging has become a popular activity among Canadian women precisely because it matches the rhythms of women's lives and fits easily into a busy schedule since a blog post can be made quickly, at any time throughout the day.

With regard to the issue of secrecy, Betty Jane Wylie contends that reticence represents part of the diary writing experience whereby women life writers hide, lock away or encode their work so as to prevent others from gaining access to their words (Wylie 26). According to Wylie, in some instances, "diarists in their later years report pulling out and burning pages or recopying them" (Wylie 26). In the blog world, rather than destroy diary pages, authors can alter, copy or erase their entries. As Laurie McNeil observes:

Reading online diaries can be a frustrating and discomforting experience for a reader-and a researcher-accustomed to published print materials. In an online diary, I do not know what will come next, and I cannot jump to the last entry or glean the final outcome from the summary provided by the 
book jacket; I may even find one day that the diary has disappeared entirely. Since online diaries incorporate the familiar alongside the strange, they are unsettling narrative territory—uncharted, with the potential for both thrills and peril for writers and readers. (44) In the course of writing this thesis, some of the blogs in my sample were deleted from the Internet midway through the research process. I explore this point more fully in Chapter Three.

Moreover, as a public, digital medium, just as the a blog author is able to quickly and easily manipulate her content, anyone else with access to the Internet can copy, alter and re-post her work elsewhere. The fact that a blog author's work can be manipulated without an author's knowledge or consent raises a number of ethical and copyright issues. For example, does the author retain ownership of her content once it has been broadcast online? If a blog author posts via an online commercial service such as www.blogger.com, what rights does she have over her content, where it is reproduced and under what circumstances? When author content, either in the form of images or text, is downloaded to another computer ${ }^{6}$ without the author's knowledge, does this represent an ethical or copyright infringement? Although all of these questions are important, they fall outside of the scope of this particular project. Future research could address the issue of blog ethics and copyright.

The final point to be made with regard to understanding the diary form relates to autobiography as activism. Margo Perkins notes: 
As resistance literature, their narratives invite readers to interrogate hegemonic ways of knowing and understating. Writing autobiography is a way for them to document their experiences, to give voice to the voiceless, to amend the historical record, and to expose repressive tactics of the state. (149)

Although Perkins' statement was written with regard to the American Black Power Movement of the 1960s, and focuses specifically on the autobiographical work of Angela Davis, Assata Shakur and Elaine Brown, her words nonetheless are useful when considering female authors and the blog medium. Perkins adds that 'activists' texts give voice to oppositional or counterhegemonic ways of knowing that repeatedly invite readers to challenge their own assumptions and level of comfort with the status quo" (Perkins xii). Providing one has access to the Internet and is computer literate, therefore, that person can become an activist author-a role that is taken quite seriously by third wave feminists who produce online resistance literature-from ezines, to Web sites and, of course, blogs.

Likewise, in discussing the work of Annie Dillard, Cherrie Moraga, Jo Spence, Helene Cixous, Gloria Anzaldua, and Donna Haraway, Sidonie Smith states:

Influenced by modernist, postmodernist, and postcolonial theories and by increasingly sophisticated interrogations of a multitude of differences, these women use autobiography as one prominent ground for cultural critique and resistance. While negotiating various identifications (of 
gender, race, class, ethnicity, sexuality), they discover points of resistance to the integumentary strains of provided subjectivities. Their contradictory and fluid subject position leads them to intervene in those cultural fictions, interrogating, cannibalizing, rereading the stories to their own purposes. (Smith 63)

Smith argues that these authors use the autobiographical form to challenge and disrupt dominant discourses surrounding subjectivity, identity and the body (63). As an autobiographical medium, the blog also carries with it the same potential, particularly since it is also a public site of expression. How the blog is used, to what end, and by whom, however, is another question. The point to be garnered in this, is that the blog technology itself, while imbued with specific characteristics, can be used to disseminate a wide array of information. Thus, some women-authored blogs can be read as resistance literature, while others represent more ambiguous forms of feminist activism.

\section{Women and the Mass Media}

Although blog content can be understood as being resistance literature, the significance of this writing becomes even more visible when it is considered within the context of women's experience of the mass media. In order to better understand the blog and how it operates in relation to normative cultural constraints associated with gender, this section provides a brief introduction to Canadian women and their relationship to the mass media, both with regard to gaining access to the means of media production and in relation to the types of limited, stereotypical representations that permeate the mainstream media. 
As primary agents of socialization, the mass media play a pivotal role in the creation and dissemination of Canadian culture. According to Michèle Martin, "most of our knowledge of the world comes to us either directly through the media, or through someone who uses them" (Martin, Communication 1). She contends that this would not pose such a problem if the messages conveyed by the mass media presented accurate, value-free depictions of reality. Martin argues that they are not neutral, adding that "every medium communicates certain values, beliefs, myths or prejudices, that are founded either in the economic conditions, or political and ideological tendencies they support" (Martin, Communication 1). Thus, women's experiences within Canadian society are affected by messages conveyed via the mass media. This is problematic since women have experienced difficulty in gaining access to the means of media production and are, therefore, less likely to occupy positions of power in which they can affect what content is produced.

Martin states, "Men and women are not equally represented in the economic and political spheres of the media. Whereas women are generally excluded from positions of power, they make up a large segment of those employed in subordinate jobs" (Martin, Communication 98). What is even more disturbing is that even when lower-level media positions are taken into consideration, Canadian women are still underrepresented in this sector. For example, in the 1990 s, women accounted for $28 \%$ of journalistic staff employed in the daily Canadian newspaper business_an increase of only $7 \%$ since 1974 and received approximately 71 to 78 cents for every male dollar earned 
(Robinson and Saint-Jean 20). These findings also support Martin's claim that women are excluded from higher level media positions, as $11 \%$ of female Canadian newspaper professionals held senior level newspaper position of editor-in-chief, an increase of only $1 \%$ since 1974 (10).

The problems that Canadian women face with regard to the mass media do not just revolve around their under-representation as media producers but also relate to the ways in which women are portrayed by the media. Over the past thirty years or so, much research has been generated on the depiction of women and the portrayal of female stereotypes in the mass media ${ }^{7}$ (Friedan, 1963; Gerbner, 1993; Graydon, 1995; Kilbourne, 1992; Signorielli, 1985; Tuchman, 1979; and Valiquette, 1993). If these media representations of women are to be read exclusively, Shari Graydon contends that one would be forced to conclude:

[Women represent] about 30 percent of the population and are uniformly beautiful, obsessively thin, surgically reconstructed, and scantily dressed objects of male sexual desire. They derive pleasure primarily form clean dishes and being dominated by men. Furthermore, they conveniently die off before reaching middle age, no doubt in order to avoid the mortification of gray hair, wrinkles, and cellulite. (143)

What makes the blog so interesting, therefore, is that it disrupts this maledominated, mass media stronghold by providing female authors with access to and control over a novel broadcast medium. This raises a number of interesting questions, which are addressed in Chapters Three and Four. For example, when 
Canadian women gain control over the production of their own content, what do they write about and how do they choose to portray themselves? Are they more likely to create content that perpetuates and reinforces mass media stereotypes, or do they take this opportunity to expand, empower and challenge the status quo? According to the Media Awareness Network, ethnic and visible minorities are under-represented in the Canadian media despite the fact that " 15 per cent of the population are immigrants and visible minorities comprise 25 to 51 per cent of the larger urban centres". ${ }^{8}$ Since anyone, in theory, can become a blog producer provided they have access to the Internet, are blog authors more representative of Canada's multicultural population?

\section{Anatomy of the Blog}

In order to gain greater insight into how this novel broadcast medium is used by women, this section describes what a blog is and provides a discussion of its history and present popularity. On the surface, the blog can be thought of as being an online diary. According to www.blogger.com, "the content and purpose of blogs varies greatly-from links and commentary about other web sites, to news about a company/person/idea, to diaries, photos, poetry, miniessays, project updates, even fiction." As entries are added to the blog, they are automatically date-stamped and usually displayed in reverse chronological order, placing the most recent entries at the top of the page (see Appendix A).

In general, there is one author who is responsible for creating a blog site and generating its content. Occasionally a blog will be co-authored by a number of other participants. When this occurs, a primary author sets up the blog and 
provides a group of users with access to a password protected posting area. When a group member publishes an article, her name is displayed in conjunction with her post, enabling the blog's readership to distinguish between authors.

Although early forms of the blog arose during the mid 1990s, host sites catering specifically to the blogging community did not emerge until roughly 1999 when Pyra Labs ${ }^{9}$, LiveJournal ${ }^{10}$ and Diaryland ${ }^{11}$ came online. These companies provide free and subscription-based access to user-friendly blogging tools that allow participants to quickly and easily create and maintain blog sites. The use of a commercial service also means that an author does not need to have any specialized knowledge of domain name registration procedures ${ }^{12}$ or HTML coding ${ }^{13}$ in order to produce her blog. In essence, these services provide simple Web content management systems that can be accessed conveniently from any Internet-enabled computer in the world. They are also usually quite flexible in providing more advanced users with the ability to enhance their blog spaces using HTML or java scripting.

\section{Origins of the Blog}

The blog is closely related to first generation personal homepages, which emerged on the Internet in the early to mid 1990s. These sites were predominantly text-based ${ }^{14}$ and housed content associated with subjects of interest to their respective authors, corresponding resource lists and limited information about the author. In general, the primary goal of the first generation homepage was to disseminate impersonal, topic-based information, as opposed 
to the blog, which is structured around the sharing of personal experiences and opinions.

As the decade progressed and Web browser technology advanced, second generation homepages emerged in the mid 1990s. Now able to support images that could be viewed inline (i.e., within the Web page itself), homepage creators began to experiment with more elaborate page layouts. At this time, the type of content that was online shifted as more individuals from a greater variety of backgrounds gained access to the Internet. ${ }^{15}$ Of particular relevance to this study is the fact that during the early to mid 1990s, the majority of those who were online, and thus had the potential to produce personal homepages, were male. As Arnold and Miller note, in 1995 "few [home]pages were authored by women, and few women had pictures of themselves on their pages" (1). According to their research, however, by "1998, the proportion of women who had personal home pages had increased enormously (though they were still outnumbered by men's pages by about two to one)" (1).

Some of the second generation homepages were quite similar to the contemporary blog. An excellent example of an early female-authored homepage that resembled a blog was produced in 1996 by Christina Craft, a Canadian Web author and journalist. Among other personal details, Craft published transcripts from her teenaged print diary under the title, The Totally True Diaries of an 80 s Barrie Queen. ${ }^{16}$ These entries were of a tongue-in-cheek nature and detailed various teen escapades including personal confessions regarding adolescent infatuations, in addition to satirical biographies and 
accompanying photographs of the 'characters' involved. Although Craft's homepage featured a digital version of her old print diary, it differed from a blog in that it was not updated frequently and did not contain an unfolding life narrative.

Another key distinction between the blog and the homepage relates to the ease with which pages can be produced. In order to create a homepage, particularly during the early to mid 1990s, publishers had to be familiar with UNIX (i.e., a complex command line prompt operating system) and able to code in HTML (i.e., Hypertext Markup Language). In contrast, contemporary blog creators can either manually code their sites or use commercial hosting services such as www.blogger.com or www.livejournal.com, which do not require any knowledge of how to code HTML. The ease of publishing that results from the use of these commercial sites may help to explain why we are now witnessing an explosion of blogs on the Internet.

With regard to contemporary personal homepages, these sites are even more closely linked to the blog than were their forerunners. In some instances, these homepages are now used to house blogs; at other times, they serve as blog companion sites in which authors post additional information about themselves and various topics of interest. Across both forms, the content that is published generally is a mix of original documents, images and a collection of remediated content taken from other sources. Daniel Chandler aptly points out that the process of constructing a homepage centres around the notion of 'bricolage, ${ }^{17}$ where, "the virtual and digital nature of the Web as a medium 
supports the re-use in bricolage of existing materials since the model may be abstracted limitlessly whilst remaining untouched in the site where the bricoleur found it" (1). The analogy of bricolage is well-suited to describe part of what transpires in blog space since blog components-words, images, sounds and even the underlying HTML code-may be reclaimed, reworked or reconstituted by the blog author.

\section{How Big is the Blogosphere?}

Establishing the size of the blogosphere is a difficult task given the nature of the Internet itself. As an interconnected 'network of networks', the Internet has no single exhaustive index that details all existing blogs. Commercial search engines and directory sites such as www.google.com or www.yahoo.com are the most common means used to locate blogs but these services cannot provide accurate measures of the blogging population. What they can do, however, is provide a general measure of the degree of mainstream interest that exists with regard to the blogging phenomenon. For example, in February 2004, a search on the word "blogs" at www.yahoo.com returned 9,920,000 entries. Likewise, a search during the same period on www.google.com yielded a result of $5,920,000$ entries. When the search criteria were refined to "women" and "blogs" and "Canada" 188,000 entries were found on www.yahoo.com and 78,400 entries on www.google.com.

When considering these numbers, it is important to remember that they are generated by search sites using two separate methods. Either individuals must register their Web page or blog with the service or wait for their site to be 
spidered ${ }^{18}$ by the search engine. In either case, this means that not all blogs are listed in their indices. Furthermore, these specific search results do not just reflect the number of indexed blogs that are registered but also include other online documents, such as newsgroup posts, Web sites and online newspaper articles that contain references to blogs.

Another method of estimating the size of the blogosphere is to examine the number of users who have registered with commercial blog hosting sites. For example, in January 2003-only four years after its public launch— www.blogger.com's subscription base passed the one million mark. Blogcount ${ }^{19}$ examined a number of top commercial hosting sites and concluded that, as of June 2003 , there were approximately 2.4 to 2.9 million blogs online. Likewise, in 2004, Perseus Development Corporation examined blog activity across eight leading commercial hosting sites in order to gain insight into both the size and behavioural patterns of the blogging population. They found that while an estimated 4.12 million blogs had been created, 2.72 million of these had a publishing duration of less than two months and 1.09 million blogs were abandoned after only one entry was made.

Although helpful, the surveys conducted by Blogcount and Perseus do not take into account blogs that are housed on individual Web sites under personal domain names. A more complete picture is offered by Blogcensus.net, ${ }^{20}$ which uses software to search the Internet for blogs that are housed on both commercial and non-commercial sites. As of February 2003, they estimate that there were $1,153,539$ active blogs on the Internet. What all these figures 
illustrate is that the blog phenomenon represents a very popular form of online activity - so much so that in Canada, even the Prime Minister now maintains a blog! 21

In order to become a blogger, one must first gain access to and feel comfortable using the Internet. Despite concerted effort on behalf of the Canadian federal government to increase Internet participation rates, ${ }^{22}$ in 2001 only about half of all Canadians (i.e., $53.8 \%$ ) were online (Statistics Canada, Access 7). With regard to Canadian women specifically, in 1994 only $14 \%$ had access to the Internet compared to $50 \%$ by the year 2000 (Dryburgh 2). When these figures are broken down across age, an estimated $83.4 \%$ of all Canadian women under 24 years of age are online, in comparison to only $14.8 \%$ of women over the age of 55 (Statistics Canada, Overview 7).

Although these statistics present general information as to who is online, they do not provide a definitive picture as to who exactly engages in blogging. What these figures suggest, however, is that the female blogging population in Canada is likely composed of young women. Part of the research associated with this thesis, therefore, seeks to flesh out some of the demographic characteristics associated with Canadian women bloggers. Who exactly are these women and why do they write blogs? Are there any particular characteristics that they have in common with one another?

With regard to women's participation in the world of blogging, this activity does not just represent an isolated practice among a small, homogenous group of Canadian women. Rather, it is an activity that is rapidly growing in popularity 
on an international scale, ${ }^{23}$ and which is intimately tied to the development of the 'Information Age' and to the emergence of a knowledge-based, global economy. To put things into perspective, in 2003 it was estimated that women authored $2,310,000$ or $56 \%$ of all blogs housed on commercial hosting sites. ${ }^{24}$ This figure does not take into account the number of female-authored blogs that are maintained on personal Web sites, nor does it account for female blog participants who may read and post to blogs on a regular basis but who do not maintain their own individual sites.

\section{Feminist Scholarship on Gender and ICTs}

Over the past decade and a half, issues associated with gender and access to information and communication technologies (ICTs) have come to represent a central area of investigation for feminist media scholars. Accordingly, much research has been generated with regard to barriers women experience gaining access to and participating in the world of ICTs (Balka 1997; Harcourt, 1999; Reddick et al., 2000; Rideout, 2000; Shade, 1999; Shade 2002a; and Sutton and Pollock, 1997). These studies stress the need to correct this disparity, given that we are now in the midst of an information revolution that is fundamentally altering the way in which our society is organized. As Dale Spender suggests:

the computer is not a toy; it is the site of wealth, power and influence, now and in the future. Women... cannot afford to be marginalised or excluded from this new medium. To do so will be to risk becoming the informationpoor. It will be to not count; to be locked out of full participation in society 
in the same way that illiterate people have been disenfranchised in a print world. (xvi)

Spender's statement encapsulates nicely the concerns that underlie much of the feminist access literature; that is, in order to ensure that women do not become further marginalized in a knowledge-based economy, they must gain access to and competency in ICTs. Since the blog represents an ICT in which women appear to be actively engaged, developing insight into why this is the case could prove helpful in developing women's increased ICT participation.

Leslie Regan Shade and Barbara Crow suggest that there are five major contemporary themes that Canadian feminist media scholars have investigated including computer mediated communication as gendered space and language; the new economy; everyday uses; advocacy and activism; and relations of technology and art (Shade and Crow 163). They state:

This research has followed a familiar feminist trajectory of intervention in the disciplines, from trying to fit women into existing research paradigms to more fundamental challenges to the conceptualization of technology through the lens of gender. Moreover, many of these themes overlap and engage with one another reflecting its interdisciplinarity. (163)

Within these five categories, the range of feminist work generated is quite impressive. For example, some studies examine issues pertaining to women and online consumer culture (Martin, 2001; Medhurst, 2000; Meehan and Riordan, 2001; Shade, 2002b). With regard to activism, feminists have investigated a range of ways in which women engage in acts of resistance and 
transformation (Harcourt, 2002; Korenman, 1999; Meekosha, 2002; Ollivier, and Robbins, 1999; Sutton and Pollock, 2000; Sutton and Pollack 2003; Scott, 2001; and Scott-Dixon, 1999). Examples of this work focus on topics which range from how survivors of breast cancer use the Internet as a social support space (Fogel et al, 2002; Winzelberg, Andrew J. et al 2003; and Lieberman et. al, 2003) to the ways in which third wave feminists engage in activist practices through the creation of e-zines or political based Web sites (Chandler, 2003; Scott-Dixon 1999). Studies also centre around online virtual communities (Addison and Hilligoss, 2001; Kaplan and Farrell, 1994; King and Hyman, 1999; Koerber, 2001; Roberts and Parks, 2001; Travers, 2000; Turkle, 1995; Ward 1999); online harassment and cyberstalking (Adam 2001; Herring 1999; Hughes, 1999; and Spender, 1996); and even extend to topics such as Internet mail-order brides (Pehar, 2003).

While all of this research is important, a gap exists in the literature with regard to the blog medium. As Laurie McNeill aptly states, "despite having been a part of the World Wide Web since 1995, and despite the astonishing number of journals presently being written... Web diaries and blogs have received little academic attention" (26). In 2002, Torill Mortensen and Jill Walker wrote, "there is a considerable amount of popular writing on weblogs, but there is to date no published research on the topic, neither looking upon blogs as an aspect of digital culture, as a media phenomenon nor as a method or a publication tool for researchers" (252). At the time of writing this thesis in 2004, Mortensen and Walker's assertion still holds true. Of the very limited academic material that is 
available on the subject, none of it focuses exclusively on female-authored blogs (Kennedy, 2003; Kitzmann, 2003; McNeill, 2003; Mortensen and Walker, 2002; Sorapure, 2003 and Zalis, 2003). When emphasis is placed on female authors, however, these studies tend to compare blogging with other non-technology based autobiographical forms and are more likely to focus on the content an author produces as opposed to the process of its production or the social and cultural consequences that follow from this production (McNeill, 2003; Sorapure, 2003).

With regard to mainstream rather than scholarly treatments of the blog, in some instances the former draws on and reinforces stereotypes associated with the diary form. For example, in an Ottawa Citizen article entitled, "I think therefore I blog", Peter Darbyshire states, "A blog is an online cross between news and diary... Some blogs are nothing more than online diaries, others have become critical sources of information." ${ }^{25}$ What is interesting about this statement is that the author makes a distinction between something that is nothing more than a diary versus something that is a critical source of information. One of the underlying premises of this thesis is that femaleauthored blogs can always be understood as critical sources of informationwhether it be with regard to how women engage in feminist activist practices, how they negotiate issues of identity and body online, or how they participate in supportive, interactive, online communities. In this way, knowledge emanating from lived experience is valued. 


\section{The Present Study}

The present study addresses the gap that exists in the literature with regard to women and the blog medium by offering a feminist exploration into the secret world of Canadian women bloggers. A sample of sixty-two Canadian women bloggers is examined across an array of demographic and descriptive characteristics including age, physical location, education, ethnicity, sexual orientation, blog secrecy, ${ }^{26}$ type of blog service used (i.e., commercial or noncommercial) and the authors inclusion of photographs and biographical material. The general sample is further narrowed in order to analyze a smaller data set. Here, I select four long-term bloggers from the general sample and conduct a content analysis on their work, focusing primarily on three distinct dimensionsactivism, identity and community. I also examine their interaction patterns among other bloggers as indicated by their cross linking and cross posting behaviours.

\section{Chapter Outline}

Organizationally this work begins with a discussion of the conceptual framework that informs this research and writing. Chapter Two outlines the theoretical constructs that pertain to this study of female-authored blogs and the key concepts of activism, identity, and community. Chapter three introduces the methodological approach used in this study. It also provides a description of the subjects, presents a discussion of the findings and details the associated methodological challenges that arose during the course of this research. In Chapter Four, an analysis of the general sample and the case study is 
presented. Finally, in Chapter Five I conclude by demonstrating how the blog medium represents a complex, contradictory yet important space for enacting community activism and identity in the lives of a select group of Canadian women. The thesis illustrates how the blog extends well beyond being just a digital version of the traditional diary. The chapter concludes with a brief outline regarding future research. 
${ }_{1}$ Blogs are also known as Web-logs, weblogs, online journals and online diaries.

2 According to Microcontent News, the term "blogosphere" was coined by William Quick in 2002 and refers to "the shared intellectual space inhabited by bloggers. Also referred to as Blogland, Blogistan, and Blogspace ". See <http://www.microcontentnews.com/resources/glossary/ blogosphere.htm>.

${ }^{3}$ As Mary Klages states, "There are two key points to the idea of deconstruction. First is that we're still going to look at systems or structures, rather than at individual concrete practices, and that all systems or structures have a CENTER, the point of origin, the thing that created the system in the first place. Second is that all systems or structures are created of binary pairs or oppositions, of two terms placed in some sort of relation to each. Derrida says that such systems are always built of the basic units structuralism analyzes--the binary opposition or pair--and that within these systems one part of that binary pair is always more important than the other, that one term is "marked" as positive and the other as negative. Hence in the binary pair good/evil, good is what Western philosophy values, and evil is subordinated to good. Derrida argues that all binary pairs work this way--light/dark, masculine/feminine, right/left; in Western culture, the first term is always valued over the second. See Klages, Mary. Structuralism/Poststructuralism.

$<$ http://www. colorado.edu/ English/ENGL2012Klages/1derrida.htm 1>. For more information on the deconstruction of oppositional binaries, see Derrida, Jacques. Of Grammatology. Baltimore, Md : Johns Hopkins University Press, 1997.

${ }^{4}$ For example, some key feminist issues that are the same across generations are sexuality and reproductive rights, violence towards women, inequity within the family and inequity within the workplace.

${ }^{5}$ DiCaprio and Wiesner's reference to women's writing includes, "petitions, diaries, letters, articles, pamphlets, speeches, autobiographies, leaflets, and manifestoes" (8).

${ }^{6}$ It is important to note that whenever an individual surfs the Internet, copies of the pages she or he views are generally stored on her computer in the Web browser's cache folder. In this sense, every time a user surfs the Internet, potential ethical and copyright infringements may be occurring.

${ }^{7}$ Stereotypes are limited when they depict women predominantly occupying domestic and maternal roles. They are also limiting in that they affect how women conceptualize their roles within society. For more information see <http://wuw.mediaawareness.ca/english/issues/stereotyping/women and girls/index.cfm>. It is also important to note that stereotypes also have an adverse effect on men as well, however, their depictions tend to portray men in powerful positions as opposed to the subordinate associations that are linked to women. For a discussion on the impact of male stereotypes in the media, see $<$ http://www.media-awareness.ca/english/issues/stereotyping/men and masculinity/index.cfm >. ${ }^{8}$ For general information on Media Awareness Network see <http://www.media-awareness.cas. For reference material on ethnic and visible minorities see $<$ http:/hww.media-awareness.ca/english/issues/stereotyping/ethnics and minorities/index.cfm>. 9 Pyra Labs created www.blogger.com. See http://www.blogger.com/about/pyra.pyra.

${ }^{10}$ See http://www.livejournal.com/support/faqbrowse.bml?fagcat=about.

11 See http://diaryland.com/fag.html.

${ }^{12}$ Domain name registration can be a confusing process as it requires some knowledge about server names, IP (Internet Protocol) addresses and hosting services. If an author wants to create a blog that is housed on a personal homepage as opposed to a commercial site like blogger, she/he must go through the domain registration process and secure and coordinate server space with an ISP (Internet service provided).

${ }^{13}$ HTML is also known as Hypertext Markup Language and is the code that underlies all web pages, including blogs, regardless of what authoring application is used. 
${ }^{14}$ The first Web browsers such as WWW or Links did not support inline graphic images. Users could, however, use FTP servers to upload and download image, movie and sound files. This process was arduous, however, as file transfer speeds were very slow since they relied on dial-up modem connections to the Internet.

${ }^{15}$ During the early $1990 \mathrm{~s}$, few Internet Service Providers (ISPs) existed so most people online were connected in some way to either government or educational intuitions with direct access to the Internet. By the mid 1990s, the mass media had picked up on the notion of an 'Information Superhighway' and had begun to hype the Internet.

${ }^{16}$ Although this web page no longer exists, a review of its content can be found on http://www. brokenpencil.com/reviews/reviews. php?reviewid=689.

${ }^{17}$ In The Savage Mind (i.e., La Pensée Sauvage), Lévi-Strauss introduced the notion of the bricoleur versus the ingenieur. Here, the bricoleur engages in the process of reassembling or reconstructing that which already exists in order to create new forms while the ingenieur makes use of abstract systems such as language, logic and mathematics in her creative endeavours. See Lévi-Strauss, Claude. The Savage Mind. London: Weidenfeld \& Nicolson, 1974. According to Chandler, "the bricoleur works with signs, constructing new arrangements by adopting existing signifieds as signifiers and 'speaking' 'through the medium of things' - by the choices made from limited possibilities". See <http://www.aber.ac.uk/media/Documents/S4B/sem09.html>.

${ }^{18}$ According to www. searchengine.com, "To compile their databases, search engines rely on computer programs called "robots" or, more specifically, "spiders." These programs "crawl" across the web by following links from site to site and indexing each site they visit. Each search engine uses its own set of criteria to decide what to include in its database. For example, some search engines index each page in a web site, while others index only the main page." For more information see <http://www. searchengines.com/search engines $101 . \mathrm{htm} />$.

${ }^{19}$ This estimate is based on the reported number of registered users on www.blogger.com, www.livejournal.com and www.diaryland.com as well as domain registrations that incorporate the word 'blog'. See <http://dijest.com/bc/2003 0623 bc.htm|\#105638688729256217 >. ${ }^{20}$ See <http://www.blogcensus.net/>.

${ }^{21}$ The Right Honourable Paul Martin's blog can be found at $<$ http://www.paulmartintimes.ca/personal-paul/blogs e.asp>

${ }^{22}$ Part of "Canada's Innovation Strategy" geared towards increasing online participation includes the "Connecting Canadians" agenda . Officially launched in 1998, the primary goal of "Connecting Canadians" is to position Canada as a competitive leader in the global marketplace. This positioning is to be achieved by providing Canadian citizens with physical points of access to the Internet to encourage its use. According to McKeough, "the Government of Canada has made a commitment to make sure all Canadians have access to the Internet, regardless of where they live or the size of their income" (1). McKeough also states that "by being connected, Canadians are equipped with the information tools they need to succeed in the knowledge-based economy of today and tomorrow" (1). McKeough, Tim "Canada On-line - Facilitating Access and Building Infrastructure". Connecting Canadians, April 2000.

$<$ http://www.connect.gc.ca/en/ar/1003-e.asp>. For more information on "Connecting Canadians", see <http://www.connect.gc.ca/en/100-e.asp>.

${ }^{23}$ By using the term 'international', it should be noted that I am referring predominantly to industrialized nations that have a well-developed ICT infrastructure.

${ }^{24}$ These figures were taken from a survey conducted by Perseus Development Corp. in which 3,634 blogs on eight leading blog-hosting services were randomly surveyed. For more information see <http://www.perseus.com/blogsurvey/>. It is also important to note that people who use these commercial services could be located anywhere in the world, therefore, these figures do not represent Canadian blog statistics specifically but rather serve to illustrate the point that many women participate in this medium.

${ }^{25}$ Nov 2, 2003. pg. C. 10 
${ }^{26}$ If a blog did not contain the author's alleged full name, her geographical location and some form of personal contact information (e.g., a work or home mailing address, an e-mail address or a telephone number)-it was coded as a secret blog. 


\section{Chapter Two \\ Theoretical Considerations}

\section{Introduction}

This thesis presents a feminist exploration of the secret world of Canadian women bloggers and is grounded predominantly in third wave feminism. As such, this chapter provides an overview of the major tenets associated with the third wave that are relevant to the study of blogs, placing emphasis on three central feminist constructs-activism, identity and community. Since I am also interested in generational tension and the overlap that exists across the waves, I begin this chapter with a brief discussion of second wave feminism. In doing so, I highlight a number of feminist issues and debates that arose during 1960s and 1970s that are still relevant today. In order to further illustrate the interconnection between these generations, I compared the second wave feminist CR group to the blogging practices of contemporary Canadian women. Although many of the issues remain the same, what is different for third wave feminists is not only the context out of which issues arise but the novel ways in which they engage in feminist activism. The blog represents an excellent example of how changes in technology facilitate new and creative ways of addressing old problems.

\section{Second Wave Feminism}

Second wave feminism arose during the 1960 s when much social change was taking place. According to Roberta Hamilton, the women's movement began, in part, due to the discontent women experienced as marginalized 
participants in various social right movements such as "the civil rights movement, the student movement, the new left, the resurgence of the old left, the antinuclear and peace movement, the black power movement, and the anti-Vietnam War movement" (48). Although Hamilton contends that the "origins of discontent" for women were visible prior to the 1960s, she points out that organizational efforts did not really begin to gain momentum in Canada until the latter part of the decade as a result of the leadership of two central feminist activists_-Laura Sabia and Judy LaMarsh. ${ }^{1}$ Their combined lobbying efforts placed pressure on Prime Minister Lester B. Pearson to respond formally and publicly to women's concerns. As a result, in 1967 he appointed a Royal Commission on the Status of Women. According to Barbara Freeman, the function of this commission was to "listen to complaints and suggestions regarding the systemic legal, economic and social inequities that were making the lives of Canadian women difficult" (3). While the commission tabled a report in December 1970 that listed 167 recommendations (the bulk of which still have yet to be implemented), it can be argued that one of the positive byproducts of this effort related to the publicity the commission generated with regard to the issue of women's rights and their experiences of oppression. $^{2}$

As the women's movement continued to grow, various key issues came to the fore. For example, feminists explored sexuality and reproductive rights by lobbying for the decriminalization of abortion and birth control. In addition, feminists: 
exposed the double standard of sexuality through which men were applauded for 'sowing their wild oats' and women divided into 'whores' (more recently 'sluts') and 'virgins'. Critics insisted that women's sexual pleasure be a goal in itself, and some raised the argument that men were not necessarily the best sexual partners for women. (Hamilton 64)

Other issues included violence towards women, oppression within the family structure, gender equity within the workplace and making issues such as sexual harassment visible by naming them. One of the key aphorisms of the second wave was that "the personal is political." Although political and economic times have changed, many of these women's issues persist in slightly different forms and to varying degrees within contemporary Canadian society; many of these issues and concerns appear in women's blogs.

Indeed, my research on Canadian women bloggers demonstrates the overlap in concerns of women in both the second and third wave. For example, with regard to sexuality and reproductive rights, since abortion and obtaining birth control are no longer illegal activities, women bloggers do no write about the necessity of being able to access these services. Rather, they write about issues that pertain to new birth control technologies such as Depo Provera. Women bloggers also write about difficulties they experience within the family in relation to managing the roles of mother, partner and career person and of issues that pertain to violence against women. They also write about the inequities they experience in the workplace and society. A complete discussion on the content of women's blogs is presented in Chapter Four. 
In all of this, what is important to note, is that a connection exists across feminist generations as a result of shared issues of oppression with which all women must still contend. The main difference between second and third wave feminism, therefore, relates more to the methods or activist approaches taken by each generation as opposed to differences in their feminist agendas-the underlying goal for all being to end sexist oppression. ${ }^{3}$ Central to these differences is the development of technology. For example, while second wave feminists have adapted effectively to the Internet, their approach to its use reflects a structured, organizational method of engaging in feminist activism. In second wave feminist terms, what makes the Internet so powerful is that it functions as a communication tool that enables widespread, cost-effective dissemination of feminist material. PAR-L (i.e., Policy, Action, Research List/Liste politique, action, recherche), a moderated listserv that allows subscribers to post and review messages focused on Canadian feminist policy, research and activism, illustrates a second wave approach to using the Internet. In a moderated listserv, messages are delivered to subscribers via e-mail only after they are reviewed and approved by the list owners. As a moderated group, therefore, PAR-L represents a formal, hierarchal communication network in which very clear boundaries exist between what content is and is not permissible. Any post deemed inappropriate by the list owners will not be circulated throughout the network.

While using the Internet for the purposes of disseminating information represents an important component of all feminist endeavours, it does not take 
into consideration how the Internet can be used in other progressive, novel and personally empowering ways. When viewed through a third wave feminist lens, the Internet is revealed to be much more than just a digital communication tool; it is also a vast array of overlapping virtual spaces that can be inhabited and harnessed by women to bring about personal and social change. While third wavers may subscribe to and participate in forums such as PAR-L, they also occupy a myriad of other Internet spaces such as personal Web sites, Web rings, e-zines, chat areas, instant messengers, yahoo or msn groups and blogs. Likewise, some who associate themselves with second wave may explore the capabilities of the Internet beyond information dissemination. Thus there is an overlap between the waves which makes locating the "end" of one wave and the beginning of another a moot point. Since these online spaces are often informal and created by individual women, the type of content produced and the nature of the interaction that takes place among participants can differ significantly from that of second wave feminists.

\section{Third Wave Feminism}

As elusive and contested terrain, third wave feminism can be difficult to define because it represents "an active resistance to the imposition of labels, closures, boundaries, and categories" (Mitchell and Karaian 59). Allyson Mitchell and Lara Karaian also suggest that third wave is very much about extending and re-visioning the work of second wave feminists to fit with the current socioeconomic and political tides of the twenty-first century. In doing so, they contend 
that third wavers "push the boundaries of the second-wave mantra 'the personal is political'"(59).

Although the mantra may be the same, there are a number of factors that distinguish the waves. For example, second wave activist practices generally tend to be focused outward and are geared towards overcoming gender inequity by placing emphasis on structured, organizational change. In this formulation, change is brought about by either altering the system (e.g., lobbying for legislative reform) or by creating new systems (e.g., the development of women centred spaces such as women's co-operatives or women's centres). In contrast, third wave feminist activism includes participation in second wave efforts but also takes place on an individual level, whereby an individual actively alters the way in which she thinks about her position in the world by reframing and reclaiming cultural artifacts and practices. ${ }^{4}$

Another distinguishing factor associated with third wave feminism is its challenge of constructed categories of meaning. For example, third wave feminists reject the essentialist category of "woman" in which all female persons are thought to share a common experience of oppression based on their biological membership in a seemingly homogenous category. The irony here is that this approach to 'doing feminism' seems to undermine the very foundation upon which feminism is built. Third wave feminists, however, would contend that that by rejecting fixed, oppositional binaries like that of gender, more inclusive spaces open up in which identities can be expressed and realized. In keeping with this statement, Judith Butler suggests: 
If a stable notion of gender no longer proves to be the foundational premise of feminist politics, perhaps a new sort of feminist politics is now desirable to contest the very reifications of gender and identity, one that will take the variable construction of identity as both a methodological and normative prerequisite, if not a political goal. (5)

What emerges from a third wave feminist perspective, therefore, is an emphasis on diversity and intersectionality. Depending upon one's particular positioning within society (e.g., age, class, ethnicity, sexual orientation and able-bodiness), one's lived experience will vary greatly. Leslie Heywood and Jennifer Drake suggest that it is this inclusivity, coupled with its contradictory nature or "messiness," represents one of third wave feminism's main strengths and defining features:

Third Wave makes the inclusion of persons of various genders, sexualities, nationalities, and classes a top priority and combines elements of equity feminism and gender feminism in a grassroots feminism that still fights for equal access and equal pay for equal work but also seeks to transform the structures within which young women work.(8) Third wave feminism, therefore, can be understood as representing a progressive, alternative activist form-one in which diversity is celebrated and the inherent power structures associated with socially constructed categories of meaning are exposed and debunked. 


\section{Generational Tensions}

Another important aspect associated with third wave feminism is the generational tension that exists across the waves within the broader Canadian women's movement. For the most part, third wave feminists are more likely to have grown up during a time in which feminist ideology has, to greater or lesser degrees, formed part of mainstream cultural discourse. As a result, third wave feminism is often thought of and referred to as young feminism. ${ }^{6}$ In contrast, those who occupy positions of power or influence within the movement are more likely to be older and associated with second wave feminism.

One point to consider, when thinking about these feminist waves and their positioning within the Canadian women's movement, is that all social movements are constructed after the fact by those who occupy positions of power-either internally by movement leaders and/or externally through various social institutions such as the mass media or the educational system. These constructions attempt to capture the essence of a particular movement by identifying and grouping sets of seemingly similar events, activities and people together into tidy, compartmentalized components or dominant taxonomies. In doing so, however, these taxonomies carry political, social and economic consequences. With regard to the women's movement specifically, Donna Haraway suggests:

these taxonomies tend to remake feminist history so that it appears to be an ideological struggle among coherent types persisting over time, especially those typical units called radical, liberal, and socialist-feminism. 
Literally, all other feminisms are either incorporated or marginalized, usually by building an explicit ontology and epistemology. Taxonomies of feminism produce epistemologies to police deviation from official women's experience" (156).

By placing emphasis on the work of second wave feminists, those employing a third wave approach to 'doing feminism' are at risk of having their work go unnoticed, misunderstood or even dismissed as being irrelevant to feminism. This passage on dominant taxonomies, therefore, helps to explain why third wave efforts do not occupy a more central and visible role in the contemporary Canadian women's movement.

A concrete example of generational tension ${ }^{7}$ within the women's movement is offered by Candis Steenbergen. She points to the work of Germaine Greer, a high profile second wave feminist, who claims that young women offer nothing new to the women's movement. ${ }^{8}$ This assertion casts third wave efforts as being little more than feeble attempts at reinventing the wheel. "Essentially, Greer negated the struggles of young feminists with her own mainstream feminist privilege: the power to dictate feminist membership, the control over deciphering "good" feminism and "bad" feminism, and the ability to captivate a popular audience" (Steenbergen, Whose Generation 261)..$^{9}$ Many third wave feminists, however, do acknowledge the efforts of those who have come before and do not equate their work with a 'reinvention of the wheel' but rather view it as an extension or evolutionary development in feminist thought. For example, Leah Thompson notes that "although gains have been made in the 
past there are still many roads left to travel and young feminists have much to say... I want to learn from the past but I also want to explore the present" (138). Likewise, Miriam Johnson, a fifteen year old Canadian feminist writes:

Feminism to me is fully embracing your identity as a woman. It is being aware of the role your gender plays in society, and being willing to stand strong and fight for your team. We've come a long way in the last fifty, even twenty-five years, but cast your eyes over some issues again and you will see that there is still a long way to go. (253-254)

Part of the concern related to generational tension is that in order for the Canadian women's movement to survive and flourish, it must continue to attract, welcome and integrate successive generations of feminists. Generational tension, therefore, can function in a counterproductive manner by discouraging or alienating new or potential participants. Nancy Whittier cautions that while both intergenerational cooperation and conflict are expected byproducts of political generations, the longevity of a social movement is tied directly to its ability to integrate new participants. "I have come to believe that the question of how social movements endure is inseparable from the question of how they change" (Whittier 255). With regard to the women's movement, specifically, she adds: Conflicts among political generations in the women's movement are painful for all involved, and certainly detract from the effectiveness of feminist organizations. But the conflicts do not signify the degeneration of the movement, nor are they the result of aging or adolescent rebellion. Rather, they are an expected outcome of societal and movement change 
and grow from political generations' divergent experiences within and outside the women's movement" (Whittier 254).

The primary goal of the women's movement is to overcome the marginalization and oppression of all female persons within society, yet it too operates around a centre/margin model in which some experience disadvantage so that others can occupy positions of power and privilege. For third wavers, their experiences, ideas and efforts do not always receive the same weight or visibility awarded to established second wave feminists. This marginalization can become even more acute when resources are scarce-as has been traditionally the case with the Canadian women's movement. Candis Steenbergen comments:

Most young women with legitimate concerns and critiques of feminism and the women's movement have not lined bookstore shelves with massmarket bestsellers, done the talk-show circuit, nor made countless headlines. Instead, their voices appear in independently-produced zines, in book reviews hidden in the backs of journals, on walls and across public advertisement, in non-mainstream publications, and in other lessconspicuous (and less financially rewarding) spaces. (Still Kicking 9) Third wave marginalization is also further exacerbated due to the confusion brought about by the work of popular, mainstream postfeminist authors such as Katie Roiphe (1993), Rene Denfield (1992), Christina Hoff Sommers (1994) and Danielle Crittenden (1999). Within the Canadian context, Steenbergen adds Amy Friedman (1992), Kate Fillion (1995) and Donna 
LaFramboise (1996) to the list. The rhetoric espoused by these authors verges on being anti-feminist. As Steenbergen states:

[They] present the women's movement as the mastermind behind stringent sexual and moral codes, as the promoter of a villain-versusvictim mythology, and as antiquated protectors of 'political correctness'. Feminists (on the whole) are portrayed as anti-men, anti-sex and obsessed with notions of women as hapless victims. (Steenbergen, Whose Generation 259)

Steenbergen adds that part of what makes postfeminism so dangerous is that it has "chic, inoffensive, commercial qualities" (Whose Generation 260). The very mainstream nature of these pseudo-feminist representations can adversely affect the perceptions of how those within and outside of the Canadian women's movement view the work done by third wave feminists.

The inclination to clump all young women into the media-friendly, postfeminist category has been strong, leading many to assume that the next generation does in fact think the war's been won, that the sole pursuit of pleasure and possessions is paramount, and that feminism, in effect is passé. (Steenbergen, Still Kicking 9)

Despite this generational tension, third wavers continue to seek out and experiment with novel, creative and cost-effective ways to participate in feminist endeavours. 


\section{Central Feminist Constructs: Activism}

Third wave feminist activism is based on a 'Do-It-Yourself' (DIY) politic. This is a grassroots, media-based strategy that facilitates female empowerment, in part, through creative, political self-expression. Although these young feminists still engage in and employ a variety of second wave activist strategies, such as participation in women's marches, protests, women's centres, women's clinics, women's co-operatives and through the development and distribution of educational materials, they also have their own unique activist practices. Allyson Mitchell and Lara Karaian suggest that "young feminists use DIY cultural production tactics as a way to open up spaces where we can learn and challenge the hegemonic ideologies within our society" (Mitchell and Karaian 67). As is my contention in regard to the blog, through the process of becoming cultural producers in addition to cultural consumers, third wavers open up discursive fields through which they are able to articulate and share their own unique lived experiences. Some examples of alternative third wave forms of resistance include:

writing zines, publishing on-line ezines, contributing to magazines of the mainstream and alternative varieties, guerilla stickering, postering, graffiti writing, boycotting, critiquing both mass media generally and popular culture specifically, negotiating and re-negotiating relationships, contemplating the contradictions of sexuality, challenging paradigms, questioning dogma and resisting, resisting, resisting in their own 
innumerable private and public ways." (Steenbergen, Whose Generation 263)

By seeking out and creating new spaces, tools and techniques through which feminist resistance and transformation can occur, third wave feminists become active and empowered agents of cultural change.

\section{The Zine Medium}

Of particular interest in this thesis on women bloggers is the zine and its online counterpart, the e-zine,${ }^{10}$ both of which are similar to the blog in some respects. In general, the zine, e-zine and blog are all inexpensive, individually produced and self-promoted publications. ${ }^{11}$ Krista Scott-Dixon states "that many female creators [use zines] as a forum to respond to, critique and envision alternatives to the often sexist and misogynist mainstream media" (Revolution, 24). She adds that "the fact that ezines operate within a traditionally maledominated sphere, that of cyberspace, means that they also exist as a form of resistance" (Get On-line, 303). I contend that the very same statements can be made with regard to the blog. Further, Melanie Ferris points out that the most prevalent subject matter in zines relates to "sexuality, body image, politics, and feminism... [and] tend to deal with issues in a very confrontational, honest, and frank manner, an approach which may make some readers uncomfortable" (52). As is discussed further in Chapter Four, I contend that the same holds true with regard to the type of content found in many blogs and the way in which this content is presented by female blog authors. 
Ferris also indicates that "zines can serve as a way for feminists around the world to connect" (54). Krista Scott-Dixon concurs by suggesting that "the significance of ezines for feminist resistance lies mainly, but not exclusively, in the possibility for networking, connection, and community" (Ezines, 131). Again, the same can be said about blogs. What is different between these forms is that the blog is a dynamic publication comprised of brief, daily entries that reflect the author's lived experience and contain snippets of daily life. In contrast, zines and e-zines are published less frequently and generally contain brief articles, poems or stories about particular subjects. Furthermore, even though e-zines and blogs are both online publications, e-zines do not, as a rule, incorporate comment posting technologies that enable and encourage groups of individual authors, who maintain their own respective sites, to come together in conversation.

\section{Not Quite Activist Enough}

In their anthology, Leslie Heywood and Jennifer Drake state:

Third wave feminists often take cultural production and sexual politics as key sites of struggle, seeking to use desire and pleasure as well as anger to fuel struggles for justice. These forms of third wave activism don't always look "activist" enough to second wave feminists. (4).

This sentiment can be found running throughout much of the literature on the third wave feminism. In the Canadian third wave anthology entitled, Turbo 
Chicks: Talking Young Feminisms, on alternative approaches to activism, Lisa Bryn Rundle comments:

In my own life it hasn't been the marches that l've been to that felt the most political. It was things like telling my family I had a girlfriend. That took courage for me, and I think that type of action changes more about the way people think than walking topless down Yonge Street in the Dyke March does, which also takes courage. A lot of young women change the world just by being who they are in the world and challenging the ways others think and see them in it. (22-23)

As with other forms of third wave resistance, it may well be that part of the reason that very little academic research exists in regard to female authored blogs is that they represent a form of third wave activism that 'doesn't quite' look activist enough and thus has not attracted the attention of established scholars.

\section{First Person Narrative}

Another defining element of third wave feminist activism, which is also relevant to the study of blogs, is the predominance of first person narrative that runs throughout the bulk of this work. Allyson Mitchell and Lara Karaian point out that this "proliferation of autobiographical writing can be seen as a form of resistance to inaccessible writing. To some third-wavers it is a political tactic to write in a way that everyone can understand and be inspired or excited by" (65). They also suggest that writing in the first person positions female authors directly within the text as opposed to forwarding a seemingly objective position through the use of third person narrative. In the case of the blog specifically, it is not just 
the author who is positioned within the text but the reader as well. Through the process of posting comments, the reader is automatically integrated into the unfolding narrative. What this integration does is to break down the oppositional binary of author/reader in which author is privileged over reader. In this way, it is more useful to think about the blog medium as having participants who engage in varying degrees in both posting and reading behaviours.

\section{Continuities Across the Waves}

The links between the blog and more traditional forms of second wave feminist activist strategies provide a bridge between the waves. By examining some of the similarities between second wave and third wave activist practices, it is my hope that this will reduce some of the generational tension that exists within the contemporary Canadian woman's movement. One particularly useful connection can be drawn between the blog and the second wave consciousnessraising (CR) group of the late 1960 s and 1970 s.

\section{Consciousness Raising Groups}

In the late 1960s and early 1970s, women's liberation activists organized an array of strategies geared towards helping women combat sexism based on the underlying premise that 'the personal is political'. One such strategy was the creation of $\mathrm{CR}$ groups. Initially originating in a number of large American cities,

"the idea spread quickly, and in the early 1970s hundreds of such groups met weekly in Canada. The groups were small, perhaps eight to fifteen participants, but the atmosphere was often electrifying as women shared 
experiences and feelings formerly considered too personal, shameful, or guilt provoking to discuss" (Hamilton 56).

CR groups were non-hierarchical and membership was restricted to female participants, in order to create a safe environment in which to talk openly-a space dedicated to women's experiences. In a 1972 pamphlet written by Piercy and Freeman for Cape Cod Women's Liberation entitled, Getting Together: How to Start a Consciousness-Raising Group, the authors state,

We are trying to learn to communicate and to move away from viewing our 'neuroses' as personal problems to perceiving them as social issues. For instance, when we go around the room talking about how each of us feels about her appearance, and we hear every single woman expressing the same dissatisfaction with her body or her personality (my breasts are too small, too big, too flabby, my stomach is too round, my legs are too thick, I'm too loud, too quiet, etc.), we begin to realize we are dealing with something larger than a personal hang-up. The consciousness-raising group aims at changing our heads and our behavior but also at preparing us to change the attitudes of society and the structured roles that women, men and children must play today. ${ }^{12}$

In one sense, "CR groups were confessional; but the response was more often anger than guilt, and the answer was not penance but personal exoneration and social change" (Hamilton 56). In this way, the CR group served to elicit feelings of solidarity, strength and empowerment among female participants in the hope that this energy would spill over into the daily lives of women. Hamilton adds that 
CR groups were also, "similar to group therapy; but while individuals altered their lives, the problems were defined as collective and systemic" (56).

An important part of the CR process, therefore, was that it provided participants with a venue through which they could express themselves and give voice to their experiences of oppression. In these safe, supportive, environments women had the opportunity to discover that they shared many similar concerns with one another. In essence, part of the disclosure process that took place within the CR group was very much connected to issues of self discovery and identity. As women struggled to improve their positioning within the public and private spheres, at the core of this effort, many began to question just what it meant to be a woman within Canadian society. Today, constructs of identity have been greatly complicated with the introduction of social spaces on the Internet that can be understood as functioning to fragment the self. The following section examines some of the key issues associated with the negotiation of online identity and how these issues are reflected in the work of Canadian women bloggers.

\section{Central Feminist Constructs: Identity}

The process of transposing the self through representation online, not only provides a way of personalizing individual blog spaces but also disrupts and destabilizes one's own connection to self that is derived from physical engagement with the corporeal world. By extending the self symbolically into the virtual realm of the online, these women renegotiate and reconstruct identity 
through the technologies associated with the blog. As Madeleine Sorapure states, "in an online diary, pieces of information about the self may be brought together in different configurations, signifying multiple and shifting ways of understanding the self"(8). As a result, participants are afforded the unique opportunity to explore alternative, dynamic constructions of self based on what information they choose to include, exclude or fictionalize in their blogs. In this way, "the Internet has become a significant social laboratory for experimentation with the contradictions and reconstructions of self that characterize postmodern life. In this virtual reality, we self-fashion and self-create" (Turkle 180). Online, everything is up for renegotiation and reconstruction. Even the gender of an author can be altered or erased. As a result, the terrain of the body as a more or less fixed system, which is manifest in specific ways in the physical world, is transformed through the mediated process of blogging.

Judith Donath suggests that in "the physical world there is an inherent unity to the self, for the body provides a compelling and convenient definition of identity. The norm is: one body, one identity. Though the self may be complex and mutable over time and circumstance, the body provides a stabilizing anchor" (1). She juxtaposes the physical experience of self with the virtual by arguing that online, one is "free from the body's unifying anchor. One can have, some claim, as many electronic personas as one has time and energy to create" (1). While I do not take issue with the assertion that individuals are free to construct and reconstruct multiple enactments of self online, I contend that for women 
bloggers at least, their online disembodied representations of self almost always are anchored both in and to the physical body.

On the one hand, online descriptions of self are the product of tangible bodies, sitting at real computer terminals. As such, the blog product stems from and remains linked to a body that inhabits the physical realm. On the other hand, the blog is manifest on a virtual plane and any expression of identity is, therefore, the direct result of a conscious act on the part of its author to select out and project specific, desired characteristics via textual or visual representations. Since women authored blogs are saturated with descriptions of self in relation to the body, this would suggests that even online where there is no corporeal presence, women remain bound to their bodies. Given the historically troubled relationship women have had to the body_as a site of both empowerment and oppression - the ability to control what is communicated about one's self may well represent a positive, liberating experience for female bloggers. Despite this tethering, I contend that enactments of self online can be interpreted as an empowering exercise for women, as they begin to explore and question what it is about themselves that is worthy of remediation within the blog.

With regard to the third wave and issues related to identity and body, Amy Richards states:

In the late 1990s, among the rising third wave of feminists, image and body are at the center of feminist analysis. For many women, our bodies have become the canvasses upon which our struggles paint themselves. 
Body image, in fact, may be the pivotal third wave issue-the common struggle that mobilizes the current feminist generation. (196)

An excellent example as to how identity and body is negotiated in third wave space can be found in an article entitled, "Art of the Ponytail", in which Akkida Mcdowell presents a humorous but serious narrative about the trouble with her hair. Being a woman of mixed racial heritage (i.e., African and Caucasian), her white skin and coarsely textured hair create a point of tension for her. She states, "My crowning glory is a war zone. Every day I wake up prepared to do battle, to fight both for and against the enemy that lies on top of my head" (124). Her 'tale' is allegorical. The battle is fought, both internally with regard to her own relationship to and with the body, and is fought externally as she negotiates prejudice and racial tension in the world. Mcdowell concludes by stating that, "Body image issues, like most any other painful life experience becomes less difficult once an open dialogue begins" (200). From a third wave perspective, this dialogue simultaneously extends outward toward 'the other', while at the same time is cast inward and directed toward 'the self'. With regard to identity and the blog specifically, Laurie McNeil states:

[O]nline diaries can be read as assertions of identity, and arguments for the importance of an individual's life. Even as their authors retain a degree of anonymity, these texts make very personal connections to a reading audience that recognizes and confirms these individual life assertions. (26) 
Here, McNeill suggests that part of the value associated with blogging relates to the fact that participants enter into a space in which they are able to assert identity to receptive audiences. This statement underscores not only the importance of self expression and online self construction, but also the importance of the readership.

\section{Central Feminist Constructs: Community}

The term community is "one of the most elusive and vague in sociology and is by now largely without specific meaning" (Penguin 64). In this thesis, community is understood as having occurred when "people have a reasonably clear idea of who has something in common with them and who has not. Communities are, therefore, essentially mental constructs, formed by imagined boundaries between groups" (Penguin 65). Hence, community members need never have any direct contact with one another. All that is necessary is the perception of belonging. This definition is based on the work of Benedict Anderson who defines the construct of 'nation' as representing an imagined political community. Anderson states, "It is imagined because the members of even the smallest nation will never know most of their fellow-members, meet them, or even hear of them, yet in the mind of each lives the image of their communion" (225). Online communities, such as those associated with the blog, fit nicely into this definition. Even though blog participants may never actually meet one another in real life-as is particularly the case with regard to a secret blog-I argue that they do experience a sense of belonging and group 
membership, as demonstrated by their own descriptions of community experience discussed in Chapter Four.

This notion of imagined communities is also relevant to third wave feminists who form communities around individual and unconventional acts of public resistance. A good example of this is offered by Allyson Mitchell in her examination of lesbian, feminist graffiti writing in Kensington Market. Although graffiti writers may never come into contact with one another, their public statements help to foster "a feminist, subcultural and anti-corporate community" (226). Mitchell adds that "feminists are in dialogue through graffiti writing, a kind of call and answer system where one message is erased only to be replaced with another" (226). Through culture jamming acts such as graffiti writing, therefore, third wavers are able to communicate their presence not only to the public, but also to one another.

Another point to consider with regard to online community is brought forward by Laurie McNeill. She suggests that the online diarist's awareness of, and interest in, her readership serves to foster a sense of community among participants. She states, "having readers means that the diarist has both joined and created communities" (32). Drawing on the work of John Swales, McNeill suggests that what the online diary does is to link the author and her readership via "discourse communities," which form around rhetorical goals. She explains:

To remain a community member, one has to participate actively in the group, and acknowledge one's allegiance to the community... [The online diarist] makes this community conversation a part of the process, often 
incorporating readers' responses into the diary itself, thus creating a dialogue between herself and her readers... The diary then becomes a meeting place and starting point for further discourse among previously disconnected readers. (McNeill 34)

Since the bulk of blog authors go to the trouble of incorporating links to one another's sites, actively cross posting on these sites and even sometimes incorporating software applications to track their readership, this would suggest that bloggers are not just interested in broadcasting their lives as they unfold; some bloggers also seem very interested in attracting and monitoring their audiences.

\section{Conclusion}

This chapter began with a brief introduction to second wave feminism in which I detailed some of the key issues that arose during the 1960s and 1970s that are still relevant today. In addition, I provided an introduction to the main constructs associated with third wave feminism and elaborated on issues pertaining to activism, identity and community. In order to illustrate just how interconnected these feminist generations are, I compared the second wave feminist CR group to the blogging practices of contemporary Canadian women. Since much of the work that occurs within blog space draws on alternative, third wave approaches to 'doing feminism,' these practices may not always look 'activist enough' when viewed through a second wave feminist lens. Nonetheless, as will be demonstrated in following chapters, the blog spaces 
created by Canadian women are filled with examples of third wave feminist resistance that are very much rooted in second wave feminist ideology. 


\footnotetext{
${ }^{1}$ At the time, Laura Sabia was the President of the Canadian Federation of University Women and the Honourable Judy LaMarsh was the Secretary of State. For more information see Hamilton, 1996.

${ }^{2}$ For a complete discussion on the Royal Commission on the Status of Woman and the media, see Freeman, 2001.

${ }^{3}$ One area of difference that exists across generations is that third wavers often incorporate and address issues that are connected to ecology and globalization.

${ }^{4}$ Third wave reclaiming/reframing can range from deciding to embrace and thus play with mass media stereotypes of feminine beauty by wearing make-up and frilly pink dresses, to creating alternative women-centred pornography.

${ }^{5}$ See Butler, Judith. Gender Trouble: Feminism and the Subversion of Identity. New York: Routledge, 1990.

${ }^{6}$ As Allyson Mitchell and Lara Karaian explain, "young feminism" is not bound by a specific age range. They state, "We try to maintain an ambiguous relationship to the membership of 'young' or 'third wave' so that it includes politics and aesthetics as much as it does generational positioning. We take our cue from Riot Grrrl, an anti-masculinist punk rock (some call it the original) girl-power movement that was active in North American in the 1990s. Riot Grrrl made it clear in their zines and publications that their revolution was open to all girls regardless of age and other identities." For more information see Mitchell, Allyson and Karalian, Lara. "Third-Wave Feminisms." Feminist Issues: Race, Class, and Sexuality. "4th ed. Mandell, Nancy, Ed. Toronto: Pearson / Prentice Hall, (58-82).

Another excellent example of generational tension is found in Bernikow, Louise. "Political matricide: Feminism's second wave, third wave, and the amnesia problem." Paper read at the National Women's Studies Association $16^{\text {th }}$ Annual Conference, Women's Movements: Cultural, Intellectual, Political (R)evolutions, University of Oklahoma, 1995.

${ }^{8}$ In particular, Candis Steenbergen is referring to Germaine Greer's text entitled, The Whole Women. London: Bantam-Dell-Doubleday, 1999.

${ }^{9}$ Within the Canadian context specifically, Steenbergen equates the work of feminist journalist, Michele Landsberg to that of Geer, referring specifically to Landsberg's October 1999 Toronto Star article entitled, "A Teenager for a Generation to Look Up To" in which she "discounts the work of young feminist activists who have been vigorously engaged in complex critiques of popular culture and consumerism" (Steenbergen, Whose Generation 261).

${ }^{10}$ The Zine phenomenon is not new and has itself a rich history dating back to the 1920s when Hugo Gernsback launched a small independent publication entitled Amazing Stories See www.factsheet5.com/history for more information. The origin of the word zine comes from fanzine as opposed to magazine. The 1930s through to the 1950s saw an explosion of science fiction related fanzines in which individuals published their own stories and lists of contributors so that readers could write directly to contributors.

${ }^{11}$ In the case of the print zine, it is often self-distributed and is usually created using a fusion of high tech (e.g., word processing, scanning, digital image manipulation, digital reproduction) and low tech methods (e.g., cut, paste and glue, hand drawing, hand writing). Zine creation, is in itself, an empowering act as it allows the author to express herself in an unmediated manner; as a non-commercial product, the zine does not require the approval of editors and publishers before it goes to print or is published online. The
} 
e-zine can also have a very similar "cut and paste" to that of the print zine, if the author elects to digitize and post her illustrations or collages. Alternatively, it might also have a very polished, high-end look and feel to it if the author is well versed in image and web publishing software.

${ }^{12}$ The full pamphlet is available online at:

http://research.umbc. edu/ korenman/wmst/crguide2.html. 


\section{Chapter Three}

\section{Research Methodology and Observations}

\section{Description of Sample}

This research is based on sixty-two female authored blogs drawn from BlogsCanada-an online, Canadian blog registry service located on the world wide web at www.blogscanada.ca (see Appendix A). Blogs were drawn from this particular service because it enabled me to easily identify Canadian women bloggers. The sample was drawn from a total of 8,500 indexed blogs during the first week of August, 2004. All active blogs (i.e., those whose authors had posted at least once in the thirty days prior to collecting the sample) of a non-commercial nature, authored by individuals who identified as Canadian women were included in the study. Since individuals are not required to specify their gender when registering with this service, female bloggers were identified using a two step process. First, the BlogsCanada search engine was used to locate all registered blogs in which authors included at least one of the following keywords in the their blog's description field: girl, grrrl, grrl, woman, women, womyn, wommin or female. ${ }^{1}$ Second, in order to eliminate blogs whose subject matter centred around one of the keywords but that was not actually authored by someone identifying as female, each blog was reviewed individually and a subject's gender was confirmed based on her biographical statement.

In order to gain greater insight into the secret world of Canadian women bloggers, I also conducted a case study analysis on a smaller subset of the sample. The general content review enabled me to identify major recurrent 
themes, while the case study provided me with a more in-depth look at the secret world of women bloggers by focusing my observations across three distinct dimensions-activism, identity and community. My case study inclusion criteria consisted of all authors who had maintained a secret blog for more than two years, on a personal Web site with a registered domain name and who posted photographs of themselves and biographical information. To produce and maintain a blog on a personal Web site, a blogger must possess a reasonable amount of Web expertise, including the knowledge of how to register a site, how to configure a blog application, how to create Web images and how to generate HTML code. By limiting my case study to only those women who possess this knowledge, I assume that my subset represents a more experienced group whose blog work is not limited by a lack of technical skill. A more experienced group, therefore, have the potential of creating highly individualized, creative blog sites, with a wide array of additional or augmented blog functionality. In short, the more technical experience a blog author has, the better able she will be to manipulate the medium to meet her own goals. The point of this inclusion criteria was that it enabled me to view how more experienced woman bloggers engage with the medium. Out of my general sample, only four female bloggers met this criteria (see Table 1). 
Table 1

List of Case Study Blogs

\begin{tabular}{|c|c|}
\hline Delicious Juice & http://wnw. deliciousjuice.com/ \\
\hline Dirty Olive & http://umw . dirtyolive.net/ \\
\hline Grass Is Always Greener & http://wnw. grassdiaries.com/ \\
\hline Just A Girl & http://wwww.justagirl.cal \\
\hline
\end{tabular}

\section{Methodological Approach}

Qualitative data were gathered from the general sample of sixty-two bloggers based on a number of variables including author age, physical location, education, ethnicity, sexual orientation, type of blog service used (i.e., commercial or non-commercial) and whether the authors had included photographs and biographical information about themselves. I also noted whether authors made a distinction between maintaining public or secret blogs. ${ }^{2}$ This information was then used to construct a demographic outline of Canadian women bloggers. Since the collection of data was done using an ex post facto observational method, it was not possible to compile a complete dataset in which information was gathered across all variables for each blogger. Rather, I drew on the information individual bloggers had already chosen to publish on their sites. While this approach to the study of blogs is useful when conducting an exploratory investigation, future research should include additional methods of data collection such as the administration of questionnaires or by conducting interviews directly with bloggers.

In addition to the compilation of characteristics associated with Canadian women bloggers, I also collected quantitative data on their posting frequency, the 
duration in months that blogs were maintained and the number of visitors individual blog sites received. This data enabled me to measure how active female bloggers are over time and how much public interest they are able to generate with regard to their blogs.

\section{Methodological Challenges}

Conducting online blog research poses a number of methodological challenges for researchers. In this particular study, the first challenge relates to obtaining a representative sample of Canadian women bloggers. As no exhaustive Internet index exists from which all authors have an equal opportunity of being drawn, it is not possible to obtain a random sample. Furthermore, since blog authors do not always identify their nationality, using a general Internet search index or directory ${ }^{3}$ to locate Canadian subjects was not practical. As a result, I decided to gather my sample by using a popular Canadian blog registry known as BlogsCanada. ${ }^{4}$ Although registration is free, not all Canadian bloggers are aware of this service nor do they all make use of it. It may well be that certain unidentified, extraneous variables affect who decides to register with BlogsCanada. If this is in fact the case, the results of my study could be skewed. For example, it may be that only those bloggers who have a particularly strong sense of Canadian identity feel compelled to register with a Canadian identified registry site as opposed to one that focuses on particular topics of interest. As a result, generalizations about the behaviours of Canadian women bloggers, as a whole, must be made with caution. 
Another problem associated with conducting research on blogs is that they represent a moving target. They can disappear just as quickly as they are created and since many blog participants post quite frequently-in some instances multiple times each day-all blogs are constantly in a state of flux. As a point of interest, during the course of my case study analysis, one of the four long term bloggers (i.e., Just $A$ Girl) decided to stop writing and removed all of her blog content from the Internet. In order to conduct blog research without interruption, therefore, during the first week of August, $2004 \mathrm{I}$ captured and downloaded all of the content associated with each of the blogs in my case study. To accomplish this, I used a software package (i.e., WinHTTrack Website Copier, version $3.30^{5}$ ). Due to computer resource limitations and time constraints, the information taken from the general sample was gathered by visiting each live site and then immediately recording pertinent information for later analysis. This approach meant that if a subject removed her blog from the Internet, there would be no way to access it again at a subsequent date. This occurred in three instances after the initial data collection. By the time this text is published, many more of these blogs may no longer be available online. With regard to the case study, an advantage to capturing complete blog sites is that they are saved in digital format and can thus be subjected to fast, accurate, automated text searches. Having these sites in digital format allowed me to sift through thousands of blog entries ${ }^{6}$ quickly to determine the frequency and location of feminist related material. The software package that I used for this purpose was Funduc Search and Replace for Windows 95/NT, version 3.0.7 
All of this raises important concerns with regard to conducting research online and the issue of ethics and blog ownership. This study examined the work of Canadian women who chose to broadcast their blogs publicly over the Internet. By virtue of this, their blogs became accessible to anyone online. Although these women are aware of their readership (to greater or lesser degrees depending on their level of Internet sophistication) and are posting their work for the world to see, they still seem to maintain a strong sense of blog ownership. It stands to reason that when an individual invests a considerable amount of time and creative effort into the production of a blog site, which is then used as a forum to discuss highly personal issues, the blog author is bound to feel connected to her site.

The Internet, however, is a public, digital medium. What this means is that each time a reader accesses a blog site, it is temporarily downloaded to the reader's personal computer and held in a temporary Internet folder. The contents of this folder can remain on the reader's computer indefinitely, depending upon her Internet browser settings. At any point in time, multiple copies of someone's blog can exist in many locations across the Internet, as is also the case with the blog sample that I purposefully downloaded to my computer. What is of note here, is the fact that the authors in my study are unaware of my presence as a researcher and do not know that I have a copies of her blog sites-copies that, in theory, I could alter or repost to the Internet without their knowledge or permission. 
All of this leads to various ethical and ownership questions. Although I have conducted a study on publicly broadcast material, given the nature of the material and the way in which it has been procured, somehow it feels as though a line has been crossed-one to which the authors of these blogs seem to be oblivious. Another ethics point centres around the issue of protecting subjects' identities. Initially I considered changing the names of women bloggers who appeared in this study, however, I decided that it was not necessary since the blog is public space and those who do not want their real names known have already altered them by writing under pseudonyms. Future studies could investigate the issues related to ethics and blog authors' awareness of privacy and copyright issues.

A final point relates to the fact that it is not possible to verify the truthfulness or accuracy of statements made online by blog authors. For example, the blogs that I identify in my sample as being authored by women, in some instances, may in fact be the product of male authors (see the Plain Layne gender switching example in Chapter Four). It is also not possible to determine the degree to which female authors fictionalize or edit elements associated with themselves. Although it falls outside of the scope of this project, examining issues of fictionalization in online life-narrative would make for an interesting additional study. With regard to the issue of gender switching specifically, since I am exploring the blog via a third wave feminist lens-within which the essentialist category of 'woman' is disrupted — whether an individual author has female or male appendages is less important, compared to how an author identifies. In 
fact, the ability of online spaces to challenge seemingly natural divisions, such as gender, represents one of the facets that makes this work so exciting. Additional research with regard to the blog could also focus on conceptualizations of gender categories, self expression and gender identification as it pertains to blogging.

\section{Observations: General Sample}

A total of 41 of the 62 Canadian women bloggers identified their age. The age range for the larger sample of subjects was 18 to 52 years. The average age was 28 years. The majority of these women (i.e., $n=31$ or $69 \%$ ) were between the ages of 20 and 29 years and $93 \%(n=42)$ were under 39 years of age. In the case study, which consisted of 4 subjects, these figures differed only slightly. For example, the average age of this blogging subset was also 28 years, however, a much smaller age span was noted that ranged from 25 to 31 years of age. In the general sample, there were only three women who fell within the 50-54 age range, no women between 40-49 and only two between 35-39 (see Table 2).

Another interesting point is that the age distribution in this sample does not reflect general Canadian Internet access trends. Based on data gathered via Cycle 14 - Access to and Use of Information Communication Technology, of the General Social Survey (GSS) ${ }^{8}$ by Statistics Canada, we know that in the year 
Table 2

Distribution of Age - Main Blogging Sample

\begin{tabular}{|lrr|}
\hline A Age Range & Freq & \multicolumn{2}{c|}{ Percent of Bloggers } \\
\hline $15-19$ & 2 & 4.4 \\
$20-24$ & 15 & 33.3 \\
$25-29$ & 16 & 35.6 \\
$30-34$ & 7 & 15.6 \\
$35-39$ & 2 & 4.4 \\
$40-44$ & 0 & 0.0 \\
$45-49$ & 0 & 0.0 \\
$50-54$ & 3 & 6.7 \\
\hline TOTAL & 45 & \\
\hline
\end{tabular}

$2000,92 \%$ of women between the ages of 15 and $17,86 \%$ of women 18 to 19 and $79 \%$ of women between 20 and 24 years of age had access to the Internet (Rotermann 5). What is surprising with my sample is that there are only two young women between the ages of 15 and 19 in spite of the fact that this group of women represents those most likely to be online. Since $29 \%(n=18)$ of my sample did not indicate their age, however, this may account for the discrepancy.

The majority of women in the general sample (i.e., $85 \%, n=53$ ) kept secret blogs. For the purposes of this study, a secret blog is operationally defined as one in which the author's real full name does not appear anywhere in the blog. In the secrecy condition, however, some women simply avoided using their real names and replaced these with pseudonyms, while other authors went to greater lengths to conceal their identity. For example, some authors also changed the names of the people and places about whom they wrote or used coded abbreviations in lieu of proper names. In some instances, authors made it clear that they did not want anyone who knew them in real life to find out about their 
sites. All of the blogs that were coded as being not secret contained three distinct identification elements-the author's alleged full name, her geographical location and some form of personal contact information (e.g., a work or home mailing address, an e-mail address or a telephone number).

Even though the majority of women in this sample felt compelled to maintain secret blogs, a total of $65 \%(n=40)$ chose to post photographs of themselves online. Among those who included photographs of themselves, $25 \%$ $(n=10)$ or were visible minorities identifying as Chinese, Filipina, Malaysian and Trinidadian. Based on the findings in this study, $50 \%(n=31)$ of the women opted to include detailed biographical statements about themselves within their blogs. Slightly more than one third of the sample (i.e., $39 \%$ or $n=24$ ) also included information pertaining to their sexual orientation, in which $75 \%$ or $(n=18)$ clearly identified themselves as being heterosexual, $12.5 \%(n=3)$ identified as lesbian and $12.5 \%(n=3)$ identified as bisexual.

With regard to blogger location, the vast bulk of these women (i.e., $91 \%$ or 54 subjects out of a total of 59 who identified their location) resided in Canada. The most common area of residency was the province of Ontario in which $40 \%$ $(n=22)$ of the sample was located. The least common residency areas were Manitoba, Quebec ${ }^{9}$ and the Yukon-each representing only $1.8 \%(n=1)$ of the total sample size. No female authors indicated that they lived in Newfoundland, the Northwest Territories or Nunavut. Of the sixty-two authors, three did not specify where they lived in Canada and seven indicated that they lived in other locations outside of the country including Africa, China, Cuba, India, Japan, 
Uganda and the United States (see Table 3). Among those in the case study subset, $50 \%(n=2)$ indicated that they lived in Ontario, $25 \%(n=1)$ in British Columbia, $25 \%(n=1)$ in Alberta.

Approximately one third of the general sample (i.e., 21 women) provided information about their education. Here, $62 \%(n=13)$ were completing or held undergraduate university degrees, $24 \%(n=5)$ were completing or had obtained master's level university degrees and $9 \%(n=2)$ were completing or held doctorate degrees. Only $5 \%(n=1)$ of these women indicated that they were enrolled or had

Table 3

Breakdown of Blog Author Location by Province

\begin{tabular}{|llr|}
\hline Location & TOT & AVG \\
\hline Bloggers in Ontario & 22 & 40.0 \\
Bloggers in BC & 12 & 21.8 \\
Bloggers in Alberta & 5 & 9.1 \\
Bloggers in Nova Scotia & 4 & 7.3 \\
Bloggers in Sask & 4 & 7.3 \\
Bloggers in New Bruns. & 2 & 3.6 \\
Bloggers in Manitoba & 1 & 1.8 \\
Bloggers in Quebec & 1 & 1.8 \\
Bloggers in Yukon & 1 & 1.8 \\
Unidentified & 3 & 5.5 \\
\hline
\end{tabular}

Note: Seven blog authors indicated that they lived outside of Canada.

completed a college degree and no women indicated that they were still in high school or lacked a high school diploma.

In this sample, $66 \%(n=41)$ of women maintained their blogs via a commercial hosting service such as www.blogger.com, www.diaryland.com or www.livejournal.com. The remaining $34 \%(n=21)$ of female bloggers maintained 
their blogs on personal Web sites under registered domain names. Just over half of these women $(n=12)$ opted to use a .com registered domain name, compared to $25 \%(n=5)$ who maintained their sites under a .org or .net domain name and $20 \%(n=4)$ used the Canadian .ca domain name. The only exception to this was one female blogger who identified herself as a university professor and maintained her site on a Canadian university server.

With regard to the physical layout of these sites, when authors choose to house their blogs on personal Web sites, they generally must create their own blog layouts-some of which may be quite complicated and highly creative (see Appendix B). Whether hosted on private sites or on commercial services, $63 \%$ $(n=39)$ of the blogs in this sample contained either a picture of the author, a caricature of a woman or the silhouette of a woman on the main page. It would seem, therefore, that within this virtual environment, there exists some desire on the part of many female bloggers to incorporate female representations into their blog spaces.

The average duration that women in the general sample maintained their blogs was 19 months. Their posting frequency ranged from 2 to 68 posts per month, with an average of 19 posts per month. In contrast, the average duration that women in the case study maintained their blogs was 36 months. The case study bloggers also posted on average 24 times per month with a range of 8 to 39 posts per month. To provide an additional perspective on the amount of work generated by these women, the total number of blog entries that the sample of sixty-two posted to the Internet was 21,628 . In some instances, bloggers 
incorporated third-party Web counters, such as Site Meter, ${ }^{10}$ into their blogs in order to track the number of visitors they received to their sites. Third-party counters provide a useful measure of Web traffic in that they cannot be altered substantially by individual bloggers in order to generate inaccurate Web traffic statistics. ${ }^{11}$ In the general blog sample, $19(n=12)$ women used publicly accessible Web counters and generated an impressive total of 217,657 visits.

In summary, based on data gathered in this research, the typical Canadian woman blogger is a 28 year-old, heterosexual, Caucasian woman who lives in Ontario and who posts to her blog just over 4 times per week. Furthermore, she is likely to be using a commercial blog hosting service-the most likely of which is www.blogger.com. She is also likely to have posted pictures of herself (i.e., $63 \%$ ) and there is a $50 \%$ chance that she has included a detailed biographical section in her blog. She is also likely to either have an undergraduate degree or to be in the process of completing such a degree. $\mathrm{A}$ comparison of the findings for the general and the case study are presented in Table 4.

Table 4

Comparison between the General Sample and the Case Study

\begin{tabular}{|l|r|r|}
\hline \multicolumn{1}{|c|}{ Description } & General Sample & Case Study \\
\hline Age Range & $18-52$ & $25-31$ \\
Average Age & 28 & 28 \\
Kept A Secret Blog & $85 \%$ & $100 \%$ \\
Resides in Canada & $91 \%$ & $100 \%$ \\
Average Blog Duration & 19 Months & 36 Months \\
Range Posts Per Month & $2-68$ & $8-39$ \\
Average Posts Per Month & 19 & 24 \\
\hline
\end{tabular}




\section{Case Study: Activism}

The first dimension that I explored with regard to the smaller subset related to issues of feminist activism practices. I wanted to determine whether and under what circumstances these blogs could be thought of as vehicles through which feminist resistance and transformation occurs. I was interested in observing how much overt and covert feminist content was present. Do women bloggers identify and employ the feminist label? Do they discuss issues of gender inequity, marginalization and oppression? If so, what types of discussions transpire? When feminist activism is present, is it more likely to resemble a second or third wave approach? For example, linking to or creating an online gender equity petition represents a digital form of second wave activism. In contrast, initiating online dialogue about the problems associated with the commercial feminine hygiene industry ${ }^{12}$ and encouraging women to explore menstrual alternatives (e.g., keepers or homemade pads), constitutes an alternative third wave form of resistance.

\section{Case Study: Identity}

My observations about identity were based primarily on a content analysis conducted on the four case study blogs. I examined all visual and written material posted to the blogs by their respective authors. Given women's historically troubled relationship to the mass media, particularly with regard to female representations, I was interested in ascertaining how this subset constructed online identity in relation to issues of the body. What physical characteristics did they transpose and emphasize in blog space? What 
personality traits did women equate with themselves? What was the nature of their relationship to self? Were they happy with their bodies and personalities or did they express areas of concern and displeasure? With regard to the visual elements they posted, I assessed the complexity of their blog layouts in relation to the use of graphics (particularly original graphics created specifically for their sites), HTML code and java scripting. I looked at the originality of their layouts and what these layouts communicated about their authors. For example, were colours and images used that displayed soft, stereotypical feminine imagery or were alternative messages about womanhood communicated visually? How did they present visual treatments of their bodies?

\section{Community}

The final dimension that I examined focused on community and women's engagement with one another online. A diary is a static record of everyday life that is authored by a single individual. In the case of the blog, there is often one initiating author, however, the interactive nature of the medium associated with its comment functionality enables blog participants (i.e., both author and reader) to communicate with one another. I was interested, therefore, in ascertaining how much interaction occurs in blog space.

Based on my initial, informal observations, it appeared as though small groups of five to ten women seemed to form interactive blog clusters in which they posted regularly to one another's blog sites. As a result, it is my contention that Canadian women bloggers tend to spontaneously arrange themselves into loosely-bound, online communities as evidenced by their cross linking and cross 
posting behaviours. For the purpose of this research, cross linking is defined as occurring when an author posts a link to another site in her list of 'Frequently Read Blogs'. Although not all bloggers post such lists, when they are present, they usually form part of a blogger's template and thus appear on every page that she generates. The more links that are posted to other sites, the greater the opportunity and likelihood that these sites will receive increased traffic. In this sense, every individual blog can be framed as forming its own hub around which other blogs are connected. Sometimes these Web hubs are heavily cross linked, while at other times, they may contain only a small number of links.

In contrast, cross posting is defined as occurring when a blog author publishes a comment to another individual's blog site. Although cross linking can be measured easily by noting the links that appear on any given blog, cross posting is much more difficult to track. In order to do so, a list of linked blogs must be generated and compared with the names of those who post comments. This is a time-consuming process that does not necessarily yield an accurate figure regarding the degree to which interaction occurs, particularly when those who post do not identify themselves by using their corresponding blog pseudonyms. Comment sections are also sometimes susceptible to spamming. ${ }^{13}$ Here, various 'form letter' comments are posted that are accompanied by links to commercial Web sites. The point of this spam is to entice those reading the blog to click on the link, thus increasing the amount of traffic the commercial site receives. These sites are most often dubious enterprises associated with the pornography industry. 
An additional point to consider with regard to cross posting is that blog clusters are not necessarily composed entirely of other blog authors. An individual may be an active blog participant by regularly reading various blogs and posting frequently to these sites without starting a blog of her own. In this instance, I contend that she would qualify as being a member of the blog cluster to which she participates, yet it is difficult to track her presence. Further complicating the matter is the fact that a blog author will sometimes respond to a comment by either posting a new entry to her own blog site or by posting directly on the commenter's blog site. Although cross posting can be difficult and time consuming to record, it provides a method whereby blog clusters can be made visible.

\section{Conclusion}

This chapter introduced the methodological approach used in this study. It also provided a description of the subjects, presented a discussion of the findings and detailed the associated methodological challenges that arose during the course of this research. It concluded with a brief discussion of the three key feminist constructs of activism, identity and community that function as a focal point for this research. 
${ }^{1}$ Although 67 blogs (62 of which were current) out of a total of 8,500 met this criteria, it is important to note that this does not reflect the total amount of female BlogsCanada registrants. Frequently, the keyword description area is used to outline a blogger's interests rather than personal descriptors such as gender. Therefore, the only way to ascertain how many female bloggers are registered with BlogsCanada would be to review all 8,500 blogs individually -a task that falls outside of the scope of this project.

${ }^{2}$ For the purposes of this study, a secret blog is operationally defined as one in which the author's real full name does not appear anywhere in the blog.

${ }^{3}$ An example of a Internet search index is www.google.com. An example of an Internet directory is www.yahoo.com. Both of these services are used to help people locate information on the world wide web.

${ }^{4}$ See www.blogscanada.ca for more information.

${ }^{5}$ For more information on this product see <www.httrack.com>.

${ }^{6}$ In my case study sample of 7 bloggers, 5051 blog author entries were captured and searched.

${ }^{7}$ For more information on this product see <www. funduc. com $>$.

${ }^{8}$ According to Statistics Canada, "The General Social Survey (GSS) program, originating in 1985, conducts telephone surveys. Each survey contains a core topic, focus or exploratory questions and a standard set of socio-demographic questions used for classification. More recent cycles have also included some qualitative questions, which explore opinions and perceptions. The two primary objectives of the GSS are: to gather data on social trends in order to monitor temporal changes in the living conditions and well being of Canadians; and to provide immediate information on specific social policy issues of current or emerging interest." The dataset boasts an impressive sample size of 25,090 respondents who were polled via telephone during 2000 . For more information see $<$ http://www.statcan.ca/english/sdds/4505.htm > and $<$ http://www. statcan.ca:8096/bsolc/english/bsolc? catno=56-505-XIE >. To review the questionnaire package for GSS Cycle 14-Access to and Use of Information Communication Technology, see < http://www.statcan.ca/english/sdds/instrument/4505 Q1 V1 E.pdf>.

${ }^{9}$ It is important to note that BlogsCanada is an English-based Web site. In part, this may account for the low registration rate among Quebec authors.

${ }^{10}$ For more information on Site Meter, see <http://www. sitemeter.com>.

${ }^{11}$ The only way to increase the amount of traffic that a third party Web counter records would be by repeatedly surfing one's own Web site. While bloggers do re-read what they have written and thus add to the number of hits their site receives, this re-reading activity would not substantially alter the blog's Web site traffic. Furthermore, in some instances Web counters do not record hits that come from the blog author.

${ }^{12}$ Blood Sisters engages in this type of feminist resistance. They describes themselves as, "an exciting launching pad girl base fueling action to combat the silence surrounding our female bodies. we are girls using our own feminine protection to work against the corporate and cultural constructions of menstruation. we are concerned with the serious health, environmental and psychological ramifications of the toxic feminine hygiene industry and are fighting to stop the whitewash on all fronts. born out of a guerilla girl recyclable pad distribution network, we are an ever growing group generating more creative projects to raise awareness surrounding menstrual girl-body politics". For more information see <http://www.bloodsisters.org/bloodsisters/>.

${ }^{13}$ The comment sections on some blogs are riddled with spam as is the case with Mostly Emily Jones . For example, on August 3, 2004 at 4:39, the user "mature sex photos" posted the following message on her site on, "Great site. Enjoyed it." This comment links back to a commercial pornography site. 


\section{Chapter Four}

\section{Analysis and Discussion: Understanding the Secret World of Canadian Women Bloggers}

\section{Introduction}

This chapter begins with a brief discussion of the findings associated with the general sample of sixty-two Anglophone, Canadian women bloggers. It is followed by a more in-depth blog content analysis associated with the smaller subset of four Canadian women bloggers as it pertains to third wave feminism and activism, identity and community. The chapter concludes with an examination of the continuity between second and third wave feminism in relation to the blog and consciousness-raising groups of the late 1960s and 1970 s.

\section{Recurrent Themes in the General Sample}

In the general sample, a number of recurrent themes were observed.

First, there is the issue of secrecy. In this study, $85 \%$ of all blog authors chose to maintain some degree of secrecy with regard to their blog writing practices. In some instances, this meant that blog authors wrote under pseudonyms so that the general Internet public would not be able to identify them. When this occurred, blog authors did not seem to mind if their real-life friends and family members read or participated in their blogs. For other authors, the issue of complete secrecy is very important. In this instance, she is likely to alter any information that might give away who she is, including her name, location, the names of her family members, her school name or place of employment. 
Although some degree of secrecy is important to the majority of Canadian women bloggers in this sample, they tended to write very openly about a wide range of female-centred subjects including identity and body image; sexuality and personal relationships; politics and social justice; and various challenges associated with daily life, including issues of motherhood, illness and well-being and pop culture. These themes are similar to those identified by Melanie Ferris as being central to the third wave feminist zine which include sexuality, body image, politics and feminism (52).

In some instances, Canadian women bloggers identify explicitly as being feminist. For example, Janua Diaboli, a female blogger from Saskatoon, describes herself as "a feminist, but not a fiend-like one. I'm also an anarchist, but in Emma Goldman's sense of the word, not that of the mainstream media". 1 She makes a point to define feminism by including the catchphrase, "feminism is the radical notion that women are people." ${ }^{2}$ She also makes it known to her readership that she engages in activist practices such as the Gender Petition and encourages others to explore this type of online activism by including a link in her blog to this petition. ${ }^{3}$ This practice is interesting in that it makes use of a second wave activist form, namely the petition, to bring about a third wave disruption regarding the socially constructed, oppositional binary of gender.

With regard to Janua Diaboli's blog content, her posts are also explicitly feminist. For example, on March $17,2004,{ }^{4}$ she writes about her outrage at the controversial decision made by the American government to press criminal charges of first-degree homicide against Melissa Ann Rowland who insisted on 
delivering her twins naturally after being advised against doing so by medical practitioners. ${ }^{5}$ She concludes by suggesting that the real crime here is not Rowland's "defense of her body" but society and the media's "depraved indifference and utter callousness" which labeled this woman a murderer. In other posts, Janua Diaboli discusses the "Gendering of Computer Languages" (3/24/04 10:19 pm), "The Fictional (De)Construction of Gender" (4/8/04 10:12 $\mathrm{pm}$ ) and a host of other topics ranging from stalkers, to marriage and the gendering of toys.

In the general sample, even when authors do not explicitly identify themselves as being feminist, much of their blog content displays feminist undertones. As discussed in Chapter Two, the absence of the feminist label itself is not surprising given that third wavers are opposed to the "imposition of labels, closures, boundaries, and categories" (Mitchell and Karaian 59). Furthermore, there may also be a reluctance on the part of these women to employ the feminist label due to the confusion brought about by postfeminists in the 1990 s and/or the negative connotations feminism received during the 1980 s as a result of the feminist backlash. ${ }^{6}$

A good example of a blog site that contains feminist undertones was created by Sandee and is entitled, I Will Survive. The blog chronicles her experiences as a woman and mother dealing with breast cancer. In addition to her very frank commentary, she has opted to include a photographic essay detailing her chemotherapy treatment (see Appendix C). Likewise, the fat activist ${ }^{7}$ blog work of Patty Thomas, who identifies as a "person of size," 
represents another good example of the feminist undertones that proliferate in these blog sites. Even her choice of blog name, Fat Patties, is politically significant, in that it draws attention to the issue of body politics. ${ }^{8}$

Finally, the last major theme to emerge in the general sample relates to the interconnectivity that occurs via the use of embedded links. While cross linking is discussed later in this chapter with regard to community, the majority of these Canadian women bloggers also use their blog spaces to link to many women-centred and/or feminist related Web sites and blogs. Thus, linking is understood as being a political strategy, employed purposely by women bloggers in order to assist one another in gaining access to pertinent information online.

\section{Case Study: Introduction}

This case study analysis examines the blog work of four authors drawn from the general sample. The four blogs are: Delicious Juice, Dirty Olive , Grass Is Always Greener and Just a Girl. My case study inclusion criteria consisted of all authors who had maintained a secret blog for more than two years, on a personal Web site with a registered domain name and who posted photographs of themselves and biographical information. This section begins with a description of each case study blog. I then examine what happens to three distinct feminist constructs-activism, identity and community-when they are transposed via the blog to an interactive, online space that is produced both for and by women. What is revealed through my analysis is that the technology of the blog provides women with the potential of engaging in more dynamic and expansive forms of feminist activism, identity construction and community 
participation, all of which are rendered visible when viewed through a third wave feminist lens.

\section{Delicious Juice}

Delicious Juice describes herself as a 29 year-old, bisexual Malaysian/French Canadian woman. She lives in Calgary, Alberta with a male partner. She maintains a blog site under the domain name www.deliciousjuice.com. In August 2004, she had been writing her secret blog for a total of 40 months and had posted 1542 entries. She had also received an impressive 5525 comments from her readership. Her blog layout is nonconventional in that she has designed a custom graphical user interface that blends images seamlessly with written content as though it is one structure (see Figure 1).

With regard to activist practices, the issues she discusses, as well as the way in which she writes, are reflective of an alternative third wave feminist style. Her entries range from topics such as body image to detailed entries about her feelings on menstruation and black panty liners. She also specifically identifies as a feminist. In typical third wave fashion, however, the first person narrative that runs throughout the blog site is filled with contradiction. For example, after she and her male partner decide to get married, she writes:

I can't take his last name. It makes my insides hurt. It's not for lack of love - hey, I'm marrying the guy - it's because it really does sound horrible. And the feminist in me is threatening to burn my bra while l'm still wearing it if I do. So we're down to two options: a) We each keep our own 
respective names and worry about the spawn factor if it happens .. or b) I delve into the unexplored world of hyphenation. What to do? (Friday, May $10,2002)$

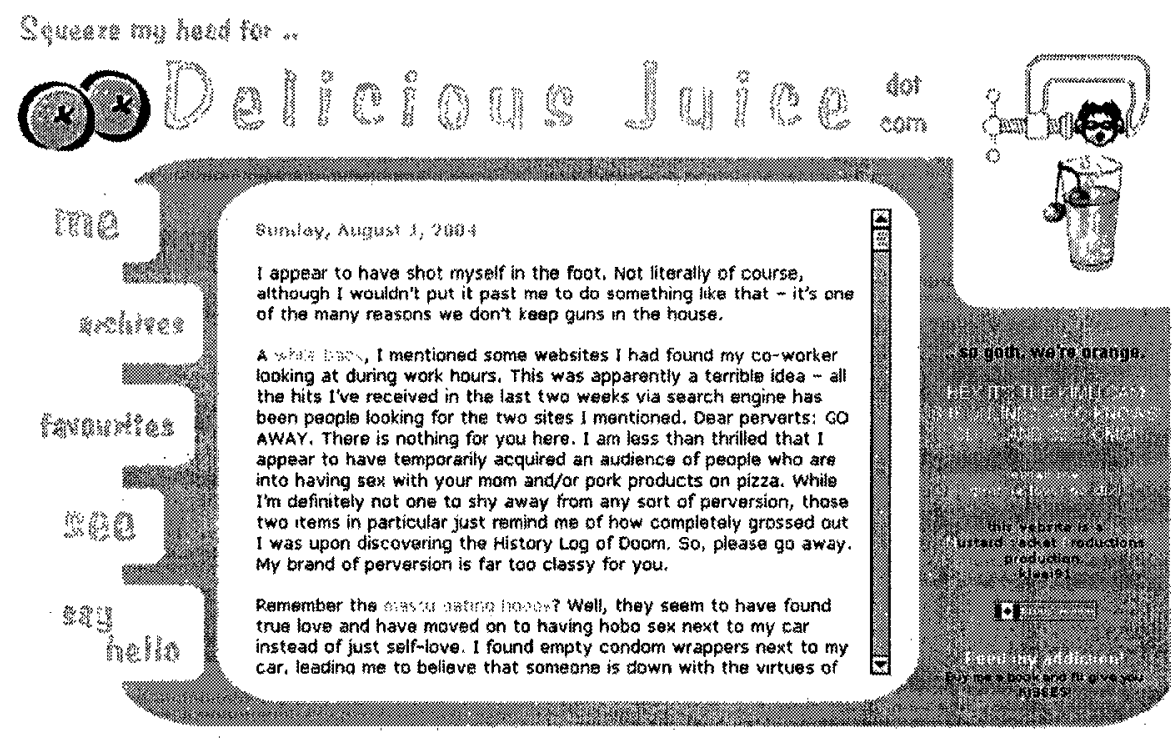

Figure 1

Screenshot of www.deliciousjuice.com

Delicious Juice is also aware of and writes about the contradictions that she experiences in her life. On March 20, 2003, she posts an anecdote about getting her car fixed in which she acknowledges that she "played the Dumb Girl card" in order get assistance in changing the air filter on her car. She writes:

I went to an auto parts store and bought [an air filter] and went back out to my car to install it. Except .. I had no idea what I was doing. I would have liked to have taken it home and tinkered with it to figure it out, but I had places I needed to go and I wanted it changed now... So, I readjusted the neckline of my tank top and waltzed back into the store to ask for help. A 
nice man came out and changed it for me, because I am a wee dumb girl who knows nothing about cars ... I have a nice new air filter, and some guy got to play the knight in shining armour to the helpless female. So what if I don't look like your stereotypical princess - I can be very charming when I have to. Shut up.

Examining the gender and cultural codes associated with Delicious Juice's tale, the reader is presented with, on the one hand, a liberated young women who perceives herself as being capable and comfortable engaging in a stereotypical male activity (i.e., car repair). On the other hand, she openly admits to manipulating the situation by readjusting the neckline of her tank top in order to play the 'dumb girl card' and get assistance with the repair. Using a third wave lens, Delicious Juice can be read as experiencing empowerment through actively and purposefully reclaiming her own objectified female body and using it towards obtaining her specific goal. The contradictory nature of this position is evident in her statement: "The feminist in me is horrified; the girl wearing the white shirt and peering into a filthy car doesn't care."

With regard to the visual presentation of her site, it has a playful zine-like quality to it, both in content and with regard to its look-and-feel. It has been designed around a personal logo that she has created, which appears in the upper left corner of the site. Although this image is of two oranges, it is designed in such a way as to resemble a pair of breasts. In fact, on her tattoo gallery page, she has posted an illustration of her body, in which she places the orange logo overtop of the area where her breasts are located. This represents a subtle, 
third wave act of resistance in which she reclaims a sexualized and objectified female symbol-the breasts-and transforms it into her own personal symbol of self.

Out of the four blogs in this case study, Delicious Juice represents the most heavily cross linked. This suggests that her connection to and participation in an online blogging community is strong. In order to make these cross linking patterns visible, I generated a series of illustrations that places each author at the centre of her own blogging hub and lists all of the peripheral blogs that she has linked to her site. These illustrations also show how many peripheral blog links match those on the blog hub. In the case of Delicious Juice, out of a total of twenty-one links made to peripheral blogs, twelve of these authors included links back to her site (see Figure 2). Many of the peripheral blogs associated with her site also contain multiple cross links to one another. For example, the peripheral blog entitled Renee not only has a link back to Delicious Juice but also has cross links to five of the same blogs (i.e., Arwen, Dooce, G.Girl, Just Sue and Krishenblog).

Another way of approaching the study of cross linking is to map out all of the links associated with a central blog and then to identify all of the links each one of these blogs contains that occurs across multiple sites. When all of the reoccurring blogs are highlighted, the general degree of interconnectivity 


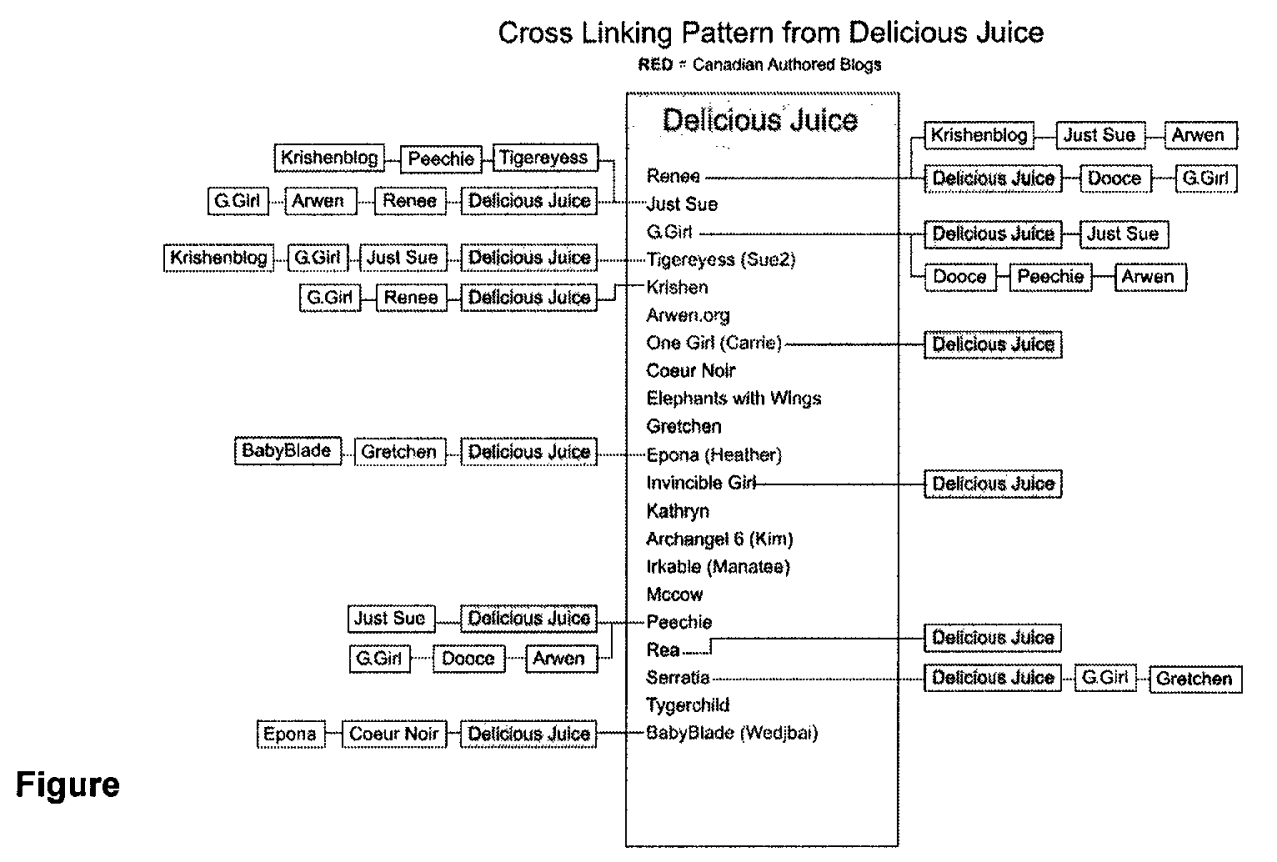

Observations made during the first week of August, 2004.

becomes visible (see Figure 3). In this instance, the initial or central blog used to generate the chart in Figure 3 was Delicious Juice. What this method does is to render visible any blogs that cross linked to interconnected blogs but that might not be listed in the initial blog. Hence, the blog entitled Dooce does not occur in Delicious Juice's links, however, it does occur across several other blogs in the cluster. $^{9}$

How these online communities or blog clusters operate and the nature of the relationships that may form within these spaces cannot be determined by focusing exclusively on cross linking. A more complete picture of blog clusters and their interconnectivity can be obtained by examining cross linking patterns in conjunction with the content of the cross posts. Since the scope of this project is limited, rather than gather quantitative data concerning cross posting, I have 


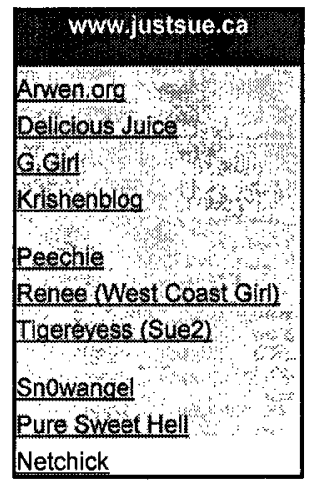

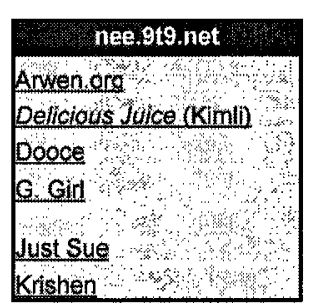

davin.wo/krishenblog

9. Girl (Devoni)

Perbefialkarma (Juie)

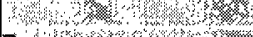

Renee 1707014

tgerevess $($ Sue $)$

Chrissie

www.tigereyess.com

Delicious wice (kimil)

Deviantgoddess

G Girl iDevon)

justsue

Kushen

and

Perpetual Karme (Julie)

Pearlbamboo (Em)

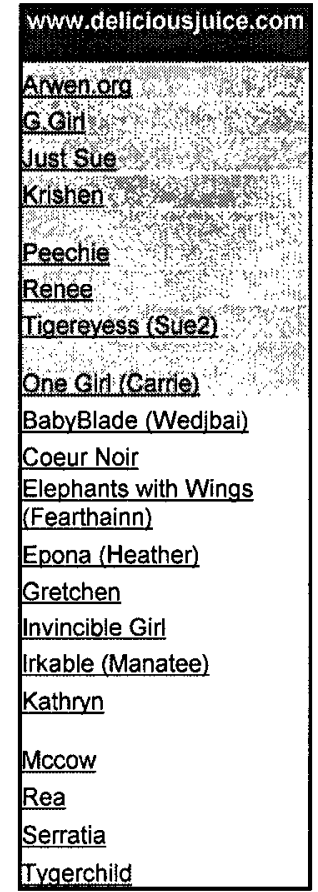

\section{deviantgoddess.} dlary-x.com

Anvery $0 . \%$

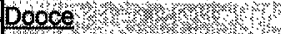
Mar Confaín Berpetual Karma Tlaceyess (Sue) Bobbi Darkviolet Rant-O-Rama Sheshe Truthteller Wonderblossom
Wwiweb.

goddess.netipeechia

Thenorg

Burthe Fuse

Delicious unice dotcóm

Discourse and Datcourse

dooce

Orchid's Garden

ho tite ver.

May Contain Traces of

Nuts

JustSue $\mathrm{ca}$

G.Gir W

pure sheethel mos

"सर

Random SManses

breebop

Buzzstuff

Cat Nastey

ConGEEK

Chix Mix

electric bugaloo

Everything Everrocks

extrametrical

freakishly prompt

go fish

Jhezika

Miss Doxie

My Mental Milkcrate

Other Side of Darkness

snowangel

Tenth Muse

This Chick's Life

trollzor

Violet's Journal

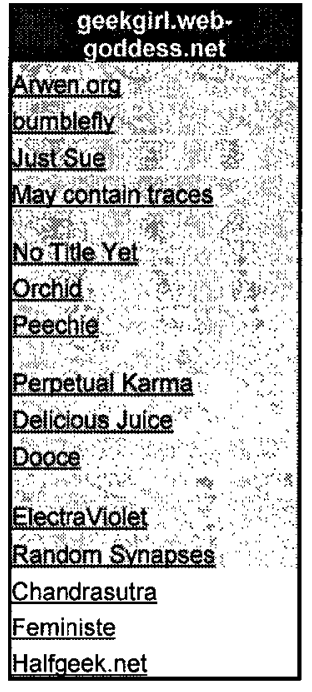

blog.fancypeanutcom

Bifd counth । Y \%?

Deviantooddess

Electra Viole:

G.Gin

Orchid's zencarden

Peecile

Discourse \& Datcoulse:

No Title Yet

www.one-girl.ors

Delicous Juice.

Archeangle6 (kim)

Birdmadgirl (esch)

Number14 (christie)

Random Muse (shan) orchid fancypeanut.com

Bumblety

Bume Fuse:

Electaviolet

Geek Gid

May Contain Traces of

Nits

No Title Yet

Angelweave

Bitch Country

Blogeois

Cafe Etiquette

Chubby Momma

Da Goddess

Furryslug

Hotel Michelle

it Only Happens to Mel Macapinlac

Musings From a Dysfunctional World

Pixie With A Crash Helmet Rockchild

Weave and Unravel

Where the Hell Was I?

Winelovers

Figure 3

Blog Cluster Example. All interconnected blogs are highlighted in gray and red highlight indicates Canadian Author.

opted to provide anecdotal evidence that illustrates how Canadian women

bloggers engage with one another in supportive, women-centred blog clusters.

This discussion is located later in this chapter, in the case study observation

section on community. 


\section{Dirty Olive}

Dirty Olive is a 31 year-old, heterosexual woman of Lebanese heritage. She is married and is the mother of a toddler. One of the interesting aspects about this blog is that she began writing it while she was a student, prior to becoming pregnant. Her blog chronicles her life journey through her first pregnancy, childbirth and in to motherhood. She identifies as a feminist and writes in an inviting and frank manner, covering a wide range of topics from birth control, difficulties associated with breast feeding, to her own anxieties associated with motherhood.

She is an active participant in various forms of feminist resistance, both online and offline. For example, in real life she assisted with a local production of The Vagina Monologues. Writing about the play and posting links to the feminist organizations ${ }^{10}$ its profits help to support, Dirty Olive extends her feminist activist practices online, into her blog.

Dirty Olive lives in Victoria, British Columbia, has maintained her secret blog on www.dirtyolive.net for 39 months, during which times, she made a total of 323 entries. She uses a standard, template style blog interface (see Figure 4). With regard to cross linking, Dirty Olive's blog is also well linked (see Figure 5). She even writes about other women's blogs that she links to via her site. For example, on June 17,2004 , she posted the following comment:

I was reading Dooce the other day and couldn't stop laughing at the insane amount of emails she gets from her personal parenting choices. I think it surprises many people (probably the ones who do not have 
children are surprised the most frequently) that a mother's blog can get

"hate mail". I am certainly not as widely read as Dooce, and my blog

hardly strays away from the topic of parenting, but I still get emails and

comments about how l'm doing something or another all wrong.

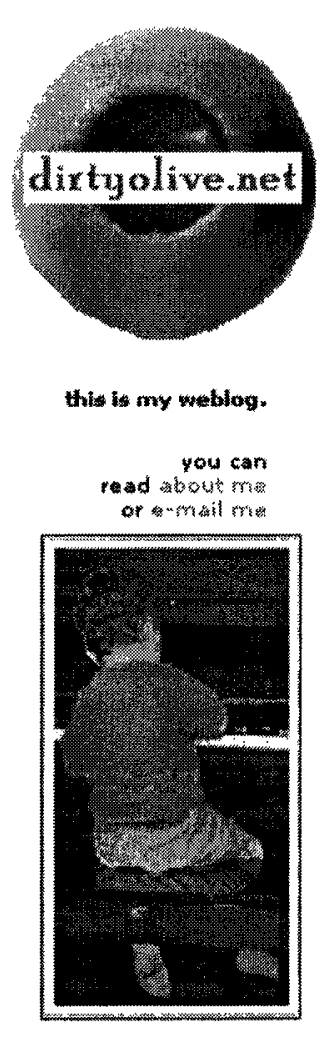

Whorias secret Guide warenting

November $11-2004$

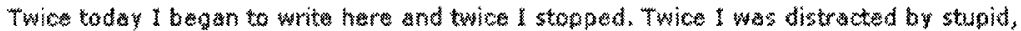

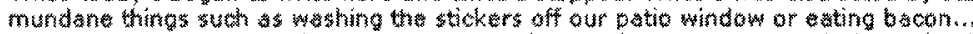

and then I look uo my webpage and see that biury photo and my admission to in adibles masts mo child will actually ingest (if distracted by the right object) and fael compelled to leav sornething more prosentable.

\$o har gows...

The journey from after dimner play up the bathroom and into the both is owting rough.

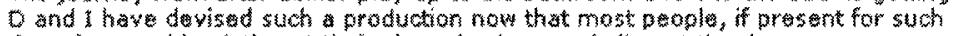

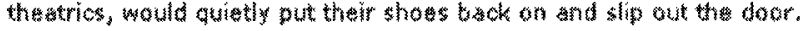

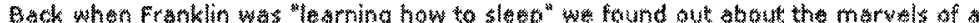

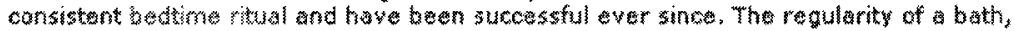
thres stories and milk beftore bed helped us hala franthin.

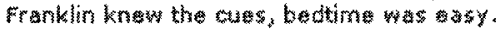

Now however bedtime rituat means.+. bedime.

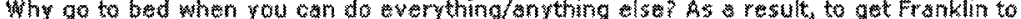

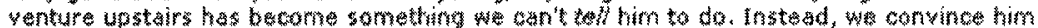

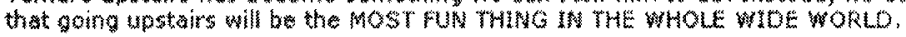

At present, the MOST FUW THWG TO DO IN THE WORLO consists of a parade complete

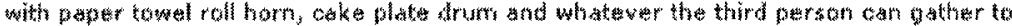

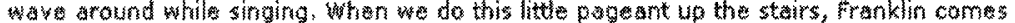
joyfuly slonte singing

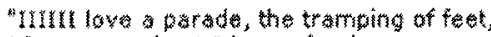

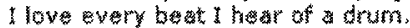

1 lave oura

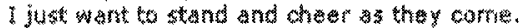

That rat-a tatrat, the blare of a horn.

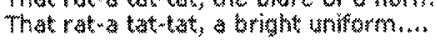

\section{Figure 4}

Screenshot of www. dirtyolive.net

This comment is interesting in that it points to another facet of online

communication, namely that not everyone will like what you write and, given the

blog's openness, other people may choose to share these differences of opinion. 


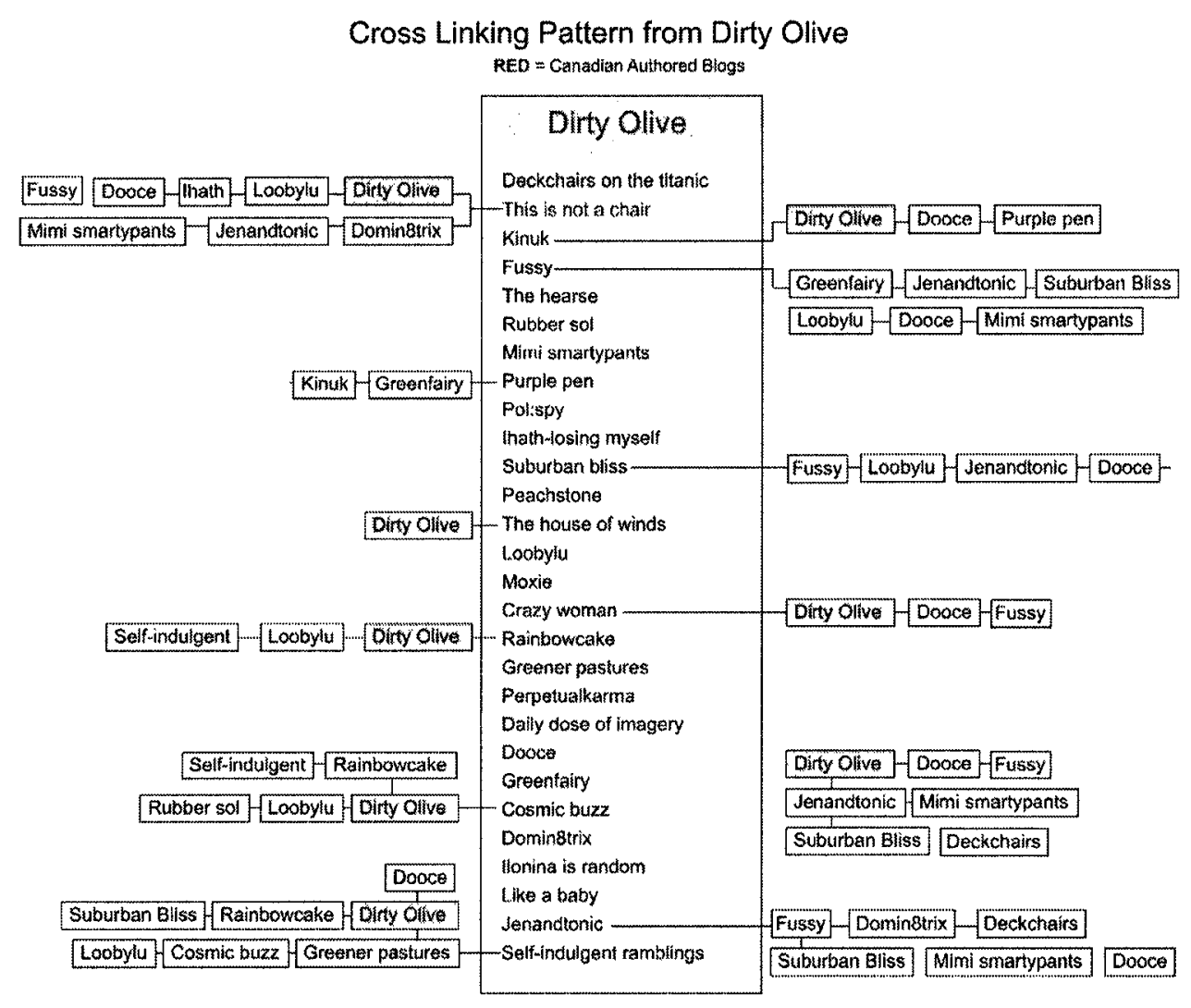

Figure 5

Observations made during the first week of August, 2004

\section{Just a Girl}

Just a Girl identifies as a 26 year-old, heterosexual Caucasian woman.

She has a B.A. in English and works as a professional writer. She lives in

Ontario and maintained her secret blog on www.justagirl.ca for a total of 35 months, in which time she posted over 1036 entries. During the course of this investigation, Just a Girl decided to stop blogging and removed her site from the Internet.

There are a number of recurrent themes that run throughout Just a Girl 's blog. For example, she writes about being an incest survivor. Based on her blog entries in regard to this subject, it would seem as though she is still working 
through the issue. This is particularly evident in the post she makes about her father/dad in her cast of characters section:

Father: the man who sexually abused me between the age of 7 and 13.1 still have problems thinking and talking about the things that happened to me during that period of my life, and that history has caused me no end of grief. It's a recent development that I talk about it at all, and one of the points of this site is to get some of it out of my system. Dad and Father are two halves of the same person; I have problems seeing them as one entity. Call it a coping mechanism.

Another key topic that Just a Girl writes about relates to birth control. This subject and that of abuse are so important to her that she has created separate catalogue pages for each discussion in which links to all of her posts on these subjects are listed. With regard to the issue of birth control, specifically, her entries chronicle a troubled sojourn through various different fiascos which she attributes to a very bad initial experience with Depo Provera.

Her site is less heavily cross linked than Delicious Juice or Dirty Olive 's blog sites (see Figure 6). Although it is interesting to note that one of the blogs to which Just a Girl links, entitled Dooce, is also crossed linked in the blog cluster associated with Delicious Juice, Dirty Olive and Grass. This case study data set, however, was drawn independently of these blog clusters, which illustrates just how interconnected these spaces can be. 


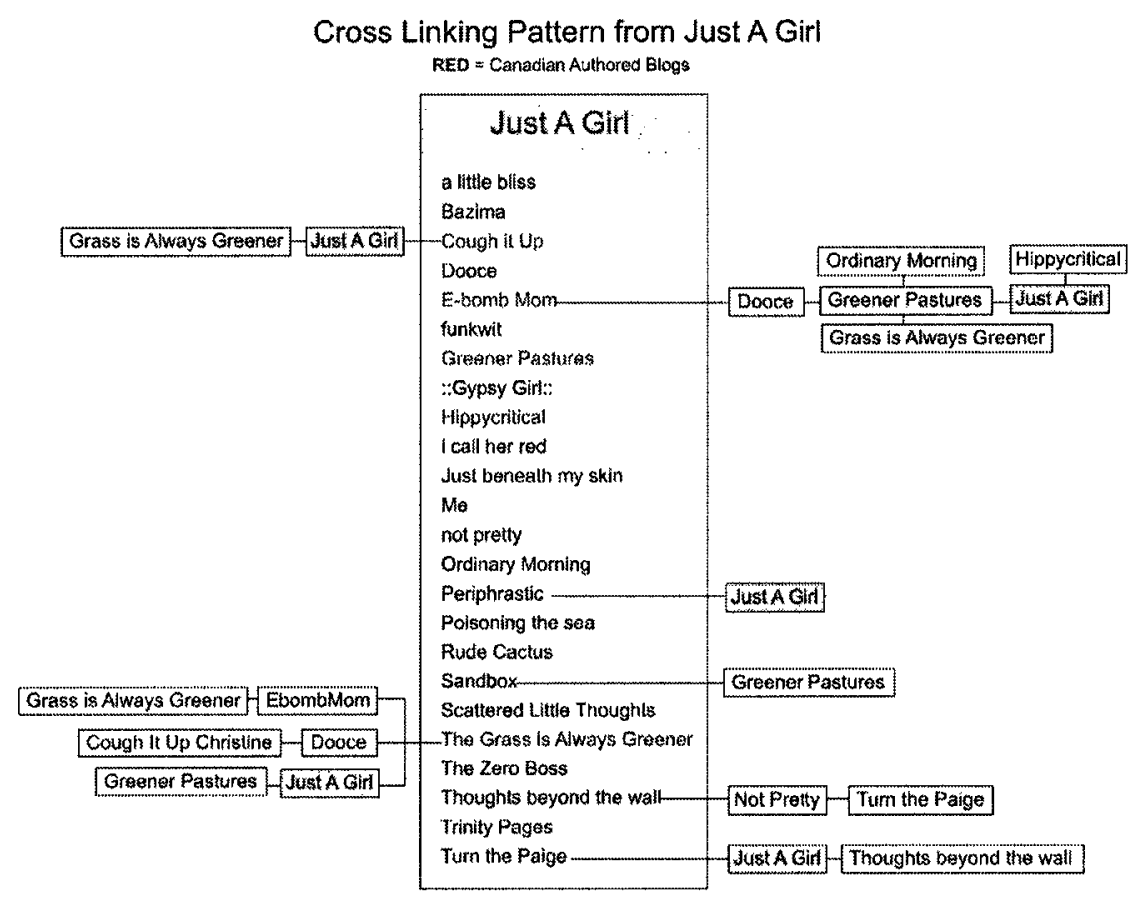

Figure 6

Observations made during the first week of August, 2004.

Based on the way her blog appears, it is obvious that Just a Girl invested time and effort in the design of her site, which she changed several times over the course of its three year lifespan. ${ }^{11}$ The final version sports crisp, clean lines and features a large image of the blog author looking off to the left towards her text (see Figure 7).

The subject matter that she discusses, coupled with the graphic prose style that she employs is typical of DIY third wave feminist publications like zines. For example, on August 28, 2002, after visiting a sex shop she comments, “The racks of porn are disturbing. I don't understand the attraction to women with basketball sized breasts, penetration in every orifice, men with huge penises, 


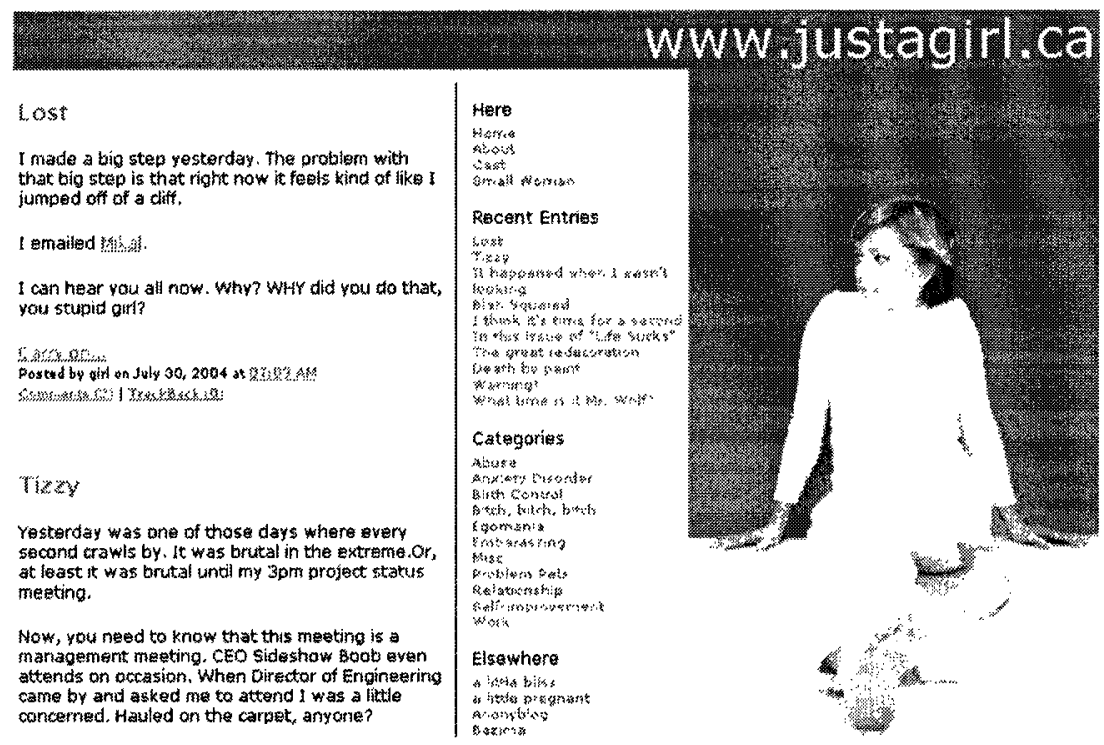

Figure 7

Screenshot of www.justagirl.ca

cum shots, any of it. Seeing it in lurid box shots makes me want to scream."

Other third wave content present in Just a Girl 's blog relates to menstrual product activism. For example, on June 30,2003 , she posts an entry on "the Keeper" and includes a link to the site, www.thekeeperstore.com. She writes:

In girly news, the Keeper was totally worth its purchase price. It's a tiny bit awkward - and vaguely uncomfortable if you're unfortunate enough to not get it positioned correctly - but the benefits outweigh the problems by a long shot. I managed to overflow the thing at one point, and I shudder to think of the mess if I'd been using tampons this month.

By discussing her use of this alternative menstrual product and by providing a link to the company's Web site, Just a Girl not only disseminates information about an eco-feminist friendly product but serves as a role model to other women. 


\section{The Grass is Always Greener}

Grass is a 25 year-old, heterosexual, Caucasian woman who is presently attending law school in Vancouver, British Columbia, although the bulk of her blog was written while she lived in Ottawa, Ontario. Her site is located at www. Grassdiaries.com and contains 569 entries written over a period of 30 months. She values her privacy and stresses how important it is to her that her diary remains a secret. As a result, she states that she has purposefully changed all names on her site so that no one she knows will accidentally locate her blog. She even notes that she also maintains a public blog for her real-life friends to read. This blog site segregation implies that there are different types of content which she is willing to share with different audiences. Grass is so concerned about her privacy that she monitors the traffic on her Web site, writes about this monitoring, and has on several occasions removed posts that she has made but later felt compromised her blog's 'secrecy'.

Grass' statements and actions may well create a heightened sense of personalization for her readers as she makes them aware that they are reading her 'highly secret diary'. In a sense, it is as though the reader is awarded the special privilege of being allowed to peer into a very private part of her life-a part so private that she will not expose it to those with whom she interacts in real life. This creates a rather curious positioning and privileging for her readership, who is at once made privy to her most personal thoughts yet who does not even know her real first name. 
The content she posts represents a mix of anecdotal entries as well as more thought-provoking personal reflections. For example, after she scores at the $98 \%$ percentile on her LSAT exam and her male partner's score is too low to gain admission into law school, she writes,

Do I go [to law school]? Do I go without him? Does he give up his job so I can go and he can come with me? Do I wait and go later? He likes his job here but I desperately want out. Is it a sign that he's meant to do something else? [His LSAT FAILURE has] been a huge disappointment, and a shock too, as I sort of thought this was a sure thing. (March 4, 2004) In contrast, prior to this on September 9, 2002 she writes, "I'm a feminist, and goddamn it, the Man of My Dreams should follow me to where I want to go." Her diary contains many examples of the struggles she faces as she moves towards finding a place in the world and a purpose for her life.

With regard to Grass' visual presentation, she also has experimented with a number of different layouts. Her most recent iteration follows a standard blog template, however, the main image she has selected for her site-a neon green Popsicle-is non-conventional (see Figure 8). This image depicts a tempting, consumable treat that will not last long; it is in a state of transformation (i.e., it is melting and has one bite missing). This imagery symbolically reflects the act of blog writing, in which the author invites her readership to sample a piece of herself through the consumption of her blog stories. Just as the Popsicle is in a state of flux, so too is the blog author as her life unfolds and is consumed by her audience. 


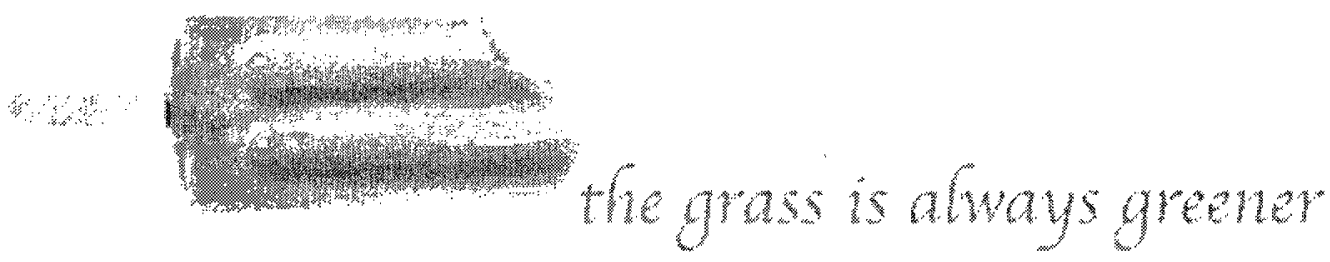

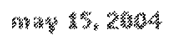

Popsicles

I haye this addiction sometimes where I get working on something web-related and then 1 just can't stop. I think: "I'll just figure out why this part of the layout isn't working." and then once that's done I'll think, "but I just need to perfect this colour schema."

This time I've been better. I've let it grow slightly more organically. I forced myseff to go to bed at one last night even though I could have easily stayed up until 4 working away. And now I'm going to put it away again, well, just after I make sure the comments section looks alright. See, I'm discontinuing $m y$ guestbook, because it's been so weird

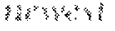

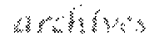
wats

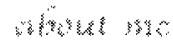
hisk
Whition

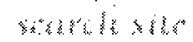
hasests
sybarans
worthy

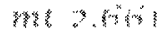

Figure 8

Screenshot of www. Grassdiaries.com

Finally, her site is not heavily cross linked (see Figure 9). It would be interesting to compare this blog with the version that she shares with the people she knows in her real life to see if she is more interconnected to that online community.

\section{Why Write a Blog?}

The most common reason cited by those in the case study for engaging in the act of blogging is that it functions like a form of therapy. Delicious Juice writes that she finds blogging "therapeutic, in a very public sort of way!" (April 4, 2002). In a lengthy post about blogging, she also 


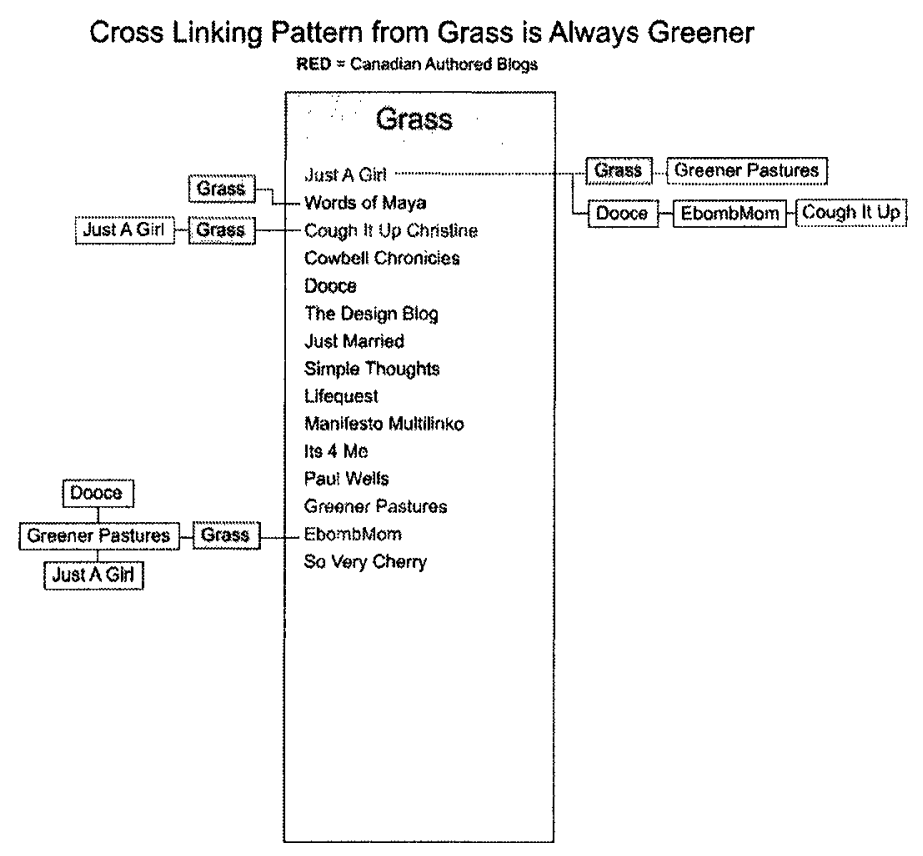

Figure 9

Observations made during the first week of August, 2004.

poses the question, "Why do we say things on blogs when we wouldn't say them to someone face to face?" To which she replies:

Well, I don't. Everything I say on my site l'd say to someone face to face.

Okay, maybe I wouldn't tell my mom what I "really* think about her, but the rest of it? I'd say it. I'm just able to say it a lot more precisely in my blog than I would otherwise. I'm really quiet in person until I get comfy; then it's really hard to shut me up. I write this site like l'm talking to a friend, and l'd like to think most of my readers are a friendly sort. Sure, I wouldn't just open up to a perfect stranger and tell them about the problems I'm having with the mysterious ass-scar I have, but l'd write about it in a journal. Is 
this healthy? It is for me. I'm too poor to afford therapy, so l'm forcing my neurosis on all of you. And it really does help, you know. (April 17, 2002) Likewise, Just a Girl states that the point of her site is so that she can "say the things that I need to say - all of it, with as little filter as I can manage. What good is baring your soul if you're ashamed of the packaging? [...] the things I say here are my version of therapy" (October 2001).

With regard to Grass, the reasons she states for writing a blog are slightly different:

I started this diary at the beginning of 2002 as a way to practice web skills. I had never read an online diary when I started one, so I actually thought having a cast page was original. I had no idea that there were lots of people out there with web diaries far racier and more original than mine. It's grown beyond that a bit, and I hope my skills have too [...] It's just a way for me to write, to share, to give back a very personal viewpoint that some readers seem to like. (February 2, 2002)

At the same time, on September 10, 2002, Grass acknowledges that she uses her blog space in a therapeutic manner when she laments over how she has been "wasting all this space writing about the my same old problems again and again" (September 10, 2002).

Dirty Olive presents a more elaborate discussion regarding why she maintains a blog. In typical third wave feminist fashion, her post provides an excellent example of contradiction. Dirty Olive states: 
I think blogging is wonderful because it is interactive. The feedback from blogging makes me reflect more deeply than if I was writing on a piece of paper. I've also found that I feel a connection with fellow bloggers and sometimes I'm very moved by their writing even though l've never met them. (July 24, 2004)

Later in the same post, she contrasts blog communication with the interactions she has in real life with her friends, the latter of which she feels leaves less room for misinterpretation. She states, "I feel so one-sided here, on my internet platform. Why do I want to write if there is no give and take?" As is often the case in the blog world, Dirty Olive 's contradictory statements are further contradicted when one of her readers responds to this entry. The fact of the response itself serves to illustrate that there is 'give and take' or exchange in blog space. Furthermore, since Dirty Olive poses the question in the first place, it implies that she is conscious of her readership and that she also anticipates she will receive a reply to her question. In the following example, a fellow blogger who identifies as Lucinda writes:

I write because it heals me, it gives me fresh perspective and I feel free to move on... I'm interested to read that you think your blog is one-way. I think blogging is wonderful because it is interactive. The feedback from blogging makes me reflect more deeply than if I was writing on a piece of paper. I've also found that I feel a connection with fellow bloggers and sometimes I'm very moved by their writing even though I've never met them. From my selfish point of view, I hope you don't stop, because I 
enjoy reading dirtyolive so much and I adore receiving your comments on my blog. (July 30,2004$)$.

There are number of significant points in this passage. First, Lucinda states that blogging represents a positive experience for her, which she describes as having 'healing effects'. This is similar to the blog-as-therapy comments made by Delicious Juice and Just a Girl. She also places emphasis on the interactive nature of the medium. In keeping with the notion of community, she writes that she feels a connection to other bloggers and appreciates their participation in her blog.

In another passage by Dirty Olive, she poses the question, "Is [blogging] all some sort of self-absorbed babble? " In her response, she writes:

I don't think so, or I certainly don't think this is what it is about for me. I don't scrutinize my stats page to see from where and with what link people are reading my blog. To tell you the truth, I get a little freaked out when people I don't know are reading it and frankly, it surprises the hell out of me - why are you here? what could be interesting about what I write? (April 8, 2004)

The contradictions continue as Dirty Olive states that she does not 'scrutinize her stats' yet is nonetheless 'freaked out' because she is aware that people with whom she has no connection are reading the words she has purposefully posted to a public space. Even more ironically, the only way to obtain this information is, in fact, by scrutinizing one's blog statistics page. Furthermore, the post itself is 
posed as a direct question to this unknown readership_-why are you here?' She adds:

Right now, weblogging is it's own little sub-culture and I know it must seem strange to many of you that I write online about my family and myself - but I do, I enjoy it, and have met wonderful people through it all. [...] The most important thing about this weblog is that it is only a story about an ordinary person doing ordinary things. If you do not know me or are not interested in the things I do in life (such as being a new parent), you will quickly become bored. I most certainly do not write this for mass entertainment - as I'm sure you have noticed (May 5, 2004).

It would seem, therefore, that in this instance, Dirty Olive is not only aware of her readership, but that this unknown entity is of interest to her, so much so that her post appears to be written in a conversational style addressed directly to them.

Finally, in Dirty Olive 's case, her entries are also of personal significance to her. She writes, "When I was in the Vagina Monologues it was nice to look back and see the progression toward our performance. Now that [my son] Franklin is here, the archives are what ultimately keeps me writing and are very precious. I am looking for a way to print out and bind my archives. I want a book of my weblog" (April 8, 2004). Based on this entry, it appears as though her blog does not just represent a medium though which she is able to express herself publicly, but also functions as an important method through which she has recorded her life-it is so much so, that she expresses a desire to create a more stable, concrete version of her blog by capturing it in print. 


\section{Activism}

As an alternative public medium through which women can gain access to the means of media production, the blog represents a unique space which can be used for feminist activist purposes. As discussed previously in this chapter, with regard to the general sample, in some instances bloggers make it known that they are feminists and that their writing represents one way in which they are actively participating in the feminist project. With regard to the issue of generational tension within the contemporary Canadian women's movement across feminist waves, I contend that it exists, in part, because much of the work that young feminists undertake is not highly visible and occurs in unusual places, such as online in blog space. Nonetheless, the feminist issues which women raise in their blogs give voice to the many ongoing, contemporary challenges that women face in Canadian society.

The blog written by Dirty Olive provides a good example of alternative feminist resistance. The autobiographical narrative that she posts begins when she is a university student. As her life unfolds, she writes about her transition through pregnancy into motherhood. By exposing her feelings about the experience, she makes visible the difficulties women face in contemporary Canadian society as they negotiate their careers, familial responsibilities and personal desires. Just before the birth of her son, she writes, "I'm scared though. I'm scared of labour and I'm scared of taking care of a baby. Sometimes I wonder if my life would have been just fine if l'd made the decision not to have children" (October 30, 2002). 
Her words reflect the very personal struggle she is experiencing as a result of her choice to have a baby. On September 17, 2002, just after she drops a university course, she writes:

I feel a twinge of guilt. I need these courses to get the jobs I want in the future but at the same time, how will I ever study with a new baby coming? As well, I want to make sure I get the grades I am capable of. I find that I am so caught up with making sure my life doesn't change too much just because of a baby yet in reality - it will and it should. I want to finish what I've started, I'm excited about my future. I don't ever want to resent not completing this and therefore, not fulfilling the "non-Mom" part of me. I want to have a baby but I also want to remain me. Is this possible? Am I a bad person for insisting on this? [...] I feel quite guilty, but also very strongly, about this. Perhaps I am just from a spoiled generation. By posting this experience to the Internet, Dirty Olive is participating in a form of feminist activism in which she becomes the producer of her own cultural space, where she shares her struggle with others, in an attempt to resolve issues that surround her own personhood in relationship to her forthcoming motherhood. Later, once her child is born, she writes about the challenges she experiences as a feminist and a woman raising a son:

When $D$ and I first found out we were having a boy I started to think about all the things I could teach my budding little feminist son. I was eager to raise someone who would see an equal distribution of chores around our home. I had visions of little Franklin reading about flowers and fairies as 
well as turtles and mud puddles. There would be no predominance of boys toys in the house. In fact, I would buy him all the dolls he desired and if he wanted to dress up in my slips and try on makeup I would encourage him to do his own thing. Try as I did to be as ambivalent as possible in terms of his gender, he is definitely leaning heavily toward the realm of mighty machinery, a stereotypical boys area of joy. (March 6, 2004).

Dirty Olive's post received a number of replies in which other women wrote to her about their feelings regarding gender, socialization and parenthood. For example, Tred Lightly wrote, "J and I are happy to hear about your determination to let Franklin find his own interests and not let stereotypical sexually inclined toys be forced... J and I plan, like you, to let our spud figure out it's own preferences." While this blog conversation does not look activist, through the act of public posting, part of what Dirty Olive is doing is modeling alternative feminist ideas about child rearing. In this particular instance, she is also raising awareness about the inherent difficulties associated with countering gender stereotypes when it comes to raising children.

Running throughout these case study blogs are examples like this, in which the activism in which women engage takes the form of sharing experiences and raising questions. On October 29,2001 , in a post entitled, Body vs. Container, Just a Girl writes, "Can you distance yourself from your body? That's what I've done. It's packaging. The container I carry myself around in. Or is it?" In this particular post, the author discusses her experience with sexuality, having survived her father's sexual assaults as an eleven year-old child. She 
conveys a conversation she has had with her boyfriend regarding her difficulty with sexual contact. Just as Dirty Olive 's post renders visible her ambivalence and the guilt surrounding her transition into motherhood, Just a Girl's post helps to raise awareness about sexual assault, incest and its permanent impact on one's life.

Another key aspect associated with the blog as feminist resistance, is how it functions to disrupt notions of public and private. For example, after realizing that she was just standing several feet away from a fellow blogger that she knows only online, Grass writes,

And it's just strange to think that there are people who are part of your life even though you don't even know them. And they could be the person standing in front of you at the grocery, or flipping you off when you cut them off in traffic, or using the lady's bathroom right before you. I haven't figured out what it means yet. If it means anything. (September 19, 2002). Although these women come together and form supportive, interactive online communities in which they frequently share very private experiences with one another in the public blog forum, their connection to one another seems bound to the virtual. Even though Grass may know a considerable amount of personal information about the blogger with whom she came into contact in real life and they may even both consider one another to be 'friends', an unspoken virtual contract seems to exists whereby to approach her online friend on the street would break some blogging mores. Women bloggers, therefore, seem to occupy 
simultaneously the precarious position of being close, personal intimates and distant, anonymous voyeurs.

As a central third wave feminist theme, women's negotiation of their own sexuality represents an important and recurrent subject in many Canadian women-authored blogs. Talking about sexuality in an open and frank manner represents an important form of resistance for young feminists. What these women write about also reflects changing social norms with regard to women and sexuality. For example, Grass writes openly about a casual sexual relationship that she had in which she states:

We did it around 6 times and I don't care what anyone says, that's a lot. I think it had to do with the fact that we're both water signs. Jacob was a water sign too and I have to tell you, the last time was fabulous. Really, much more exciting and kinky than the other time, which had been just the drunken standard. I don't think I had an orgasm though, although I did fake it. But it was a lot of fun nonetheless. (April 17, 2002).

Delicious Juice also writes in a very open and graphic manner about sexuality. For example, in reflecting upon her neighbours, she writes:

The people downstairs were fucking, and the girl is very, very vocal. She shrieks like a fucking banshee. Often. I'd give my left arm to be that multiply orgasmic. I'm all for people having gratuitous amounts of sex, but they're crazy. They kept me up til 3 am with the fucking, then they woke me up at 10 am with more of the fucking. They fuck a lot. They're fuck monkeys. (April 8, 2001). 
Being open to and willing to discuss personal, female-body related issues also extends to other subjects. For example, Grass writes:

I had my period last night and it leaked through the sheets and onto the mattress. That hasn't happened to me since my teens. I spent the first 15 minutes of my morning cleaning it up with stain remover and cleanser. Wiping away the bright red colour that matched the leaves of the trees. Wiping it away with relief. It was late. By almost two weeks. I peed on to a stick a few days ago to make sure everything was normal and almost immediately afterwards the aching started as if to say: "I haven't fooled you? Here I am." Relief and grief. (October 4, 2002).

What these posts do is to render visible important women-specific subjects that were previously kept secret and hidden. Writing about these topics in their secret blogs, ironically renders them visible and public thus functioning as sites of female empowerment as well as feminist resistance.

Delicious Juices offers another good example of online feminist activism, that does not necessarily look 'quite activist enough.' She identifies as a "Girl Gamer." ${ }^{12}$ Since online gaming is traditionally associated with and dominated by male players, girl gaming represents an inconspicuous site of contemporary feminist resistance that goes unnoticed due to the location in which it occurs. Girl Gamers band together through play and, in doing so, form their own, unique, online social enclaves. On July 22,2002 , Delicious Juice publishes an entry to her blog entitled, Girl Gamers: Fat Ugly Whores, or Cheap Sluts? Her post is in response to an article she found highly offensive that was published on 
PlanetQuake ${ }^{13}$ regarding the members of the all-female RA3 clan, Girls of Destruction. She begins her entry with a description of her experience as a women with online gaming:

The way things work in the gaming community: the instant a female player gets a little piece of the spotlight, the scum of the earth pop out to say hello and remind us how worthless we all are as humans, let alone as players. It doesn't matter what the person plays - if you're a female gamer, you're automatically going to be a) fat, b) ugly, c) slutty, d) stupid, e) in it only to attract guys, or f) all of the above. Lucky us. Anyone want to join our clan?

Her main contention with the article is that it undermines Girl Gamers by depicting them in terms of oppressive stereotypes. Her outrage is further exacerbated by some of the statements made by purported fellow Girl Gamers. For example, one statement from the article reads, "I don't think girls should get into gaming. Honestly, it's cool that girls play games, but it doesn't prove crap and it doesn't get you anywhere but 50 pounds fatter, and 50 friends deducted from your life."14 Delicious Juice responds to this by stating, "when you do an interview like this - you're putting yourself on the map as the "typical" girl gamer even if that isn't your intent. Many people will read that article, and many people will assume that this is the new face of girl gamers everywhere." With regard to the statement about gaining weight, Delicious Juice responds by stating, "try telling that to my best friends, my fiancée, the changes l've made in my body, 
this website. Fuck you... Way to do a disservice to every LEGITIMATE girl gamer out there. You rule. Have my babies."

As a testament to her feminist grounding, she also makes an interesting observation about the user names associated with one of the interviewed women:

She plays under the equivalent of me playing as "RakE'sGiRL" ${ }^{15} \ldots$ Stand up for yourself. Make a name for yourself. You are not someone's property. He got you into gaming? That's cool. You're proud of dating him? That's cool too. You feel the need to label yourself like the whore people are accusing you of being? Not so cool. Fuck, I hate that.

In response to other comments Delicious Juice has read online with regard to Girl Gamers, she writes:

As with any exposure to a female, the slugs come out of the woodwork to post comments - on at least four different gaming sites that I've seen discussing the girl's looks; how she belongs in the kitchen and not in front of the computer; how good looking girls wouldn't bother gaming because they have better things to do; blah blah only fat ugly sluts play games; blah blah look... Why can't I just play? Why can't I play the game with my friends and have fun? Why do I have to constantly put up with this bullshit JUST BECAUSE I HAVE A FUCKING UTERUS?

She concludes by stating:

I'm ashamed to be a girl gamer if this girl is the new face of our "race". And I'm ashamed to be actively involved in a community with so many 
misogynists. And on the other hand, l'm a girl gamer - one of the neatest things in the world to be - and in my own little circle of friends, l'm exactly how l'm supposed to be.

Although this post by Delicious Juice does not seek to bring about structural change to Canadian society with regard to issues of oppression and marginalization, as a form of third wave feminist resistance, her words function to counter oppressive online representations of women. Moreover, she also serves as a politically conscious and empowered female role model, both through her participation in non-traditional female activities such as gaming and the creation of a blog site through which counter-hegemonic dialogue with other women becomes possible.

One final interesting example of online feminist resistance that represents a cross-over type of activism and draws on second wave feminism relates to online polls and online petitions. In the discussion of the general sample, I provide an activist example of a blogger who links to a gender poll. Through various online services such as www.ballot-box.net, individual bloggers can create their own polls and embed them quickly and easily into their sites. Sometimes bloggers create these polls for entertainment purposes, while at other times, they ask serious questions of their readership.

\section{Identity}

In examining the ways in which Canadian women bloggers negotiate and construct identity online, a range of treatments are visible. In some instances, authors provide brief statements about themselves, while at other times, they 
provide elaborate descriptions of their bodies, sexuality, social location, feelings, opinions and attitudes-all of which function to create online constructions of the self. For example, Just a Girl describes herself in the following manner:

I'm a girl. I'm nothing all that special, in my own eyes. Just a little girl.

Maybe a smart girl. Not a particularly wise girl. I'm in my twenties; I've got an English degree from a well-known engineering school in Ontario; I'm usually kept busy and amused by my job as a writer - or is that frustrated? In contrast, Delicious Juice provides an elaborate exposé of biographical information, written in a much more graphic, third wave style (see Appendix D). Juice describes herself as "Canadian - Pagan - half Malaysian - short - curvy video-game player - e-sports caster - somewhat amusing - foul-mouthed - dirty, dirty girl - great friend - wordy, mouthy motherfucker - likes to swear for shock value - silly." ${ }^{16}$ She also includes an extensive and highly personalized list of physical characteristics:

Height: 5'3.25". As you can tell, I'm a little insecure about my lack of height. Don't you EVER forget that extra quarter inch .. it makes all the difference in the world.

Weight: Gradually shrinking.

Eyes: 2 (They're dark brown. I don't like them, other seem to. Crazy bastards.)

Hair: Black, like my soul. I'm more or less Asian .. I have Asian hair. Skin: Coffee with two cream. ${ }^{17}$ 
Her biographical information not only includes basic physical descriptors but is also punctuated by qualifying statements which provide clues as to how she experiences her body. With regard to her height, she states that she is "a little insecure". When commenting on her weight, she indicates that she is "gradually shrinking", which suggests that she places value on the reduction of her body size, presumably through dieting. She adds:

I'm almost 27 years old, I'm 5'3.25" tall, I have black hair and brown eyes. My nose and tongue are pierced, my left arm, right ankle and back of the neck are tattoo'd. Before the year is out, l'll have at least two more - right arm and left ankle. I'm all about the symmetry. I have chronically dry skin that scars easily, a terribly cute nose, and really nice lips. They make wearing lipstick fun... I'm allergic to birch. This means I can't eat half the fruit l'd like to eat, and tree pollen makes me sneeze and my eyes turn red and puffy and it's not altogether an attractive sight. Almonds are deadly, they make me stop breathing. This is a bad thing, they tell me. So I don't eat the almonds. ${ }^{18}$

Consistent with a third wave approach, the coarse quality of her prose functions to disrupt and undermine stereotypical representations of women.

The virtual embodiment of Delicious Juice not only occurs on a textual plane but also extends into a visual dimension with the inclusion of author photographs. She has posted dozens of images in which she portrays herself as being playful, rebellious and bold. These images are atypical of those of women 
produced by the mass media. For example, she has included a gallery of her tattoos, ${ }^{19}$ some of which depict female fertility goddess symbols (see Figure 10). For Delicious Juice, then, online identity is very much connected to her active transposition and reconstruction of the virtual body, both visually and textually.

With regard to Dirty Olive, she has posted a limited number of images of herself online yet these do not seem to represent a central component of her blog site. The bulk of her blog work is textual and the images she has included
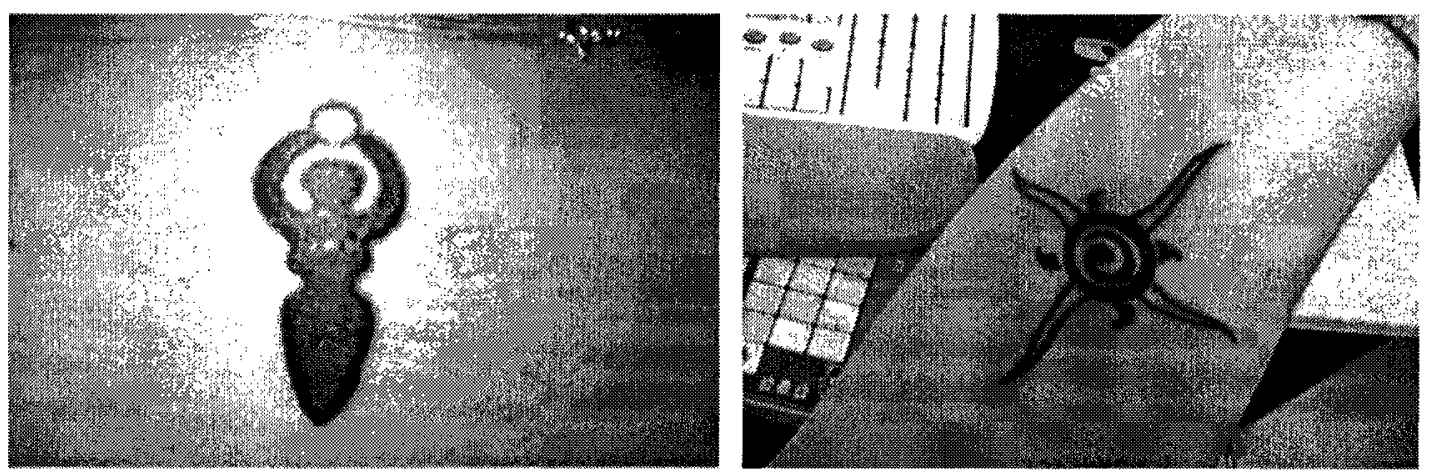

Figure 10

Delicious Juice Tattoos

seem to function as little asides to the text, in which the reader is made privy to glimpses of her life. Looking at these images, one is not left with a sense that her online presence is intimately enmeshed with body, as is the case with Delicious Juice.

In contrast to both of these blogs, Grass has opted to almost completely obscure or erase her body online, an act that she equates with the issues of secrecy/privacy. She writes: 
If you think you know me personally, have met me, know of me, please advise me that you're reading this journal. It's really only fair. All names are fictional for a reason, identifying details are mostly smudged out. If you do know me, reading this diary does not give a full picture of my life, nor is it intended to... I request that my privacy is respected as much as possible. $^{20}$

The only image that Grass has posted of herself is one that she refers to as being "a not too identifiable picture" (February 2, 2002) (See Figure 11).

Out of the four case study blog authors in this sample, Grass is the most concerned about people discovering her 'true identity'. In a post entitled, Caught, she writes:

I found out this weekend that someone I've met has read this blog and in fact passed on some of my insights/confidences about a certain person to that certain person. I guess maybe it was stupid to think that wouldn't happen, to count on the number of blog readers being so low that I would never eventually run into them.... It also made me realise I have no idea who reads this anymore. I thought I had a handle on the readers from the guestbook entries, the occasional e-mail. I thought I knew most of my regulars. But maybe I don't. I have my whole year poured out in this thing, so many secrets written on this little keyboard. But also so many things missing. While it is $100 \%$ me, it's not $100 \%$ of me. Anyway I have no idea how this will affect my blogging. I don't think it will stop me, but it's definitely making me rethink some of my entries, some of the things I've 
said in anger or frustration or when I was feeling hurt or low. I guess I just thought the changed names, the lack of detail, would shroud me from any surveillance. But I guess someone figured it out. Sadness.

A similar concern over secrecy is taken by Just a Girl , who writes, "I won't tell you who I am for a simple reason: I don't want you to know... If you figure out who I am, please keep it to yourself; refrain from talking to me about this site's existence. ${ }^{21}$ In her initial blog iteration, she posted two partially

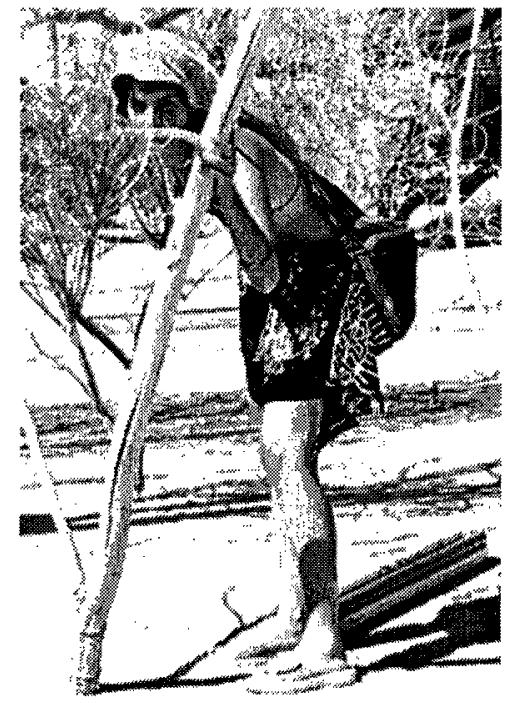

Figure 11

Partially Obscured Image of Grass

obscured images of herself (see Figure 12). One of these images shows her back, in which it is evident that she has posed naked for the photograph. This presents yet another contradiction, in that she expresses a desire for secrecy, yet has posted an image in which her body is exposed. The humorous aspect to this photograph, however, is that while the viewer is aware of Just a Girl's 


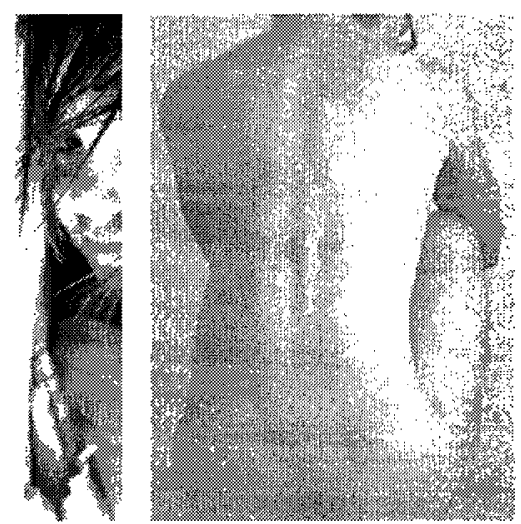

Figure 12

Just a Girl, http://www.justagirl.ca/about.html

nakedness and its implied openness and vulnerability, she remains nonetheless hidden since her back is turned to the camera.

The blog also creates a space in which issues associated with identity can be given voice. For example, Delicious Juice writes about her experience of belonging to a visible minority. She states that the most annoying thing people ask her is:

"What are you?" meaning, "What nationality are you?". I'm HUMAN, thanks for asking. I don't mind it when people say "Are you <insert incorrect nationality here>?", because it's an honest question. But "What are you?" smacks of them not knowing literally what I am .. am I man or beast?! For those who care, I'm actually half Malaysian and half French Canadian. I've been mistaken for the following: East Indian, Native Indian, Hawaiian, Indonesian, Filipino, Chinese, Japanese, Korean, Vietnamese, African, Mexican, Inuit. Plus more that I'm forgetting. Not one person has ever guessed "Malaysian". Huh! ${ }^{22}$ 
Her comments reflect and give voice to the difficulties and frustrations she experiences given her ethnic heritage. By raising this issue publicly, she not only is working through issues of identity, but is also engaged in a form of activism and education. Her words and the experiences she describes, are not those that one would typically find in the Canadian mass media. In this way, the blog functions as an alternative, public site that can be used to broadcast diverse lived experiences.

The blog is not just a site where identity is transposed via digital representations of the body, but it is also a site where women discuss, negotiate and render visible the complexities associated with the relationship between self and body. For example, after seeing some photographs of herself taken by friends, Grass comments:

I couldn't believe I was looking at a picture of myself. My bones were jutting out of my chest and my ribs were clearly visible. I really hadn't noticed how much weight l'd lost over the past few months. I'm all bones, especially in my chest area. And when I catch myself in the mirror sideways I see that I'm practically two-dimensional...I don't like the way the secretaries at work always reach out to pinch me. "You're so tiny," they say, but not in a nice way. I hate that I'm not gonna get any sympathy for bitching about being too skinny. (July 15 2002).

By posting about this experience, Grass is not only engaged in the construction of her own online identity but also appears to be actively negotiating her own real life relationship to her body. 
While this example addresses the issue of negotiations of identity, it also illustrates the recurrent third wave theme of contradiction. To put her post into perspective, Grass was approached several months earlier on the street by a modeling scout who invited her to register with the agency she represented. Grass debated doing so and in the end, did register, took their preparatory course and finally accepted work as a part-time model. On one level, this would seems to contradict the insecurity she expresses in the 'too skinny' post, since one would expect that being a model would require confidence in the body. It could also be argued, however, that she was drawn towards this work precisely because of her insecurities. On September 24,2002 , she posts an entry about her first modeling job experience. She writes, "So: last night I did my 'ho' thing. I was an event model. I had to wear silver hotpants, a silver bra shirt and feathery wings. It's part of this Club Tour they're doing across Canada. The costume actually wasn't too bad and maybe l'll even put a pic up of it later". She adds, "I tried to look at it as a learning experience that I would take something away from, sort of like Gloria Steinem's retrospective I was a Playboy Bunny."

This post points to an underlying feminist consciousness, in which Grass is aware on one level that she is engaged in an act that objectifies her own body. At the same time, she remains an active and empowered subject by choosing to harness her own body to meet her end goals. Although she labels this activity in a derogatory manner, "I did my 'ho' thing," she positions the act within a feminist context by making reference to Gloria Steinem's research on Hugh Hefner, in which Steinem worked as a Playboy bunny for several weeks. In a sense, one is 
left with the impression that despite her participation in an objectifying activitymodeling her body in a sexualized way for the "male gaze"- by not "buying into it', Grass reframes and reclaims her role as an active, empowered subject.

This entire post is filled with third wave contradiction. For example, she describes how one man attempted to complement her by stating how "cool" he thought it was for her to work as a Maxim Girl (the modeling agency for whom Grass is employed). In response, Grass writes:

And I don't know if it makes me really sad or really angry. I mean does he really think it's is my fucking lifelong dream to wear some stupid outfit and hand out glowsticks? It's just a job. It's sort of pathetic how some men think that a woman's life is vastly improved because some guy says she's hot. Does he really think I give a fuck that some twenty-year old engineering student with a cheesy shirt and beer breath thinks I'm sexy? I mean the part that was fun about it was the not caring. Being able to walk around in silver hotpants without feeling totally self-conscious. Realising that I'm so much more comfortable with myself and my body than I used to be. (September 24, 2002)

What this statement suggests is that Grass is cognizant that her actions can be interpreted by others in different ways but that the openness of her acts to interpretation seems to cause her grief. Although Grass considers her modeling to be about asserting herself in a positive and confident manner by displaying her newfound comfort with her own body, she appears to be troubled by the fact that 
"some men" might read her actions in a more shallow, limited and objectified manner.

\section{Community}

In order to determine whether online communities form in blog space, I examined two variables: cross linking and cross posting (see Chapter Three). The findings of my investigation suggest that blog participants do in fact form small, interactive and supportive communities or blog clusters, consisting of approximately five to ten members. Cross linking occurs when one blog author posts a link to another blog author's site in her 'Frequently Read' list. In both my general sample and my case study sample, the vast majority of all cross links were made to other female blog authors. If no gender effect was present, one would expect to find only $51 \%{ }^{23}$ of these links leading to other female-authored blog sites. Since this is not the case, it would suggest that Canadian women bloggers are interested in forming and participating in women-centred online communities.

In contrast, cross posting occurs when a blog author publishes a comment to another blog author's site. I contend that the conversations that arise out of this interaction represent the core of the blog cluster. Here, women exchange information, share intimate life details and provide support and encouragement to one another. This interaction occurs both publicly via blog posting and can also occur via personal e-mail exchange. For example, on January $30,2004,{ }^{24}$ Delicious Juice posted the following blog entry: 
I need help. If you are or have been on medication for depression, could you please email me? Or comment, or something? [...] I can't stop crying - and I'm at the office, which is a little embarrassing. I've had to run to the bathroom twice now to try and get a hold of myself. Even with all those quirks of mine I supposedly love, this is way, way outside the norm. I'm terrified. Everything is so dark.

This post requesting help received twenty-seven thoughtful, supportive and, in some instances, highly personal responses from other bloggers. For example, Peechie (a cross linked blog author) responded by stating:

My breaking point was when I was crying all the time for no good reason, not sleeping much (against my own will), and just felt horrible and hopeless. [...] The drugs alleviated much of the "hopeless" feelings and the being sad all the time, and allowed me to be in a frame of mind that made me more receptive to therapy. And now I have those tools to help. As an example of how conversations extend into private e-mail exchange, another blog cluster member by the name of Kristin writes, "I was about to leave a long involved comment but instead emailed you. I hope it helps you some."

The questions women pose and the answers they receive can vary greatly. For example, Dirty Olive poses a question on birth control to her readership:

I was at the doctor's the other day and we discussed birth control. I asked about IUDs and she said they would be a good choice for me since I have had a baby now...So, I am curious. What, exactly, happened to my body? 
I know the vague details but I want diagrams, flow-charts, literature, documentary footage. Does anyone have any good websites? (November $16,2003)$

Although she received seven responses to her query, no one provided her with the information she requested. One woman wrote, "IUD's scare me. I've known women who've had bad reactions. Though, of course everyone is different..."

The comments women bloggers receive are intended to provide support to the blog author and in many instances they appear to do so. One of the problems with this type of interaction-as with any informal support group-is that there exists the potential for the spread of misinformation. When a serious issue like depression or birth control is involved, poor or ill-informed advice could have grave consequences. At the same time, this virtual medium allows authors to post questions to their readerships that might otherwise not be asked as easily in real life. The anonymity of the Internet, therefore, seems to create a safe space in which personal issues can be made public, albeit in an anonymous fashion.

In commenting on how she feels specifically about this interactive medium and the connections she has formed with others, Dirty Olive explains that blogging

has become a part of my life and it is hard to separate it from everything else. I've also met some pretty amazing people and have grown closer to friends I think I would have lost otherwise. That said, this really isn't that 
personal - could you imagine how freaked out I would get if I had

published my latest feats in acrobatic masturbation? ${ }^{25}$ (April 8,2004$)$

The statement about how Dirty Olive 's blog has become part of her life illustrates nicely the blur that can occur between 'the real' and 'the virtual' when the practice of blogging becomes part of one's daily life routine. She also writes that, through this practice, she has met some interesting people. It is not clear from her statement whether this meeting is restricted to online space or whether it extends into real life. Since she does not specify, it would seem to suggest that their location is irrelevant.

Likewise, on September 30, 2004, in her final post entitled, "Done" Just a Girl writes:

This is it. September 30, 2004. This is the day this site ends. Thank you all for being here with me for the last three years. Every single comment you've left me, every email you've sent me, has meant the world to me. Her brief yet heartfelt closing post suggests that she places value on the interactions she has had with her fellow blog participants. This is underscored by the fact that she decided to write a closing post-as though she had a responsibility to inform her readership that she will no longer be maintaining her blog.

An entry posted by Delicious Juice with regard to Girl Gamers that was discussed in the activism section of this chapter also provides a good example of the phenomenon of community that occurs in blog space. In response to Delicious Juice's post, fellow blogger Kat states: 
Our worst enemies are not boys in this game it is the other freaking girls. They make the rest of us look like complete idiots. If she gets a boob implant and dyes her hair blonde I will hunt her down myself and make her write out 1 million times "I will never claim to be a girl gamer again."

\section{Grrrrrrrrrrrrrrrrrrrrrrrrrrrrrrrr.}

Another blog participant, who uses the name Lillie, writes:

It is so hard to be what we are. Ourselves. I am proud and very happy to be in the [Girl Gaming] clan that I am in. Not only do you gals understand what its like, you are damn good at what you do and are sexy too! =) We don't need to post pictures to prove to the world that we are worth excepting, we can do that in the arena.

Finally, Eschie suggests to Delicious Juice that she contact the editor and "express the fact that you found their interview biased and one-sided, offering nothing but a re-hash of the old stereotypes, and offer to do a real interview, or write a column on girl gaming, or something :) Gotsta fight the power, eh?" On average, Delicious Juice posts to her blog ten times per week, in response to which she has received thousands of comments over the past three years. These responses illustrate how women-centred blogging communities function as environments in which a fusion of social interaction, activism, mutual support and creativity can occur. In this instance, the responses offered by Kat, Lillie and Eschie all espouse a supportive third wave, 'grrrl power' positioning that serves to counter stereotypical representations of Girl Gamers. 
Contemplating the composition of one's readership and their common characteristics is a topic that runs throughout many of the blogs in this study. For example, Grass openly writes about her awareness of and interest in her readership:

But I guess it's safe to say that there are at least a few people who are interested in the daily humdrum of my life because I see the same domain names in my site statistics. There you are hiding behind your IP numbers. Secret people with secret lives. If I'm lucky I can see your time zone. (October 6, 2002)

The above comment suggests that those who write blogs are just as curious about their readers as their readers are about them.

With regard to blog statistics, some of the tracking services to which bloggers subscribe record the referring URL and search criteria which individuals use to locate blogs. For example, if someone searches for "blogs" and "motherhood" on www.google.com, this information will be displayed on the blog author's statistics page. Some blog authors write about their fascination with what attracts their readers and types of search criteria which are used to lead them to their blog sites. Grass writes:

You see I wonder about your lives too. I wonder about the scared soul who typed in secret stomachache. Why is it secret? Did you ever figure out what has caused it? Perhaps you can see a doctor? Or the one who wrote lost my virginity, diary. Are you considering losing it? Are you wondering what it's like? To be honest, I don't even remember it that 
clearly. I remember fumbling around looking for a condom, but I don't even remember the actual event. Perhaps I'm atypical. I don't remember where we had come from that night, or how many dates we had been on. I'm sure when it happened I thought every inexperienced grasp would remain imprinted on my memory, but it's all faded now like an article of clothing that's been washed too often. (October 6, 2002)

As she ponders why these individuals have come to her site, she also writes directly to them by posing questions and offering her comments. While some interaction that occurs in blog space quite clearly takes the form of dialogue when individuals post comments directly to one another some interaction is less direct.

Drawing on and extending the work of John Berger, ${ }^{26}$ part of what the blog medium seems to be about is the 'virtual gaze'. Berger contends that women can be thought of in terms of being the surveyed, in that they obtain their social presence or value based on how much appeal they have to men. A woman will "[turn] herself into an object - and most particularly an object of vision: a sight" for the male gaze (47). As a result, he suggests that women watch themselves being looked at by men. In a sense, it can be argued that something very similar is happening in blog space. Here, a female author becomes the surveyed when she posts a virtual representation of herself to the Internet via a blog. When she uses software to track who is reading her blog, however, she is engaged in the act of watching others watch her. Thus, the blog author always writes-or 
perhaps performs-within the context of an audience as opposed to simply posting anecdotal information about her life.

Although watching and being watched is part of the blogging process, attracting a readership and becoming the centre of a blog hub can elicit some ambivalent feelings in blog authors. For example, Dirty Olive writes:

I have to admit, the traffic [to her blog site] has been a little disconcerting and although you have all been quite flattering, I will be a bit perplexed if many of you outside my interest scope keep reading. I might have to start thinking of myself as an actual writer - and I am pretty aware that I do not hold any talent in that department. (May 5, 2004)

At the same time, however, some blog authors express very positive sentiments about the importance their readership has for them and their desire to interact with one another. For example, Grass writes "Can I just say, I love it when people sign my guestbook? It makes me so happy. Thanks to all who did recently and if you left URLs I surely surfed your site" (November 1, 2002).

With regard to cross posting, a good example of a multiple or chain interaction among blog participants can be found in relation to a post made by Delicious Juice on the subject of menstruation, she states:

I'm annoyed about panty liners, people. While rummaging through my collection of feminine hygiene products, I happened upon a box of black panty liners. I remember buying these; even though they were more expensive than the handily compact ones and came 32 to a box instead of 36, my inner goth gave a rousing "meh" of delight at the thought of panty 
liners as black as the midnight of my soul. It seemed like a truly excellent idea at the time, but now when my womb is shedding its lining that had been prepared for the fertilized egg it will never receive, I am annoyed. Black panty liners suck. It's not enough for me to know I am being vaguely protected 'down there', I need to see the evidence of the flower of my womanhood. Nothing shows up on a black absorbent surface - I could be bleeding out mango chutney or Ovaltine and I wouldn't know. (June 11, 2004).

This particular entry seems to have 'hit a chord' with the readership of Delicious Juice since she received twenty-nine responses to her post (see Appendix E). What is noteworthy here, is the fact that the comments these women have made illustrate how they engage in conversation with one another through the comment function of Delicious Juice's blog.

As an aside, while most of the posts she received in reply to this entry were positive, one individual by the name of $D$ wrote, "Really Gross - don't you have anything better to write about???" In typical grrrl power, third wave feminist fashion, Delicious Juice responds (in the comment section of her blog) by stating: Who are *you* to say my vagina is gross? I think my vagina is a wonderful thing to write about! Vaginas are glorious, amazing things! The womanly cycle is a miracle to behold! You should get on your knees and up close and personal with my vagina - or any vagina, really - and gaze upon it with wonder and extreme reverence, because without the existence of vaginas and their ability to do those things they do, you would not be alive to 
criticize the things I do on my own personal webspace! WORSHIP MY VAGINA, DAMNIT! LOVE IT! (June 14, 2004)

All of these entries raise questions about communities and the type of privileging that occurs with regard to real life interaction over that which occurs between people online. As Cerulo suggests, using qualifiers such as 'online' or 'virtual' with regard to the communities that form, "reify the notion that interactions void of the face-to-face connection are somehow less than the real thing" (50). The central component that seems to be missing from online interaction is co-presence. Purcell, however, points out that this contact does not guarantee that the interaction which occurs between people will be of an intimate or meaningful nature. As an example, Purcell cites the following:

Consider large-scale social gatherings in which hundreds or thousands of people gather in a location to perform a ritual or celebrate an event. In these instances, participants are able to see the visible manifestation of the group, the physical gathering, yet their ability to make direct, intimate connections with those around them is limited by the sheer magnitude of the assembly. (102)

Since blog interaction occurs as textual exchanges that are frequently of a personal nature, the issue of physical co-presence being requisite in community formation seems moot. These women are online; they write to one another and, in some instances, indicate that they form connections with each other that are important to them. 


\section{Continuities Across the Waves}

The study of Canadian women bloggers and the work they do provides a useful vehicle through which some of the continuities between second and third wave feminism are rendered visible. I argue that understanding these continuities can help to bridge the generational gap that exists across the waves of feminism because it enables both second wavers and third wavers to see how their efforts are intimately interconnected with one another. This thesis offers important and timely information that will help the Canadian women's movement continue its struggle against gender inequity, to adapt effectively to changing times, (particularly the changes associated with the development of new ICTs and Canada's emerging knowledge-based economy) and to attract new membership. In order to illustrate some of the many continuities that exist between second wave and third wave feminist resistance, I examined the blogging practices of Canadian women in relation to second wave consciousness-raising (CR) groups of the late 1960s and 1970s.

\section{Digital Consciousness Raising}

Upon examination of the interaction that occurs among women within blog space, both through cross linking and cross posting behaviours, it becomes apparent that women bloggers tend to naturally organize themselves into small, supportive blog clusters or communities. Judging by the types of exchanges these women have with one another, as discussed earlier in this chapter, a number of similarities emerge between blogging and the second wave consciousness raising (CR) group. Hence, I argue that when supportive, 
interactive women-centred blog clusters form, they function, in part, as sites of digital consciousness-raising.

A typical blog exchange begins when one author posts an entry online that focuses on a personal issue. In response, members of her blog cluster will post supportive statements and/or will disclose other relevant information about themselves. In this way, the conversation builds as women exchange life experiences and gain greater awareness of the struggles they have in common with other women in contemporary Canadian society; issues that were once private and secret become public and visible. As with traditional CR groups, blog consciousness raising, therefore, functions as both confessional and therapeutic space.

With regard to the CR groups of the 1970s, Marge Piercy and Jane Freeman write, "when we go around the room talking about how each of us feels about her appearance, and we hear every single woman expressing the same dissatisfaction with her body or her personality... we begin to realize we are dealing with something larger than a personal hang-up." ${ }^{27}$ The same type of interaction can occur online. When Delicious Juice discusses her struggles associated with being a bisexual Canadian woman of colour or when Grass shares the difficulties she experiences in becoming far more successful in her school career than her male partner and other women write back and share similar experiences, the blog begins to function like a CR group. These conversations result in the formation of a myriad of discursive spaces in which women are able to explore and render visible issues of significance to their lives. 
Likewise, when Dirty Olive exposes her mixed feelings of guilt, shame, joy and ambivalence associated with balancing motherhood, school and a career or when Just a Girl discusses her ongoing difficulties associated with becoming a healthy sexual subject after surviving her father's sexual abuse, these too illustrate how digital consciousness-raising via the blog provides participants with a public discussion forum through which they not only receive support but also through which their life experiences are legitimized.

Although the blog clusters observed in this research have similar sized memberships to those of the typical second wave CR group (i.e., approximately eight to fifteen women), what is different about this form of consciousness-raising is that it occurs in a public space as opposed to the CR meetings that were held in private spaces such as women's homes or in women's centres. This raises the question of how personal disclosure is affected by the act of public posting on the Internet. Can this environment function as a safe space in which to express voice, similar to that of the CR group? While this particular question is not addressed specifically in the research component of this thesis, since supportive, interactive women-centred blog clusters are visible online, it would suggest that some women, at least, find the blog to be a helpful CR outlet. It may be that since women have the option of participating in these online environments using pseudonyms, reservations about sharing sensitive material may be partially offset by this anonymity. Additional research could be done by conducting interviews or via questionnaires to explore how women experience personal disclosure in the public blog space. 
Thus I would argue that, from a feminist resistance perspective, one of the things which makes digital consciousness-raising so powerful is, precisely, its public presence, as well as its open membership-anyone with access to the Internet, regardless of where or when they connect, can participate in and benefit from the online blogging community. By eliminating the geographical and temporal constraints of a live meeting, in theory, the CR process becomes more accessible since women with time or mobility limitations can still participate in meetings. If one of the primary goals of the consciousness raising process is to reinforce the notion that the 'personal is political', what better way to do so than by making use of a public space?

There are, however, a number of challenges associated with digital consciousness-raising. One of the central concerns, as with all forms of online participation as discussed in Chapter One, is the issue of access. While individuals in remote areas and those with restrictive schedules can benefit from engaging in the online public, not everyone has equal access or the skills necessary to make use of this environment. When a woman does have access, however, one of the positive things about blogging is the frequency with which participants post, creating an ongoing, interactive dialogue among blog participants. In this way, digital consciousness-raising becomes an ongoing activity that is available at any time of the day or night.

The question also arises as to what is lost in the CR process when live group interaction is removed from the equation? Since blogging occurs, for the most part, when an individual is sitting at her computer, alone, how might this 
affect the CR process? Real human contact with other women in supportive, allfemale environments represents one of the key ingredients to the CR equation which cannot occur in a virtual space. Although digital CR does not involve the physical, (an important part of all people's lives), the blog does offer a number of alternative elements which could be of benefit to women. For example, some women may feel more at ease raising personal issues in an online environment in which their true identities are not known but in which they have fostered personal 'virtual' relationships with one another. Again, future research could compare the differences between women's perceptions and experiences of supportive online friendships versus supportive real-life relationships.

Finally, digital consciousness presents questions with regard to women's exclusive participation. In blog space, men can read and post comments freely to any public online space, including women-centred blogs. The implied presence of the 'male gaze' may alter the ways in which women engage with the blog medium. In addition, since a blog is predominately a text-based, 'disembodied' space, it also provides the potential for gender switching. Even if an author or reader identifies herself online as female, there is no way to verify this. An excellent example of a well known gender switch, and the construction of an accompanying fictitious narrative, occurred with the blog entitled, Plain Layne. $^{28}$ The author, Layne Johnson, who described herself as being a female person in her twenties living in Minnesota, posted detailed entries to her blog almost every day for approximately three years. In addition to her entries, she 
published detailed biographical information about her life, the lives of her friends and blurred images of herself (see Figure 13 ). Layne's site became so popular

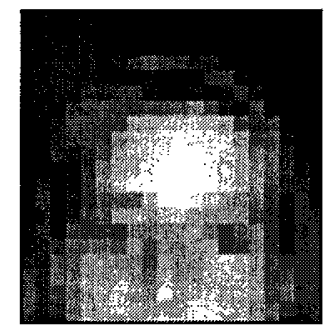

Figure 13

Hoax image of the fictitious blogger, Layne Johnson

that it was even featured in a Maclean's article by Michael Snider entitled, "The Intimacy of Blogs". Snider wrote that Layne is "an excellent narrative writer who opens her soul to her readers," (40). After requesting an interview with Plain Layne and being turned down, Snider wrote:

Johnson [explained that] her blogging is a personal exercise that's meant to be cathartic. And somehow, that's the way it should be. Plain Layne does her talking, or typing, on her blog. "I think the hardest thing about sharing your life on-line is that at some point you discover people know you," Johnson wrote in a June post. "They know you from the inside out, the way your mind works, what makes you laugh or cry, your hopes and fears." It's clear to see she uses her blog as an outlet, a place to dump her anxiety and frustration in a search for identity and understanding. (40) In reality, Layne was a 35 year-old male author by the name of Odin Soli who created Layne as an experiment in "interactive fiction" (Bazeley 1). According to 
Rex Sorgatz, Plain Layne had a daily readership of 5000 individuals, in which 'she':

recounted a rape that she suggested led her to lesbianism, became engaged to a formerly straight woman, suffered a dramatic breakup with said woman (partially because her fiancée resented being dissected on Layne's site), hooked up and noisily quarreled with a girl from her work cafeteria, met her birth parents for the first time, got involved with a risky internet startup, and had a ton of hot sex (Sorgatz 1).

When Soli's blog is reframed in terms of it being a male author masquerading as a woman, writing about various deeply personal female issues-as though they are his own real experiences-the deception becomes disturbing. Andreas Kitzmann suggests that "writers who deliberately fictionalize their autobiographical accounts are said to have betrayed the trust of the reader, and in my interviews with diarists... a few acknowledge having been hurt and outraged by deliberate acts of deception" (59-60). When it comes to the autobiographical form, then, it is as though the reader makes an assumption that the author is bound by some unspoken code to write the 'truth'. Although this also falls outside of the scope of this project, future research could address issues of gender, deception and the construction of autobiography as fiction. Thinking about women-authored blogs in terms of consciousness-raising helps to illustrate some of the ways in which second wave and third wave feminist resistance are similar. In pointing out these connections, however, there is one final distinction that is important to mention. While the CR groups of the 
1970s were formed specifically to serve as sites of feminist resistance (and perhaps also as a way in which to attract and engage new participants), this is not the case with the blog. Although the women in the case study, as well as many in the general sample, identify as being feminist, these women do not indicate in their blogs that they go online in order to engage in feminist resistance. Rather, the feminist activism that occurs in blog space is either integrated as part of the work which they do (as is the case with posting feminist commentary or feminist links), or emerges as a byproduct of their blogging (when they raise personal issues that become political in public space).

\section{Conclusion}

In this chapter, a number of recurrent themes found in the general blog sample were discussed including identity and body image; sexuality and personal relationships; politics and social justice; and issues such as those of motherhood, illness and well-being and pop culture. In addition, some of the reasons why women engage in blogging were presented. The most notable reason was that blogging seems to function as a therapeutic outlet that enables women to connect with one another. Examples were also presented that illustrate how Anglophone, Canadian women bloggers negotiate activism, identity and community. Finally, the chapter concluded with an examination of some continuities between second and third wave feminism in relation to the blog and consciousness raising groups of the late 1960 s and 1970 s. 

${ }^{1}$ See $\langle$ http://www.livejournal.com/users/thelicia w/ $>$.
2 See $\langle$ http://www.livejournal.com/userinfo.bml?user=thelicia w>.
3 The Gender Petition is a www.livejournal.com petition to expand the current list of gender
options. According to the author, "This community has been created as a petition to the maintainers of Livejournal.com to request listing more than male and female as gender options in the information / profile listings, or delete the gender field altogether. This community is for people of all sexes, genders and gender expressions. Livejournal.com currently has over 1,000 users, who list transgender as a personal interest, (and this list is growing daily!) There are also well over 200 communities that address gender variance and relevant identities. As of July 4, 2003, over 129378 users choose not to specify their gender as part of their profile for a variety of reasons. Some of these people have chosen to do so for lack of appropriate options, others are choosing to do so as a form of protesting the binaried options currently offered. Even if you identify as strictly male or female, or have never had reason to question your gender identity/ assignment, not all people feel that male or female fit their personal gender identity and expressions. Also, some people feel that checking a gendered box helps to enforce stereotypes that limit a person's ability to express their gender fully in today's society. Your membership in this community shows support for all people of all gender identities being able to express their gender identity freely." See <http://www.livejournal.com/community/gender petition/>.

${ }^{4}$ For Janua Diaboli's complete blog entry, see <http://uww.livejournal.com/users/thelicia w/22089.htm|\#cutid1>.

5 The state claims that Rowland's refusal to undergo a caesarian section represented criminal negligence, resulting in the still birth of one of the infants. In her blog, Janua Diaboli states, "to say that I'm horrified by this is a vast understatement. Not only am I appalled at the fact that the state has chosen to prosecute Melissa Ann Rowland for murder, but I am also appalled at the way in which her story has been presented in the media" For more information on this case, see $<$ http://www.cbc.ca/stories/2004/03/12/world/caesarian040312>.

6 According to Susan Faludi, the backlash represents an undercurrent in mainstream American discourse that proclaims feminism a negative force - one that has systematically undermined women's ability to seek fulfillment, happiness and purpose in life. Aligned with 'New Right' ideology, mechanisms associated with the backlash created myths that blamed the women's movement for the alleged unrest and unhappiness in women's lives. Faludi states, "the afflictions ascribed to feminism are all myths. From "the man shortage" to "the infertility epidemic" to "female burnout" to "toxic day care," these so-called female crises have had their origins not in the actual conditions of women's lives but rather in a closed system that starts and ends in the media, popular culture, and advertising-an endless feedback loop that perpetuates and exaggerates its own false images of womanhood" (xv). Faludi argues that the press didn't consciously set out with an agenda geared towards undermining the feminist agenda but rather, "like any large institution, its movements aren't premeditated or programmatic, just grossly susceptible to the prevailing political currents" (77). Just as the 1970 s news media constructed a feminist landscape in which newly liberated women were depicted as burning their bras en masse, the 1980 s press, influenced by emerging conservative political trends, constructed a landscape in which women were encouraged to abandon the destructive forces of feminism. See Susan Faludi. Backlash: The Undeclared War Against American Women, New York: Crown Publishers 1991.

${ }^{7}$ Fat Activism is a form of third wave feminist resistance. Allyson Mitchell and Lara Karaian cite the Canadian fat activist group, Pretty Porky and Pissed Off, as an example of this genre of activism. They state, "The fat body is a specific site where women are punished for exceeding the boundaries of femininity. The fat body disrupts these values and norms, while at the same time the individual remains influenced, prescribed, and implicated by these norms. Pretty Porky and Pissed Off (PPPO'd) is an example of how young women have used their bodies as a way to resist oppressive power structures. PPPO'd is a fat activist group that uses cultural production in 
the form of performance art to educate and serve up their own brand of advocacy for size acceptance" (70-71).

${ }^{8}$ See <http://fattypatties.blogspot.com/>.

${ }^{9}$ It is important to note that these blog clusters do not represent exhaustive link lists. Since blogs are organized across the Internet in complex, interconnected webs, it is beyond the scope of this project to map out more elaborate linking arrays-some of which could, in theory, extend on infinitely. The point in presenting these illustrations is to demonstrate how blogs can be thought of in terms of being loosely bound blogging clusters or online communities.

${ }^{10}$ Her links include the following organizations: Victoria's Sexual Assault Centre, UVic Sexual Assault Centre, Revolutionary Association of the Women of Afghanistan, Prostitution Empowerment and Education Resource Society, Vancouver Rape Relief \& Woman's Shelter, Metropolitan Action Committee on Violence Against Women and Children, Centre for Research on Violence Against Women and Children, Access to Justice Network, NOW and Violence Against Women, the Fredericton Sexual Assault Crisis Centre, CAVEAT - violence, crime prevention, victims' rights, violence prevention education, Bridges for Women, Feminist Majority Foundation, End Violence Against Women from the John Hopkins University Center for Communication Programs, UNICEF - Violence Against Women, and

UNIFEM - Global Campaign to eliminate Violence Against Women.

${ }_{11}^{11}$ The first sample used in Appendix A shows an earlier iteration of her site.

${ }_{12}^{12}$ For more information on "Girl Gaming" see <www.womengamers.com>.

${ }^{13}$ See <www.planetquake.com>.

${ }^{14}$ The interview comments that she includes are as follows: "Half of the guys that play quake are lonely horn bags that haven't seen a girl in any of their pathetic lives, so when they find out that one plays Quake, much less is in an all girl clan, of course they treat you differently." "What other channel in IRC has over 100 idlers?... not very many *all guys* clans that's for sure. Most of them that idle in your channel just want "sumfin" and think that they all have chances." "Quake3 is fun, but it's getting to be too fake. Too many cheaters, and too many liars." "The clan is great, and the girls that are in the clan are even better. They are never boring, and the best part is that they are real-life people, and not computer addicted freaks." "I'm not looking forward to any games, really. I'm not much of a game person, except of course for all of the Super Nintendo games. I'm an old school retard. Quake came into my life by luck, and luck kept me playing." ${ }^{15}$ RakE is the online user name that her male partner uses.

${ }^{16}$ The Delicious Juice site can be found at: <http://www. deliciousjuice.com/>.

${ }^{17}$ IBID.

${ }^{18}$ IBID.

${ }^{19} \mathrm{See}<\mathrm{http}: / / \mathrm{www}$. deliciousjuice.com/gallery. asp $>$.

${ }^{20}$ Excerpt taken from The Grass is Always Greener. See $<$ http://www. grassdiaries.com/whoami.html >.

21 Except taken from Just a Girl. See $<$ http://www.justagirl.ca/about.html $>$.

22 See <http://www. deliciousjuice.com/>.

${ }^{23}$ This figure represents the approximate percentage of Canadians who are female.

${ }^{24}$ See <http://www. deliciousjuice.com/comments.asp?id=1372>.

${ }^{25}$ As an aside to Dirty Olive's comment with regard to "acrobatic masturbation," some Canadian women bloggers write sexually explicit secret blogs. In the general sample associated with this thesis, there was one example of this type of blog site written by Jen X entitled, The Whore's Boudoir. See <http://drunkenwhore.blogspot.com>.

${ }^{26} 1$ am specifically referring to Berger, John. Ways of Seeing. Markham, Ontario: Penguin Books, 1981.

${ }^{27}$ See <http://research.umbc.edu/ korenman/wmst/crguide2.html>.

${ }^{28}$ For information on the Plain Layne story, see $<$ http://www.mercurynews.com/mld/mercurynews/ news/breaking news/9028023.htm?1C $>$ and $<$ http://www.citypages.com/databank/25/1230/article12271.asp >. 


\section{Chapter Five}

\section{Conclusions and Future Research}

\section{Thesis Overview}

This thesis explored the secret world of Canadian, Anglophone women bloggers from a third wave feminist perspective. Since very little academic research exists to date on the blog medium and no studies focus exclusively on women bloggers, this work represents a timely investigation into a highly popular form of online self-expression for female bloggers. The words these women write are important because they enable participants to engage in feminist activist practices, to negotiate issues of identity and to create supportive online communities.

The use of a third wave feminist analytical lens has been essential in rendering visible the resistance that takes place within blog space that 'doesn't quite look activist enough' when considered exclusively in second wave feminist terms. Although not all Canadian women bloggers identify themselves as being feminist nor do they label themselves as being third wavers, much of the work they do within their blogs is nonetheless consistent with third wave feminist ideology. By means of the blog medium, a diverse group of women challenge boundaries, struggle with contradiction, reframe, reclaim and actively engage in online, DIY cultural production.

The central question addressed herein was: what happens to key feminist constructs of activism, identity, and community when they are transposed via the blog to an interactive, online space that is produced both for and by women? I 
was also interested in determining who these women are, how they engaged in blogging and what recurrent themes were present in the content they posted. In order to answer these questions, I began by examining a general sample of sixtytwo Canadian Anglophone women bloggers across a series of variables including author age, physical location, education, ethnicity, type of blog service used (i.e., commercial or non-commercial), sexual orientation and whether the authors had included photographs and biographical information about themselves. I also noted whether authors made a distinction between maintaining public or secret blogs. Based on the data gathered with regard to this group, I concluded that the typical Canadian woman blogger is a 28 year-old, heterosexual, Caucasian woman who lives in Ontario and posts to her blog just over four times per week. Furthermore, she is likely to be using www.blogger.com to maintain the secret blog that she has written under an online pseudonym. She is also likely to have posted pictures of herself (i.e., $63 \%$ ) and there is a $50 \%$ chance that she has included detailed biographical information about herself. She also probably possesses an undergraduate degree or is in the process of completing such a degree.

In addition to the general sample, I also conducted a case study on four blogs drawn from the larger sample in order to assist with answering my research questions. My case study inclusion criteria consisted of all authors who had maintained a secret blog for more than two years, on a personal Web site with a registered domain name and who posted photographs of themselves and 
biographical information. The case study observations were based around the three central feminist constructs of activism, identity and community.

\section{Activism}

With regard to feminist activism, part of what Canadian women bloggers do is to challenge, disrupt and destabilize the oppositional binaries of public/private, mind/body, producer/consumer and author/reader. Since these are patriarchal constructs that are imbued with power, dismantling oppositional binaries represents an important third wave feminist endeavour-one that occurs frequently within blog space. Each pairing places emphasis or greater value on the first element in the dyad, which is also connected to men. ${ }^{1}$ For example, in Western culture men have been traditionally associated with the public sphere, with the mind and with active production. In contrast, women have been traditionally associated with the private sphere, the body and passive consumption. By challenging these core oppositional constructs, Canadian women bloggers are no longer bound to or encapsulated by rigid, limited categories of meaning. Once disrupted, these binaries collapse and new discursive fields emerge through which Canadian women bloggers articulate, share and assert their own unique, lived experiences.

With regard to the disruption of the public/private binary, specifically, what begins as a very private and personal autobiographical act-the writing of a diary-is transformed into a series of ongoing, unfolding life events that the author purposefully selects to make public. Although the author does choose what anecdotes are published and is responsible for the particular spin that is 
placed on her entries, both she and the reader are never really quite sure where the story will lead; this uncertainty or element of surprise is perhaps in part responsible for the allure of the medium. In blog space, the division between public and private is rendered moot as everything is at once both public and private. Entries are created by authors who write about their private worlds from within the private spaces of their homes, which are in turn made public through the act of blogging.

By disrupting the division between public and private, new discursive fields are created in which the seemingly trivial and previously private experiences of women are made public and take centre stage. Importantly, through the act of blogging, women assert or demarcate a virtual territory that accords value to those who generate these spaces. Women bloggers produce information which is the main form of cultural capital in the Information Age, and they do so in a non-hierarchical, co-operative fashion.

The disruption that occurs in blog space within the oppositional binary of mind/body, specifically, is also very important with regard to Canadian women bloggers, as it relates specifically to their negotiation of online identity and body image. Since blog space is virtual, it functions as a location which one must access experientially through the body and imaginatively through the mind. In this way, being 'online' really is all about projecting oneself onto a virtual plane. Although this study did not specifically seek to measure the impact that virtual disembodiment has on women, it did explore how some women negotiate this disembodied space via their blogs. What stood out was that women appear to 
be very much anchored to the body within the virtual in that they go to great lengths to (re)construct or transpose the body online, either by posting pictures of themselves in their blogs or by writing detailed physical descriptions of their bodies and posting this information in their blogs. What was interesting, however, was that, for the most part, their transposed bodies do not reflect stereotypical, mass-mediated representations of women. The bodies that appear online, in blog space, reflect a diverse and realistic array of body forms. What is curious about transposing the body online is that since it is primarily a textual space where participants write about their daily experiences, blogging does not require women to post representations of their bodies. Future research could include a comparison of male and female blog authors to see if there are any gender effects with regard to issues of identity, body and online constructions of the self.

In blog space there is a breakdown that occurs with regard to the oppositional binaries associated with author/reader and producer/consumer. These disruptions also play an important role in opening up new discursive spaces for women. On a textual level, the blog itself is easily understood as being a concrete manifestation. We can logon to the Internet, surf around and arrive at an individual's blog site. We see her entries on the screen and can print them out should we so desire. In this formulation, the blog is understood as being a cultural product in which emphasis is placed on the blog author as opposed to her readership. When considering feminist resistance and transformation from this perspective, textual analysis can be used to identify 
whether the themes running throughout a particular blog are in keeping with feminist ideology. What is not so apparent, however, is the interactive dimension of the blog. As a process, therefore, examining how the act of blogging functions in relation to feminist resistance and transformation has been vital to this project. Seeing a blog on screen does not immediately reveal the relationships that are forged between blog participants. When considering the blog in terms of process then, a rupture in the author/reader binary is exposed that decenters the authoras-subject. Thus, it is no longer sufficient or appropriate to evaluate a blog exclusively in terms of the words an individual author writes. As a dynamic social space, what is of importance in terms of feminist resistance and transformation are the conversations that unfold across blog clusters. By inviting people to respond/chat, bloggers promote the building of possible virtual communities in which all participants may simultaneously serve as cultural producers and cultural consumers. In tracing the cross linking and cross posting behaviours in which bloggers engage, I have demonstrated that blogging communities not only form online, but that, given their patterns of interaction with one another, it is more appropriate to think in terms of blog participants who sometime post to their own sites and sometimes to the sites of others, as opposed to thinking in term of blog authors or blog readers.

Another issue associated with feminist activism and Canadian women bloggers relates specifically to the concept of cultural production. As active agents in the production of their own social and cultural worlds, Canadian women bloggers are able to gain empowerment through the production of their own 
discursive spaces. The discussion, provided at the beginning of this thesis, on women's traditionally troubled relationship to the mass media and their association with the diary form displays the historical context within which Canadian women are now able to write blogs. The main point here is that it has only been within the last century or so that the bulk of Canadian women have been able to develop the literacy skills necessary to write their life stories and to gain access to the technologies that can record and broadcast these stories. An ICT, such as the blog, provides many women with unprecedented opportunity to document and share their lived experiences. Even so, I do feel it is necessary to stress that, at the time of writing this thesis, only about half of all Canadian women had access to the Internet. While I did observe some diversity in my general sample with regard to ethnicity and sexual orientation, my findings suggest that Canadian women bloggers are likely to be fairly well-educated and Caucasian. Furthermore, since they are able to afford an education, not to mention the computer equipment necessary to connect and the free time in which to do so, I would anticipate that those women who are more likely to be blogging will also be financially secure. Even though the medium has great democratic potential, whether this is, in fact, the case remains to be seen. Future research could address in more depth the issue of diversity within blog space. Identity

Canadian women bloggers negotiate and construct identity online. In some instances, these constructions take the form of brief textual statements about themselves, while at other times, they are elaborate descriptions of their 
bodies, sexuality, social location, feelings, opinions and attitudes. These constructions may also include a few images or many, highly personal photographs of the authors. Some examples of the more elaborate visual treatments found in women-authored blogs include naked photographs, images of tattooed body parts and the detailed photo-essay that a breast cancer survivor posted, in which she chronicles her experiences with chemotherapy. When viewed through a third wave feminist lens, what becomes visible are some of the tensions and contradictions which Canadian women must negotiate in their daily lives. Whether they are related to sexuality and the struggle between simultaneously existing as both subject and object, or to accepting and embracing the body, these online constructions provide researchers with a unique vantage point from which to observe some of the issues with which contemporary Canadian women must contend.

Across almost all of these online constructions, what was quite apparent was the fact that Canadian women bloggers appear to be very much preoccupied with and anchored to their bodies. Even though the blog is manifest on a virtual plane, where no mention of bodies need ever occur, these blogs are saturated with purposefully transposed and reconstructed representations of the body. Despite this tethering, enactments of self online can be interpreted as an empowering exercise for women, as they begin to explore and share their experiences of body with one another.

One question which I was interested in examining in regard to online representations was the following: when women become media producers do 
they present alternative female representations or do they perpetuate the stereotypical representations of women found throughout mainstream mass media outlets? Although I did note that different bodies shapes and different ethnic backgrounds were presented in these blogs, what was lacking were visual and textual representations of women with physical disabilities. The exceptions to this were one female blogger who indicated that she had received a mastectomy and one woman who wrote about her experience of living with multiple sclerosis. Since I used an ex post facto observational method, I was not able to determine exactly how many of the women in the general sample had physical disabilities. According to the Disabled Women's Network (DAWN), 16\% of all women in Canada have disabilities. ${ }^{2}$ Therefore, in a sample of this size, one would expect to find approximately ten disabled bloggers. As this was not the case, it raises the question of whether women with physical challenges reconstruct and transpose or edit out and conceal the unique physical characteristics associated with their disabled bodies?

On a related note, many women did indicate that they experienced psychological difficulties such as depression, anxiety and sleep disorders. It may well be that while societal norms now enable women to discuss many highly personal issues online, including mental illness, displaying 'imperfect' female bodies may still represent a serious taboo in our culture--so much so that even with a progressive, flexible and disruptive space such as the blog—disabled women's voices are silenced. Future research could examine the issue of 
gender and online representations of the body through interviews or questionnaires.

\section{Community}

The findings of my investigation suggest that Canadian women bloggers form small, interactive and supportive communities, consisting of approximately five to ten members. Here, women exchange information, share intimate life details and provide support and encouragement to one another either publicly via blog posting or privately via personal e-mail exchange. The topics that they discuss within these groups frequently centre around women-specific subjects such as sexuality, women's health and well-being, negotiation of careers and school in relation to gender and the experience of motherhood. Furthermore, many of these women write about the importance and value they place on participating in their respective blogging communities.

A recurrent theme that arose with regard to the issue of community relates to authors' preoccupation with one another. Based on their own accounts and their actions (e.g., embedding statistics tracking scripts into their sites), it appears as though blog authors are just as curious about their readers as their readers are about them. Furthermore, the words that appear in blog space are performative in that they are written within the context of and even for, an implied audience.

What I could not assess using this methodological approach was how connected Canadian women bloggers feel in relation to their online communities versus those that they inhabit in real life. Based on what I observed online, some 
of these blogging communities seem to be tightly interconnected and the relationships between some participants appear to be very close. It was not possible, however, to evaluate the degree to which Canadian women bloggers feel connected to one another. It was also not possible to determine how many of these women knew each other in real life (i.e., either before creating their blogs or later after meeting one another as a result of their blogging activities). Even if the bulk of the interaction that transpires within blog communities is virtual, these relationships may be just as important to bloggers as the relationships they have with people in their everyday lives. Again, future research could address this issue through the administration of questionnaires or by conducting interviews directly with Canadian women bloggers.

\section{Continuities Across the Waves of Feminism}

The study of Canadian women bloggers and the work they do provides a useful vehicle through which some of the continuities between second and third wave feminism become visible. By bridging the generational gap that exists across feminist waves, it enables both second wavers and third wavers to see how their efforts are intimately interconnected to one another. Understanding these connections will help forge a stronger, vibrant, cross-generational Canadian women's movement in which the varied efforts of all participants are viewed as having value and are celebrated. As a result of expanding our understanding of what constitutes legitimate feminist resistance, the women's movement will be better situated to adapt effectively to changing times, 
(particularly the changes associated with the development of new ICTs and Canada's emerging knowledge-based economy) and to attract new membership.

In this study, I opted to explore some of the continuities that exist between second wave and third wave feminist resistance by examining what Canadian women bloggers do as it compares with the second wave consciousness-raising (CR) groups of the late 1960 s and 1970 s. What this comparison revealed was that both women-centred blog communities and CR groups tended to be comprised of similar sized groups of women ranging from perhaps five to fifteen participants. Other similarities include sharing and discussing highly personal women-centred subjects in supportive community spaces. The major difference between these two forms of feminist activism is the location within which they take place. CR groups were closed, private spaces whereas women-centred blogs occur in open, public space. As a result, anyone with access to the Internet, regardless of where or when they connect, can participate in and benefit from the online blogging community. By eliminating the geographical and temporal constraints of a live meeting, in theory, the CR process becomes more accessible since women with time or mobility limitations can still participate in meetings. If a primary goal of the consciousness-raising process is to reinforce the notion that the 'personal is political', engaging online in the public space of the blog represents and appropriate and powerful feminist resistance strategy.

\section{Additional Issues Arising From the Research}

Other important variables that could not be assessed in this study but which relate to issues associated with blogging include women's competency, 
experience and attitudes towards computer technologies. Since there are more female than male bloggers, ${ }^{3}$ this would suggest that there is something particular about blogging that is of relevance to women's lives which has motivated them to get online and to explore this new ICT. Understanding what it is that draws women to this medium could be of use in developing effective, gender-based educational ICT programs geared towards increasing women's participation in the emerging knowledge-based economy. This is an important undertaking given that women still comprise only $33 \%$ of the computer and telecommunications workforce-a 4\% decrease from 1990 (Statistics Canada, Employment 1). Furthermore, despite the many opportunities available to Canadians in the ICT sector, ${ }^{4} 70 \%$ of women in the workforce today continue to end up in or opt for lower paying, traditional careers in fields such as "teaching, nursing and related health occupations, clerical or other administrative positions or sales and service occupations" (Statistics Canada, Women 12).

Although I did examine the posts that women made about why they write blogs, I was unable to ask them specific questions about how they discovered blogging, why they invest so much time and energy into this practice or how the medium impacts on their lives. The next logical step in this exploration, therefore, is to administer questionnaires or to conduct interviews with a sample of Canadian women bloggers. The information garnered from this research would provide a more complete picture of what is transpiring in the blog space of Canadian women. 


\section{Conclusion}

In exploring the secret world of women bloggers, the underlying goal of this thesis has been to render visible the words women write online and all that follows from the work they do. My research has demonstrated that the blog represents a complex and often contradictory medium that enables some Canadian women to become active producers of their own social and cultural worlds. Their efforts are important both within the academic arena and the Canadian women's movement. Although what they do within blog space may not always look 'feminist enough', their activities nonetheless represent a legitimate, creative and noteworthy form of feminist resistance and transformation. 


\footnotetext{
${ }^{1}$ For more information on deconstruction of oppositional binaries, see Derrida, Jacques. Of Grammatology. Baltimore, Md : Johns Hopkins University Press, 1997.

${ }^{2}$ See the DAWN Ontario Factsheet on Women with DisAbilities, <http://dawn.thot.net/fact.html>.

${ }^{3}$ According to Perseus Development Corporation, in $20032,310,000$ or $56 \%$ of all blogs housed on commercial hosting sites were authored by women. This figure was taken from a study in which they randomly surveyed 3,634 blogs on eight leading blog-hosting services were. For more information see <http://www.perseus.com/blogsurvey/>.

${ }^{4}$ Over the past decade, the ICT sector accounted for one sixth of the labour force growth in Canada (Statistics Canada, Changing 8). In 2002, Canada's gross domestic product increased by 58.7 billion dollars as a result of the ICT sector (Vaillancourt 5). Even those employed in the ICT industry benefited directly by earning higher average salaries than those employed in all other areas-a wage gap that is increasing (Statistics Canada, Employment 1). ICTs have also generated many new jobs. Since the early 1990 s, employment in this sector increased by 66 percent compared to 16.4 percent across all other industry groups (Vaillancourt 5).
} 
APPENDIX A

Sample Blogs Drawn From www.blogscanada.com (Case study blogs are highlighted in gray)

\begin{tabular}{|c|c|}
\hline Just in From Cow Town & http://calgal.motime.com/ \\
\hline Linealanoie.com & htto://inealanoie.com/ \\
\hline Rebecca Writes & http://www.everydaymusings.blogspot.com/ \\
\hline Caz's Corner & http://unw.xanga.com/home aspx? user=cazzac \\
\hline Donna's Journey & http://donna.innereyes.com/ \\
\hline Slushpile & http://slushpile.blogspot.com/ \\
\hline Eye of Newt & http://eveofnewt.blogspot.com/ \\
\hline Purse Lip Square Jaw & http://www.purselipsquarejaw.org/ \\
\hline BluePopcorn & http://uww.bluepopcorn.orgl \\
\hline In Bed With Ursual & hittp://wnw.ursulasbedroom.blogspot.com/ \\
\hline Dirty Olive & httolfww wadityolive.net \\
\hline Jane Crow Journal & http://ianecrowiournal.blogspot.com! \\
\hline Delicious Juice & http://www.deliciousjuice.coml \\
\hline Chaos Ensues & http://unw.chaosensues.com/ \\
\hline Dragon Lady's Journal & http://unw.livejournal.com/users/ dragon lady/ \\
\hline Stuff in my head & http://vanessa au.blogspot.com/ \\
\hline Christina In London & http://unw3,telus.net/christinalnLondon/blog/ \\
\hline Just Sue & http://mun justsue.ca/ \\
\hline Janua Diaboli & http:/lwww livejournal.com/users/thelicia w/ \\
\hline Queerly Canadian & http://www.outandproud.cal \\
\hline Ego Chick & http:/legochick.com/ \\
\hline Just A Girl & http://www.ustagirl.cal \\
\hline To Be Determinied & http://wuw.livejournal.com/users/a dawn/ \\
\hline Puckerup Buttercup & http://sour lemon.blogspot.com/ \\
\hline Renaissance Grrrl & http://renaissancegrrrl.grrrlmeetsworld.com/ \\
\hline Grass Is Always Greener & hittp:/hwww.grassdiaries.com/ \\
\hline Joyce Cajucom.com & http://www.loycecalucom.com/ \\
\hline Anna Overseas & http://wuww.telusplanet.net/public/dexx4d/anna22/ \\
\hline Mostly Emily Jones's Diary & http://emilyjones.no-ip.com \\
\hline Raisingrrrl & http://muw.livejournal.com/users/raisingrrrl/ \\
\hline Black Girl Interrupted & http://blackgirlinterrupted.bravejournal.com/ \\
\hline Whiter Canada & http://whither blogspot.com/ \\
\hline Tekgrrl's House of Tek & http://tekgrrl.blogspot.com/ \\
\hline Mac Mommy & htto://wuw.macmommy.blogspot.com/ \\
\hline Movable Peechie & http://www.web-goddess.net/peechie/ \\
\hline G is for Gladys & htto://gladys.visuallogix.net/ \\
\hline Woman as an Artist & http://saintofme.blogspot.com/ \\
\hline The Whore's Boudoir & http://drunkenwhore.blogspot.com/ \\
\hline Erica Sanderz's Journal & http://wnw.livejournal.com/users/ericasanderz/ \\
\hline Perceive My Precipice & http://emeraldblaze. diaryland.com/ \\
\hline What a Day & http://justsomechik.blogspot.com/ \\
\hline E Curls Journal & http://www.jadingheart.com \\
\hline Randomness & http://wnw.livejournal.com/users/catwoman03/ \\
\hline Poetry In Motion & http://robin2dawn diary-x.com/ \\
\hline [cynically] smiling & http://antipretty.blogspot.com/ \\
\hline Right In Canada & http://umw.xanga.com/home.aspx?user=kariba \\
\hline Scribbling Woman & http://www.unbsj.ca/arts/english/jones/mt/ \\
\hline Chandrasutra & http://chandrasutra typepad.com/ \\
\hline White Noise & http://whitenoise. united net.kg/ \\
\hline Netwoman & http://netwomen.ca/Blog/ \\
\hline The Spiny Echidna & htto://umw.petrock.cal \\
\hline Baby_gurl3 & http://mun.livejournal.com/users/baby gurl3/ \\
\hline Northbound Burrito & hittp://wnu.accesswave.ca/ yellowwood/lblog/burrito.html \\
\hline Not so Random Girl in Sarnia & http://icymotha diaryland com/ \\
\hline The Secret Diary of Ladybug & http://oladybugo. diaryland.com/ \\
\hline Sixteen Days Under the Sundae & http://raspberrusundae.blogspot.com/ \\
\hline Voxpopgirl & http://voxpopgirl.blogspot.com/ \\
\hline Have fun. Be good & http://www.havefun-begood.com/ \\
\hline DeannalnUganda & http://blogblogbaby.blogspot.com \\
\hline Vancouver Smells Different Every Day & http://vsde.blogspot com/ \\
\hline Fattypatties & http://fattypatties.blogspot.com/ \\
\hline Crazy Beautiful & htto://iavfo.blogdrive.com/ \\
\hline
\end{tabular}




\section{APPENDIX B}

\section{Canadian Women Bloggers - Layout Samples}

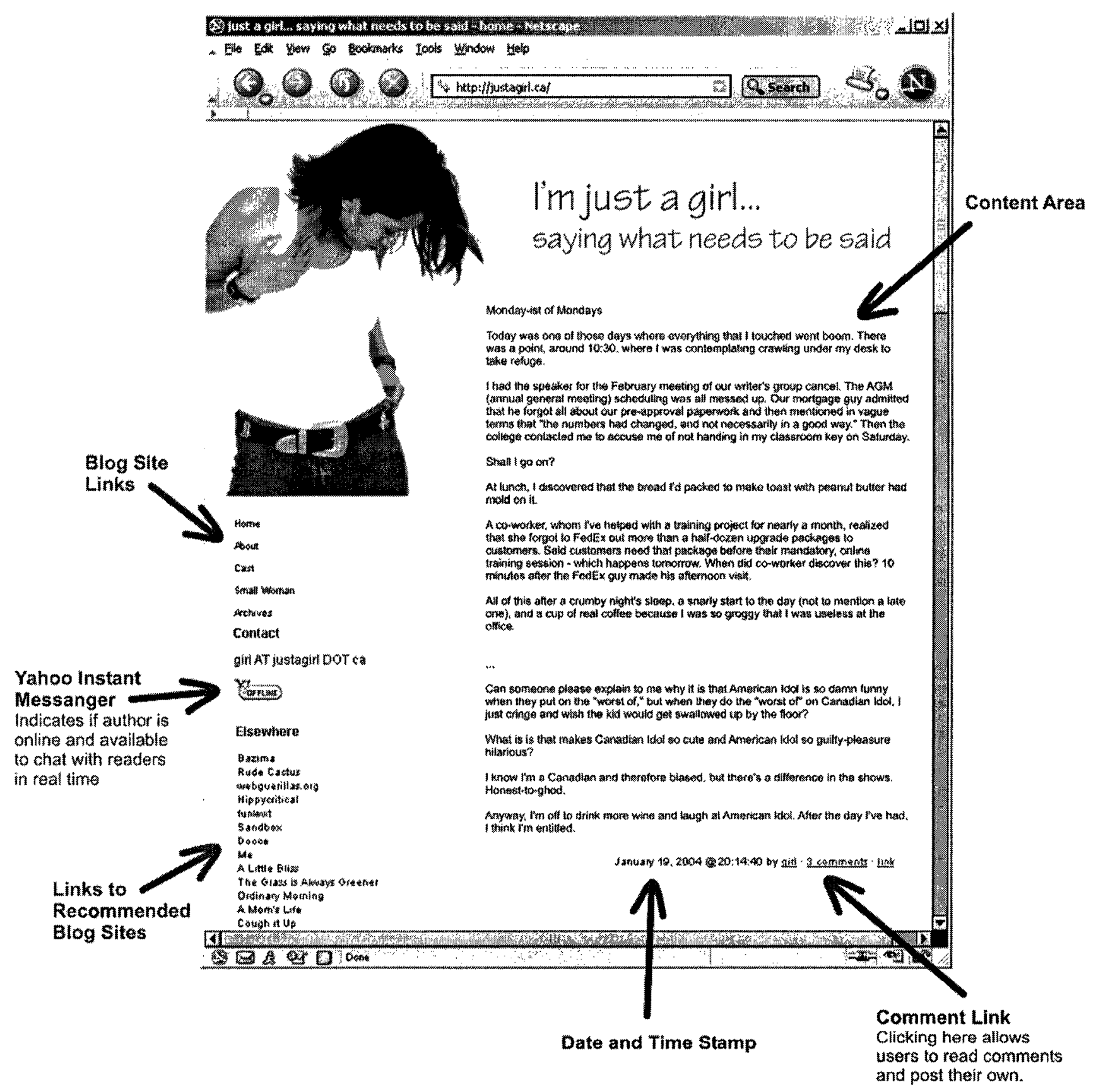




\section{APPENDIX B Continued Canadian Women Bloggers - Layout Samples}
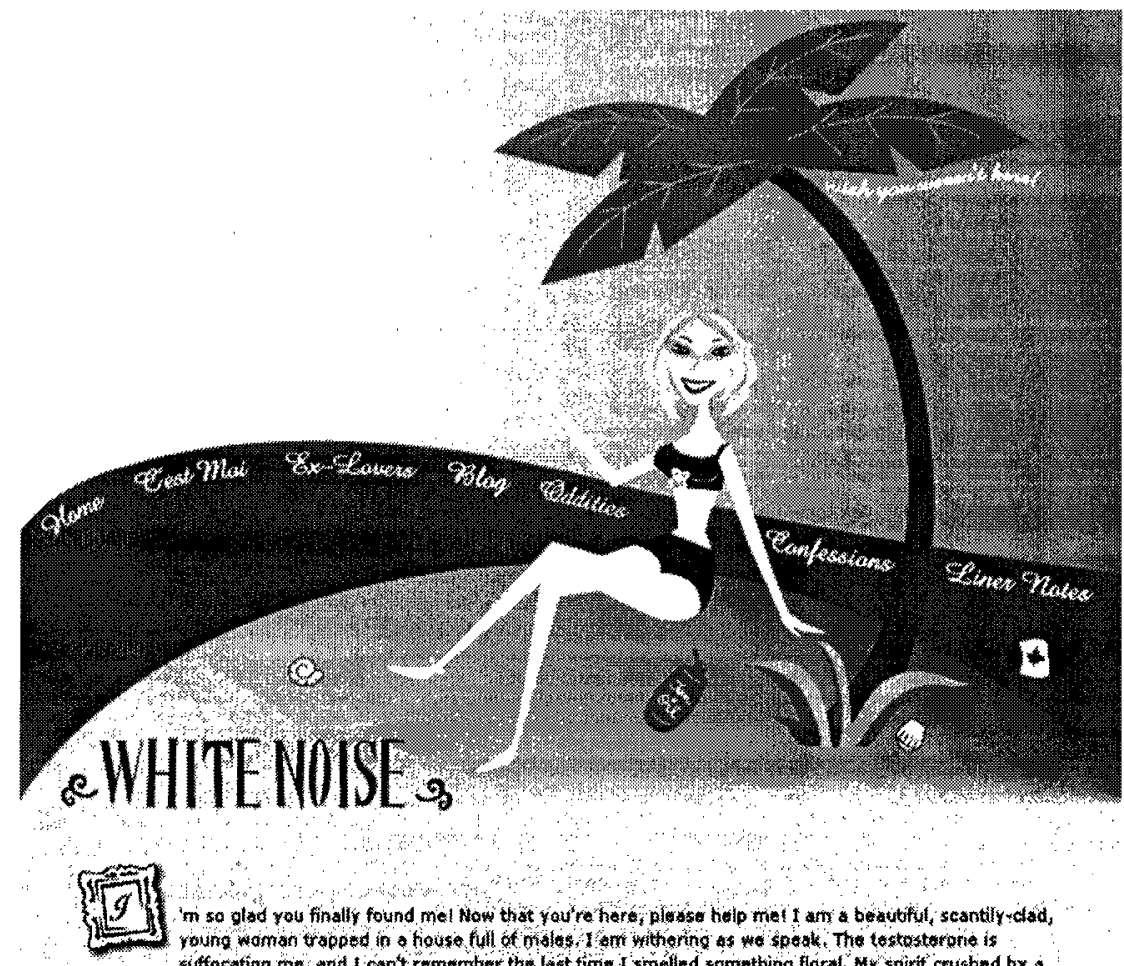

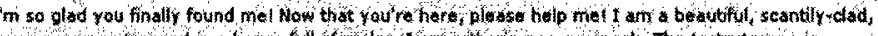

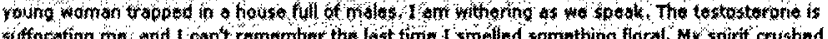

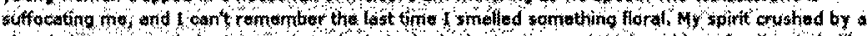

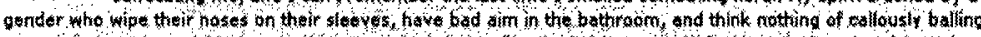

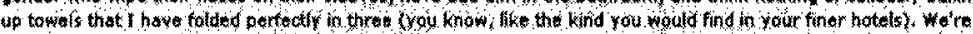

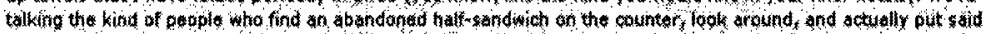

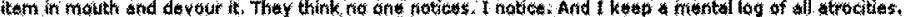

\section{http://whitenoise.united.net.kg}

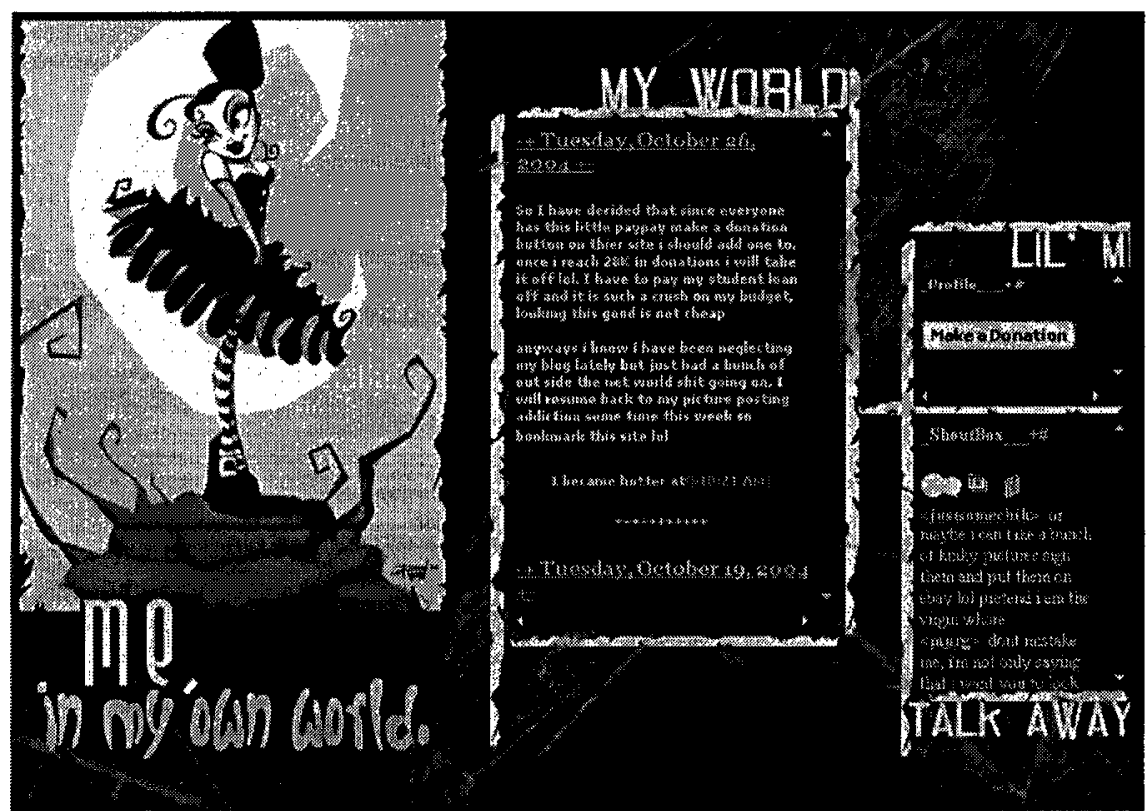

http://justsomechik.blogspot.com 


\section{APPENDIX C}

I Will Survive Photographs

http://day-without-rain.org/sandee/

Photographs found on the main blog page.

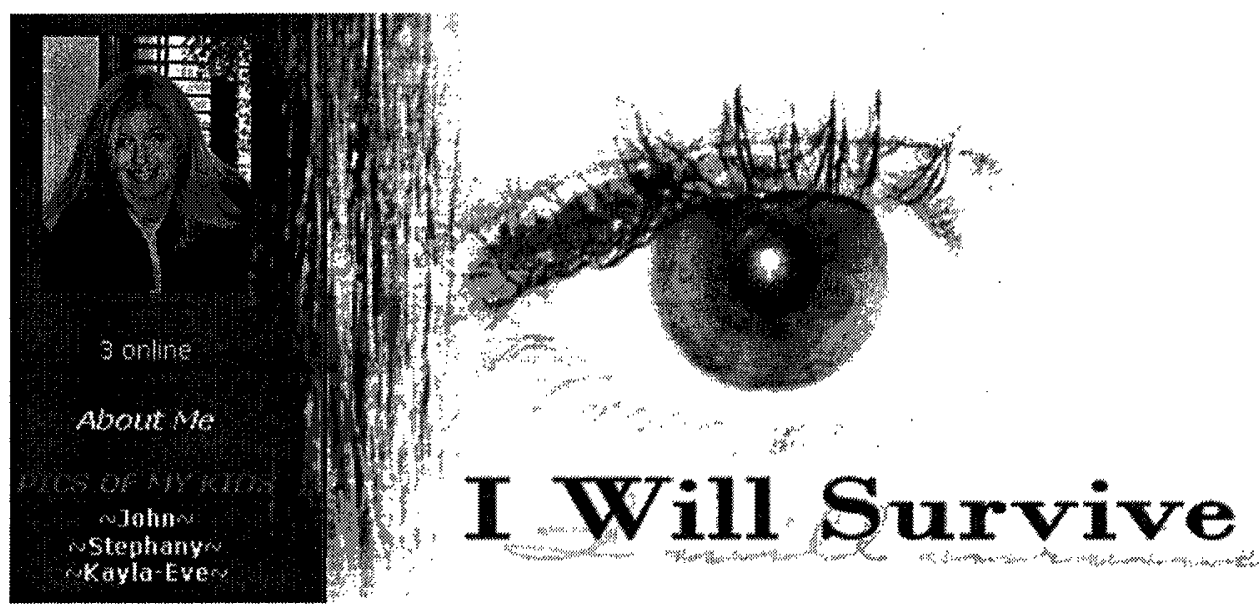

Photographs of Sandee's Chemotherapy Treatment
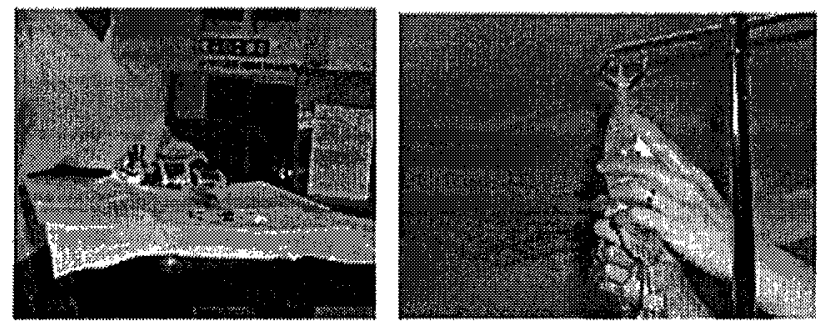

Typical Treatment Day!
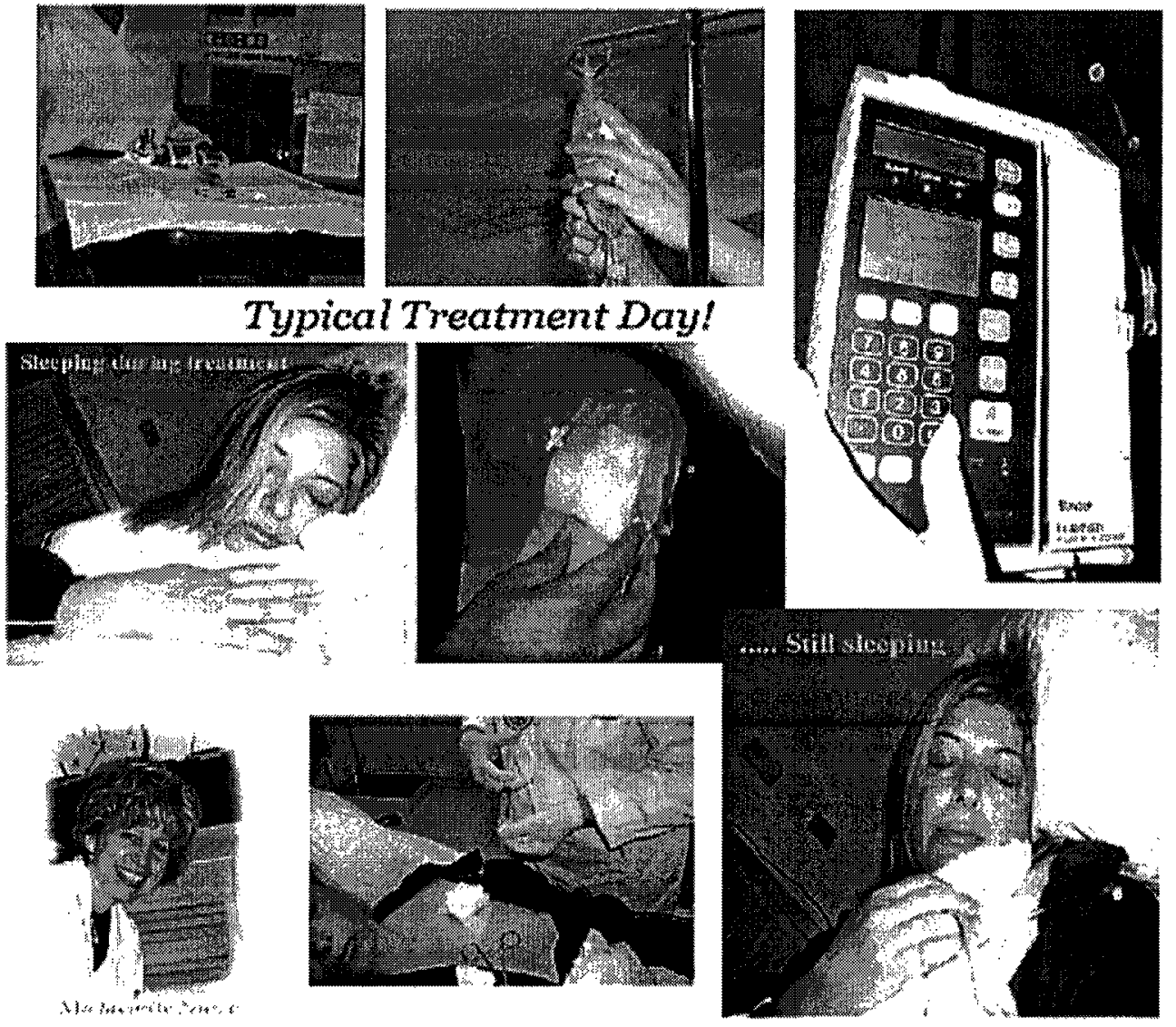


\section{APPENDIX D \\ Example of a Detailed Biographical Blog Statement Source: http://www.deliciousjuice.com/bio.asp}

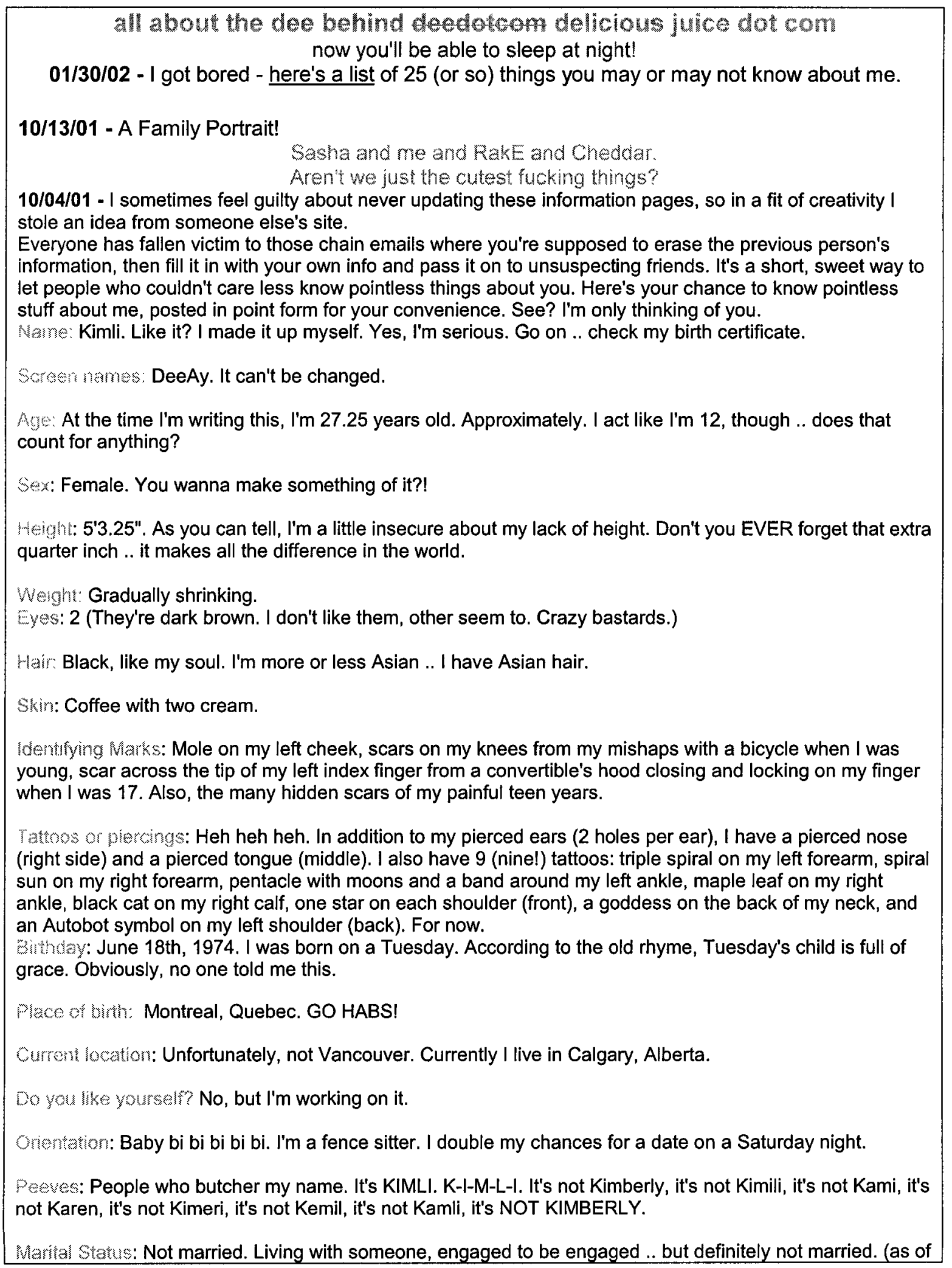


10/25/01: engaged! woo!)

Ever been skinmy dipping? Yes.

Woud you have ser with a clones of yourself? Would I be able to set up a webcam show and charge people to watch?

Do you make fum of peonle? Oh hell yes. I'm probably making fun of you RIGHT NOW. I try not to hurt people, though. Hurting sucks. If I do make fun of you, I'm either laughing with you or you really deserve it.

Are yu a hopeless romantic? I'm certainly hopeless. But a hopeless romantic? Not sure. I'm fairly untraditional, but I like getting flowers.

ho you got along wh your parants? Now that I live nowhere near them, sure! They still manage to irritate me regularly, though. My dad kicks ass. My mom .. not so much.

Beedtimo: During the week: midnight. Weekends: 2-5am.

Mhat kind of shoes do you wear? Depends on the weather. In the summer, I live in cheap Birkenstock ripoffs. The rest of the year, usually a pair of black Mary Jane ripoffs. I have many shoes, I usually only wear 2 pairs. Not at the same time.

Wow many pilows on he hed. I personally sleep with 3 , but there are 5 on the bed. l'd sleep with more if I could get away with it.

Dream an: Dark green convertible Golf Cabriolet :o

Whent car: '99 Chevy Metro. Don't laugh .. my car kicks ass.

Words sn phraes yon overuse' It's all good/Squeeze my head for delicious juice/Oh my shit.

Most momantic moment: Is this me being romantic towards someone else, or someone else being romantic towards me? Either way, it's hard to say. One that comes to mind is when RakE and I were living in different cities (he in Edmonton, me in a horrible household in Calgary) and I was really depressed and on the verge of throwing everything away and slinking back to Victoria to live with my parents. To cheer me up, Ed went online and searched until he found MP3s of the Transformers: The Movie soundtrack and sent them to me. It worked, I stayed, he rocks.

Bigesests cush: Anson Carter of the Edmonton Oilers, and Zhang Ziyi of Crouching Tiger, Hidden Dragon. :0

Pers: Two cats, Sasha and Cheddar. And a fish named Prince Albert.

Shos sizs: Depends on the brand. Usually 8 or 8.5 .

Siming: Two halves that make one whole, I guess. I have one half brother and one half sister. My sister is older than my mother. My entire family is fucked up.

Skils: I like to pretend I can write. At the very least, I can type fast. I can cook, I'm good at the sex, I'm too creative for my own good.

Aitergus: Penicillin, almonds, apples, peaches, cherries, nectarines, plums, pears, orange jello.

Reopr Card More: "Kim shows a flair for writing and a strong creative streak, but she should branch out and write about something other than Transformers once in a while." - grade 7 report card

Loved somebody so much in made you ory? Yes.

Coutons or bacon bix? Both if the bacon bits are real. If not, load me up with the crouton love.

Spine or 7up? Diet Coke. 
Fumontas Holday: The half day that the majority of Calgary gets off for the Calgary Stampede parade. Also, Christmas.

Fworlo tay of the week: Thursday and Saturday.

Toomrasie: Since I'm not contractually obligated to sprout the virtues of Crest, it's Colgate all the way.

Fuonls Fiowers: Lilies and those big weird flowers that I've gotten in three flower bouquets now. I don't know what they're called, but they're cool.

Favorte Ornk: Diet Coke/Chai/Go Mango smoothies from Juiced.

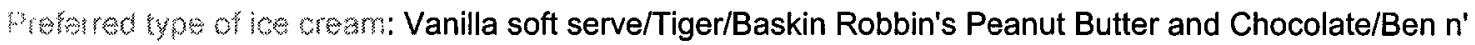
Jerry's Toffee Crunch Something Or Other.

Fanter Fost Fod kestaurant: I don't eat much fast food anymore, but I suppose I'd have to say Queen Donair in Edmonton.

Whot color is your bormom morne? Cat Puke Stained Beige.

How many hines did you lan your chivers lest? ZERO, BABY

Heve you wem ben onviched of arme? Convicted? No.

Whit smale store woult you choose wo max out your credit card? LUSH. omg omg omg.

What do you do moxt oten when von ore bored? Masturbate and/or play Word Whomp. Sometimes both at the same time.

Most amoyng ling peoples mes mat are you?" meaning, "What nationality are you?". I'm HUMAN, thanks for asking. I don't mind it when people say "Are you <insert incorrect nationality here>?", because it's an honest question. But "What are you?" smacks of them not knowing literally what I am .. am I man or beast?! For those who care, I'm actually half Malaysian and half French Canadian. I've been mistaken for the following: East Indian, Native Indian, Hawaiian, Indonesian, Filipino, Chinese, Japanese, Korean, Vietnamese, African, Mexican, Inuit. Plus more that I'm forgetting. Not one person has ever guessed "Malaysian". Huh!

Favole an thes Th show: I'm going to show my age with this: Transformers (the original series, thankyouverymuch), Galaxy Rangers, Jem. And away from the cartoon genre .. I dunno. The X-Files?

Last persen you went ou to mimer wht: Ed and Christian.

Las noye you sew m the thestr: Jay and Silent Bob Strike Back. Twice!

I'll add more when I think of them. This is a good start, though. It's all good.

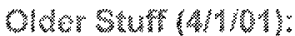

Ah, the rich tapestry that is my life. Envied by no one, admired by few, feared only by those who attack me on message boards. Life is good.

I live in Calgary, Alberta with one boy (RakE), one calico (Sasha), one stray ( Albert, all that's left of my Mighty Guppy Empire. RIP, Martin Sheen, Microfeesh and Dave the Snail). Job hunting psychopath by day, I morph into a smart-assed IRC junkie by night. It's a tough job, but if I didn't do it, Uller's quote file would be mighty slender indeed.

I fill my time by studying Wicca, cooking fancy things when the mood strikes me, and pining for British Columbia, where I grew up. I also divide my weekends between Calgary and Edmonton, because I can't go for too long without rubbing Lobot's shaved head or I go insane. I also like to go to the big mall.

Four years ago, I ran away from Victoria BC, because I was stuck in a stagnant job. I ended up in Calgary, where I soon found another stagnant job - but this one paid more, and it was a lot closer to RakE. I got an apartment, I got a car, I pierced my nose. Years passed. I moved, RakE moved, I got a second cat, I pierced my tongue, I got more tattoos. Then I lost my job.

That pretty much brings me to the present. I play Q3 TDM in the all-female clan QGirlZ; I play Black \& White and have raised an evil cow, a fat tiger and a well-rounded monkey who enjoys pooping on houses; I will soon be playing Tribes2; I play Daikatana when I feel like punishing myself (Ultimate Gas Hands? WTF were you thinking, Romero?); I'm in love with Commander Keen.

I love Transformers and Hello Kitty; I'm estranged from most of my abso-fucking-lutely insane family; ! love Diet Coke and would drink it 24/7 if I could. I don't like wearing socks; I love my friends to the best of my 
ability; I don't like myself very much, but I'm working on it. I've been described as cute, ugly, arrogant, humble, loud, quiet, hetero, lesbian, bi, cool, fat, short, silly, lovable, funny, 43 different nationalities, witty, mean, sweet, cruel, nice, clever, dumb, crazy, normal and yummy. Make your own opinion - you can't listen to me because I'Il tell you the worst, you can't listen to RakE because he'll tell you the best, and you can't listen to the trolls because they'll tell you things that are misspelled and oftentimes, cruel. But not crueler than anything I could say myself.

I'm half Malaysian and half French Canadian. I love my country, and tattoo'd myself to show it. I love hockey, and I love the idea of beer even though I hate the taste. I love Andrei Kovalenko, mostly to bug RakE but also because "Kimli Kovalenko" is so much fun to say. I love RakE because he does his best to keep me sane, and because he won't let me be a Crazy Cat Lady with 84 cats when I grow old. I love my friends and my clanmates, I love my car, I love the ocean and I miss having it close by. I love my dad. I love to write, I love to sing even though I do it badly, I love to take long hot baths and think about my day.

Obviously, I love the sound of my fingers hitting the keys.

I love Chrizz.

I smell like green tea; I prefer vanilla ice cream to chocolate ice cream; sex is natural, sex is fun, sex is best when it's one on one.

Okay, I lied about that last part.

I like to be outside, I'm trying to learn to rollerblade, I enjoy getting tattoos. I can't whistle or drink very much alcohol, I'm not into drugs (but pot's ok sometimes), I hate it when people call me names but I do it to myself all the time. I really like those strawberry marshmallow candies you can get at $7-11$ for 5 cents, but if you go to Costco you can get 100 for $\$ 3$.

The vitals? I'm almost 27 years old, I'm 5'3.25" tall, I have black hair and brown eyes. My nose and tongue are pierced, my left arm, right ankle and back of the neck are tattoo'd. Before the year is out, l'll have at least two more - right arm and left ankle. I'm all about the symmetry. I have chronically dry skin that scars easily, a terribly cute nose, and really nice lips. They make wearing lipstick fun. And kissing. Kissing is fun. I lost my virginity after school at age 16, then went on to work at McDonald's from $7 \mathrm{pm}$ to 3am. I thought it was terribly romantic. I've since altered my views on romance and sex.

I'm allergic to birch. This means I can't eat half the fruit l'd like to eat, and tree pollen makes me sneeze and my eyes turn red and puffy and it's not altogether an attractive sight. Almonds are deadly, they make me stop breathing. This is a bad thing, they tell me. So I don't eat the almonds.

More later. Maybe. 


\section{APPENDIX E \\ Post from Delicious Juice on Menstruation Products http://www.deliciousjuice.com/comments.asp?id=1530}

I'm annoyed about panty liners, people. While rummaging through my collection of feminine hygiene products, I happened upon a box of black panty liners. I remember buying these; even though they were more expensive than the handily compact ones and came 32 to a box instead of 36, my inner goth gave a rousing "meh" of delight at the thought of panty liners as black as the midnight of my soul. It seemed like a truly excellent idea at the time, but now when my womb is shedding its lining that had been prepared for the fertilized egg it will never receive, I am annoyed. Black panty liners suck. It's not enough for me to know I am being vaguely protected 'down there', I need to see the evidence of the flower of my womanhood. Nothing shows up on a black absorbent surface - I could be bleeding out mango chutney or Ovaltine and I wouldn't know. I am inconvenienced monthly because I listened to my inner goth, and I'm not happy about it. Not only that, but in order to dazzle you with packaging so you can marvel at how far vaginal technology has come, the box is designed to carry the liners at their full length to maximize the impact. This means they're not individually wrapped, making them awkward and unhygienic to carry, and they don't fit neatly into my Vinnie's Mini Tampon Case. Everything about the black panty liners piss me off. I am pissed off at the difficulties they add to my menstrual cycle. Just who do they think they are, throwing a wrench into places there best be no wrench at all? And don't even get me started on the OTHER kinds of stupid panty liners - while I personally wouldn't think to ever wear a thong while leaking out my hoo-haw, there are those who do and thong-shaped liners must seem like a good idea to them. A few years back, companies were putting patents out for panty liners that were soaked with chemicals to help you better understand your menstrual cycle. Good lord! Where has this stuff been since the dawn of time? I don't know how our foremothers were able to live without a handy colour-changing rag between their legs to tell them they're about to ovulate so they could conceive their 9 th child. These new fangled liners were to come with colour coded charts - purple on gold means you're ovulating, red means it's a little too late to be wondering when your period is going to start, blue means you've got the clap and pink indicates that the stars are in alignment on the cusp of Capricorn so today would be a good day to ask that hunky office dreamboat out for coffee and "dessert". WHY is it a good idea to drape my most delicate bits in chemicals? Who thinks of this stuff? My vagina is JUST FINE without help from your caustic concoctions. It does not need to be deodorized or disinfected or moisturized daily to avoid unsightly wrinkles. It does not need designer products once a month to help me forget the embarrassment of being a woman. I do not need a spray to mask my womanly odors. I don't need "special sized" protection for my fat girl cunt, and nobody needs you to entice an entire generation of young girls into paranoia that they vagina is too big or too small for your products which, while we're on the subject, are ridiculously expensive for something we have no choice over. I'm a woman. I bleed out my vagina for $2-5$ days a month, and you're making MONEY off my natural cycles. You're trying to introduce new and excitingly colourful ways to tell me if I'm a cheating whore who's knocked up and riddled with STDs and just to add insult to injury, you're dropping subtle hints that I stink and should cover up in case someone can tell that I'm on the rag. $\mathrm{OH}$, and you're making tampons with "silent" wrappers, too, so no one can hear us in the bathroom because other women would be MORTIFIED to learn that ANOTHER WOMAN is HAVING HER PERIOD in a PUBLIC PLACE when we should obviously be at home bedridden until our womanly cycles are through. It's punishment, you see, for BEING WOMEN. Well, here's a hearty FUCK YOU from me and my vagina and all the fun that comes with and from it, including the oh-so humiliating fluid from my uterus and the only organ on the human body specifically designed just for pleasure and any and all scents that might come from this flowering, bleeding, leaking proof that I have a fabulous set of the XX running wild through my body like Godzilla on the streets of Tokyo.

So *there*.

longest. paragraph, ever.

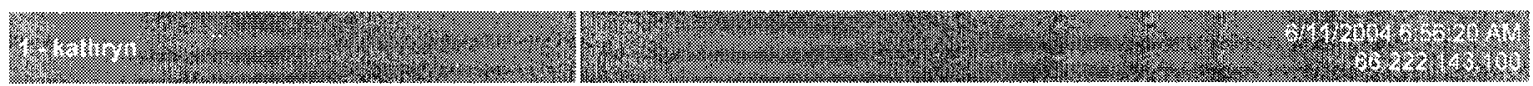

If you are truly sick of people making money off your monthly get The Keeper. It's a keeper! It's cool and all your friends have them too. Your inner granola crunching hippie should embrace it. DOWN with the man making money off my special visitor. And so forth. Your inner goth needs to meet your inner accountant. LOL.

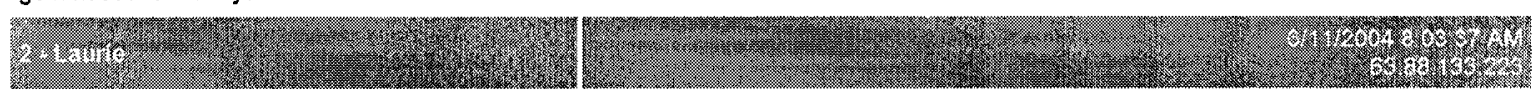

A "new" product I find bizzare are the pads that have a "quiet wrapper" so they don't make a crinkling noise when you unwrap them in the bathroom. Like, who the fuck cares that you're changing your pad in there?

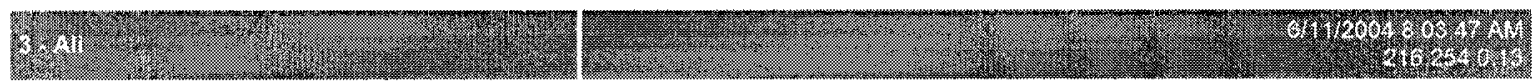

And that's why I am now taking the shot. Hello to no more periods. *CHEER!* Plus, I don't have to remember to take a pill every day. And you have no idea what a plus that is for me. : $x$

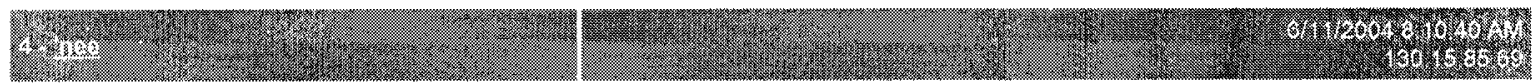

Bahaha.. that's a bloody brilliant rant.
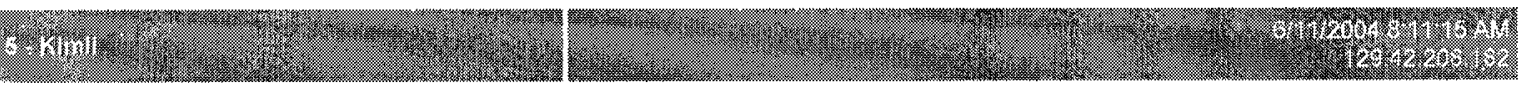

'nee, I sincerely hope that pun was intended :D 
Ali, with the shot you don't get your period? Does it mess with your hormone levels? Just curious.

F.

Men should not read this update. Can you put a disclaimer at the beginning? :)

F

Major fucking WORD, Kimli. : )

药

Yes, the pun was intended. I'm almost as clever as I think I am * $g^{*} \ldots$

kat: depo shots change the level of progesterone in your bloodstream, just like the pill does with estrogen. They discovered that progesterone is longer-lasting than estrogen, and elevated levels (just like in pregnancy) will stop a period altogether. However, about $25 \%$ of people find that increased progesterone causes depression, so it's not for everyone.

Y

And to think I wondered why our content filtering service at work blocked this...

Y

I take the pill non-stop so I don't get a period, because having one makes my fibromyalgia unbearable. My doctor said as long as one doesn't smoke or have high blood pressure there's no risk.

-

FUCK YEAH!!!!!!!!!!!!!! :D

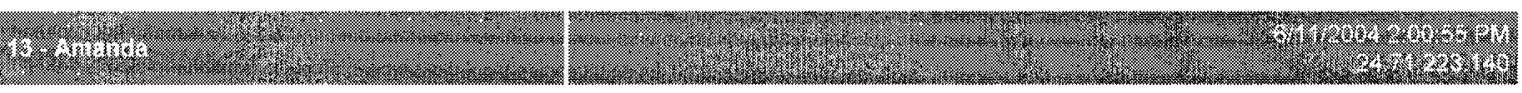

if you're taking depo - make sure you're also taking calcium supplements. Like $1000 \mathrm{mg}$ a day.

F

Also with depo be sure to stay on an excercise routine. It does cause weight gain. Either way I am going back on it because these new pills are horrible with keeping me from spotting. Plus the conveinance of only every three months having to deal with it is nice.

F

A-fricking-men.
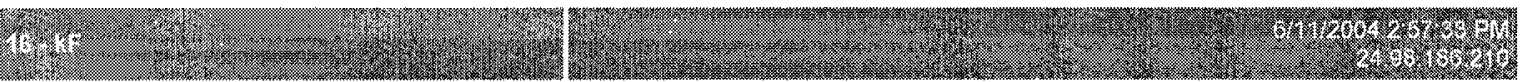

this is gross

(2)

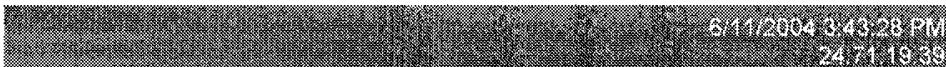

The Keeper all the way, baby. I can laugh heartily (and I do) as I walk down the isle of black, chemical-laden, thong or otherwise strangely designed 'feminine protection' at the supermarket. Even when they're on sale. I've had it for just over two years, now and it's still going strong... Let's see, even at the costly initial price of $\$ 50$ (which included some fancy washable cotton pads that I've only actually used once) I've still saved at the very LEAST a whopping $\$ 118$, and probably more than that, considering a box (or so) of tampons a month usualy ran me about $\$ 7$ per box. Not to mention the hippie-loving-granola side of me liking the low impact on the environment and not flushing/disposing of anything that l've paid $\$ 7$ for.

草

Don't forget the fucking GST. Bastards.

Ps: I loved that post. Here here!

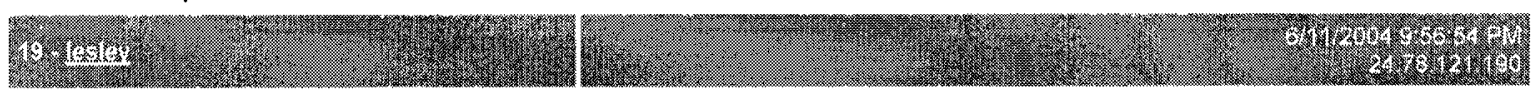

you're my frikkin' role model. well said, and bravo. "golf clap*

-


My goodness, I never knew so many people liked the keeper. I thought it was just UVic liberal arts I womens studies students. I said it on d's page and I'll say it here: if my uterus is discharging it, then I don't really want to touch it, thanks. The keeper requires me to be far too hands-on in that department when what I really want is some absorbent, comfortable fabric/cotton pads that I can toss out when I'm done. I might not be the most environmentally-friendly person in the world, but fuckit I never said I was voting Green anyways.

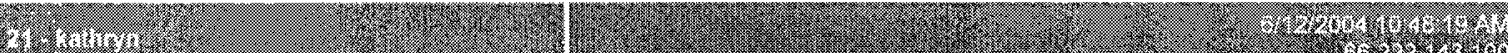
6.2.

I am not very hippie and didn't take Liberal Arts OR Women's Studies. It just makes economic sense. Also, who wants all those chemicals touching their private places? You vote with your dollars these days. I vote - no one gets to make scads of money off my natural body process.

年

ahhh. I'm with ed. This needs to be censored from the fragile eyes of men like myself that like to pretend that everything 'down there' is flowers and rainbows. All month.

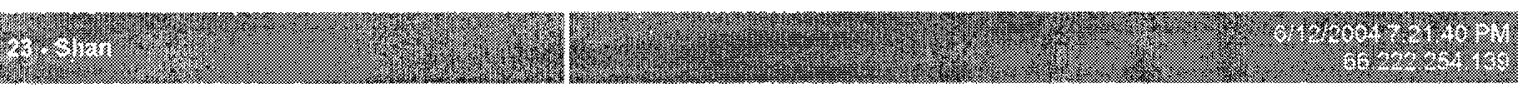

HA!

*ahem* Oh, sorry, that last one just made me laugh.. ;D

I'm with you, Kim, it's all dumb.

F.

I'm gonna have to side with RaKe on this one. The "If dangly appendage sprouts from crotch, do not read this update" disclaimer was needed. I thought the commercials were bad. Eep!

2.

Boys could have easily just not read this... it does start with you talking about panty liners, what do people expect? :P Nice rant

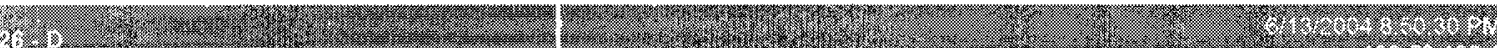

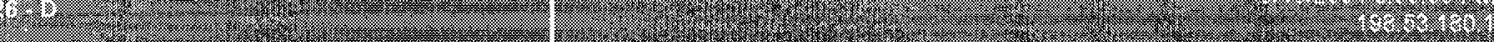

Really Gross - don't you have anything better to write about???

4.

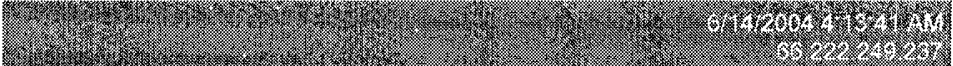

Who are "you* to say my vagina is gross? I think my vagina is a wonderful thing to write about! Vaginas are glorious, amazing things! The womanly cycle is a miracle to behold! You should get on your knees and up close and personal with my vagina - or any vagina, really - and gaze upon it with wonder and extreme reverence, because without the existence of vaginas and their ability to do those things they do, you would not be alive to criticize the things I do on my own personal webspace! WORSHIP MY VAGINA, DAMNIT! LOVE ITI

.. and screw you, hippie.

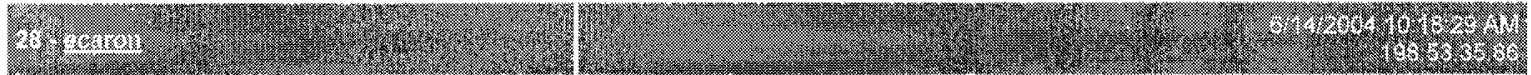

you know what i'd like? i'd like to stop discharging chunks and blobs and PIECES OF MY SOUL. you can complain about gross when you're staring that down at 8 in the morning.

等.

I take calcium every day and exercise regularly... so far depo has been a lifesaver (and a good tool for prevention). I'm one of those people who goes to take her pill and sees I've missed a day or two. YAY ME! :P

I put a lot of thought into it, did research, and for me it was the best choice. But I agree there are side-effects that must be considered and make the shot not for everyone. 
Works Cited

Adam, Alison. "Cyberstalking: Gender and Computer Ethics." Virtual Gender: Technology, Consumption and Identity Matters. Ed. Eileen Green and Alison Adam. New York : Routledge, 2001. 265-285.

Addison, Joanne, and Hilligoss, Susan. "Technological Fronts: Lesbian Lives ‘On the Line'. Feminist Cyberspaces: Mapping Gendered Academic Spaces. Blair, Kristine and Pamela Takayoshi, eds. Stamford, Connecticut: Ablex Publishing Corporation, 1999.

Ahn, Christina. "Not Post-Feminisms." Turbo Chicks: Talking Young Feminisms. Allyson Mitchell, Lisa Bryn Rundle and Lara Karaian, Eds. Toronto: Sumach Press, 2001. 256-272.

Anderson, Benedict. "Imagined Communities: Reflections of the Origin and Spread of Nationalism. The New Social Theory Reader: Contemporary

Debates. Seidman, Steven and Jeffrey C. Alexander, Eds. London, UK, Routledge. 2001.

Anderson, Linda R. Women and Autobiography in the Twentieth Century:

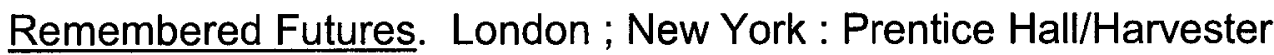
Wheatsheaf, 1997.

Arnold, Jill and Miller, Hugh. "Gender and Web Home Page." Poster at CAL99 Virtuality in Education Conference, The Institute of Education, London 28-31 March 1999.

$<$ http:/less.ntu.ac.uk/miller/cyberpsych/cal99.htm>.

Baumgardner, Jennifer and Amy Richards. Manifesta: Young Women, Feminism 
and the Future. New York: Rarrar, Straus and Giroux, 2000.

Balka, Ellen. "Women and Computer Networking in Six Countries." The Journal of International Communication. 3.1 (1996) : 66-84

. - -, "Viewing Universal Access Through a Gendered Lens" . Proceedings of Universal Access Workshop: Developing a Canadian Access Strategy. Universal Access to Essential Network Services. Faculty of Information Studies, University of Toronto, Toronto, Ont. February 6-8, 1997. Bazeley, Michael. "Plain Layne and Odin Soli: an Internet hoax."

Mercury News. Mon, Jun. 28, $2004<$ http://www.mercurynews.com/ $\mathrm{mld} / \mathrm{mercurynews} /$ news/breaking news/9028023.htm?1c $>$.

Berger, John. Ways of Seeing. Markham, Ontario: Penguin Books, 1981. Brodzki, Bella, and Celeste Schenck. Life / Lines: Theorizing Women's Autobiography. Ithaca: Cornell UP, 1988.

Broughton, Trev Lynn and Anderson, Linda. Women's Lives/ Women's Times: New Essays on Auto/Biography. Albany, New York: State University of New York Press. 1997.

Bunkers, Suzanne L., Ed. Diaries of Girls and Women: a Midwestern American Sampler. Madison: University of Wisconsin Press, 2001.

Bunkers, Suzanne L., and Huff, Cynthia A. Inscribing The Daily: Critical Essays on Women's Diaries. Amherst, MA: University of Massachusetts Press, 1999.

Buss, Helen M. "Pioneer Women's Diaries and Journals: Letters Home/Letters to the Future." Mapping Our Selves: Canadian Women's Autobiography in 
English. Montreal and Kingston: McGill-Queen's University

Press, 1993. 37-60.

Butler, Judith. Gender Trouble: Feminism and the Subversion of Identity.

New York: Routledge, 1990.

Carter, Kathryn, ed. The Small Details of a Life: Twenty Diaries by Women in

Canada, 1830-1996. University of Toronto Press, 2002.

Cavallaro, Dani. Critical and Cultural Theory: Thematic Variations.

New Brunswick, NJ: Athlone Press, 2001.

Cerulo, K. A. Reframing Social Concepts for a Brave New (Virtual) World.

Sociological Inquiry, 67.1. (1999): 48-58.

Chandler, Daniel. Personal Home Pages and the Construction of Identities on the

Web. University of Wales, Aberystwyth, 1998.

$<w w w . a b e r . a c . u k / m e d i a / D o c u m e n t s /$ short/webident.html $>$.

Coleman, Linda, S., Ed. Women's life-writing: Finding Voice/Building Community.

Bowling Green: Bowling Green State University Popular Press, 1997.

Crittenden, Danielle. What Our Mother's Didn't Tell Us: Why Happiness Eludes

the Modern Woman. New York: Simon and Schuster, 1999.

Crompton, Susan. Ed., Canadian Social Trends, 63 Winter (2001) : 3.

Culley, Margo C., Ed. A Day at a Time: The Diary Literature of American Women

from 1764 to the Present. New York: The Feminist Press, 1985.

Darbyshire, Peter . "I think therefore I blog: Literary websites serve daily tidbits to

avid readers" The Ottawa Citizen. Ottawa, Ont.: Nov 2, 2003. pg. C.10

Denfield, Rene., The New Victorians: A Young Woman's Challenge to the Old 
Feminist Order. New York: Warner Books, 1992.

Derrida, Jacques. Of Grammatology. Baltimore, Md : Johns Hopkins University Press, 1997.

DiCaprio, Lisa and Wiesner, Merry E. Lives and Voices: Sources in European Women's History. New York, NY: Houghton Mifflin Company, 2001.

Donath, Judith. "Identity and Deception in the Virtual Community." Communities in Cyberspace. Smith, Marc Smith and Peter Kollock (Eds.). New York: Routledge, 1999.

$<$ http://smg.media.mit.edu/papers/Donath/IdentityDeception/ IdentityDeception.pdf>.

Döring, Nicola. "Personal Home Pages on the Web: A Review of Research." Journal of Computer-Mediated Communication. 7.3 (2002) $<$ www.ascusc.org/jicmc/vol7/issue3/doering.html $>$.

Dryburgh, Heather. Changing Our Ways: Why and How Canadians Use the Internet. Ottawa: Statistics Canada, 2001. $<$ http://www.statcan.ca/cgi-bin/downpub/listpub.cgi?catno=56F0006XIE $>$.

Ellis, Rebecca. "Second Thoughts About a Third Wave." Canadian Women's Studies. 20/21, 4/1, (2001): 24-26.

Ferris, Melanie. "Resisting Mainstream Media: Girls and the Act of Making Zines." Canadian Women's Studies. 20/21, 4/1, (2001) : 51-55.

Fillion, Kate. Lip Service: The Truth about Women's Darker Side in Love, Sex, and Friendship. Toronto: Harper Collins Publishers, 1995.

Fish, S. Is There a Text in This Class?: The Authority of Interpretive 
Communities. Cambridge, Mass: Harvard University Press, 1980.

Fogel, Joshua; Albert, Steven M., and Schnabel, Freya. "Internet Use and Social Support in Women With Breast Cancer." Health Psychology 21. 4 (July 2002) : 398-404.

Franck, Karen A. "When I Enter Virtual Reality, What Body Will I Leave Behind?" Cyber Reader : Critical writings for the digital era. Spiller, Neil, Ed. New York : Phaidon Press, 2002.

Freeman, Barbara M. The Satellite Sex: The Media and Women's Issues in English Canada, 1966-1971. Waterloo, Ontario: Wilfred Laurier University Press, 2001.

Friedan, Betty. The Feminine Mystique. New York: Norton, 1963.

Friedman, Amy. Nothing Sacred: A Conversation With Feminism. Canada: Oberon Press, 1992.

Garrison, Ednie Kaeh. "U.S. Feminism—Grrrl Style! Youth (Sub)Cultures and the Technologics of the Third Wave." Feminist Studies. Spring 2000. Gerbner, George. "Women and Minorities in Television: Casting and Fate." A Report to the Screen Actors Guild \& the American Federation of Television and Radio Artists, June 1993. In K.E. Rosenblum \& T. Travis (Eds.), The Meaning of the Difference: American Constructions of Race, Sex and Gender, Social Class, and Sexual Orientation. $2^{\text {nd }}$ ed., McGraw-Hill, 1999.

Graydon, Sheri. "The Portrayal of Women in Media: The Good, the Bad, and the Beautiful." in Communications in Canadian Society. Benjamin D. Singer, 
Ed. Scarborough, ON: Nelson Canada, 1995.

Green, Eileen, and Adam, Alison, eds. Virtual Gender: Technology, Consumption and Identity. New York: Routledge, 2001.

Greer, Germaine. The Whole Woman. London: Bantam-Dell-Doubleday, 1999.

Hamilton, Roberta. Gendering the Vertical Mosaic: Feminist Perspectives on Canadian Society. Toronto: Copp Clark, 1996.

Haraway, Donna Jeanne. The Haraway Reader. New York, NY: Routledge, 2004.

Harcourt, Wendy. "Women's Activism on the Net." Gender, Technology and Development. 6.1 (2002) : 153-157.

Hargittai, Eszter. "Second-Level Digital Divide: Differences in People's Online Skills." First Monday. 7.4 (2002).

<http://firstmonday.org/issues/issue7 4/hargittai/index.html>.

Hekman, Susan, Ed. Feminism, Identity and Difference. Portland, OR: Frank Cass Publishers, 1999.

Herring, Susan C. "The Rhetorical Dynamics of Gender Harassment On-line." The Information Society, 15.3 (1999) : 151-167 $<$ http://www.indiana.edu/ tisj/readers/full-text/15-3\%20herring.pdf >

Heywood, Leslie and Drake, Jennifer. Eds. Third Wave Agenda: Being Feminist, Doing Feminism. Minneapolis: University of Minnesota Press, 1997.

Hogan, Rebecca. "Engendered Autobiographies: The Diary as a Feminine Form." Prose Studies: Special Issue on Autobiography and Questions of Gender 14.2 (September 1991): 95-107. 
hooks, bell. Feminist Theory: From Margin to Center, $2^{\text {nd }}$ ed., Cambridge, MA: South End Press, 2000.

Hughes, Donna M. "The Internet and the Global Prostitution Industry." Women in Action. 99.1 (1999) : 72-80.

Jelinek, Estelle. The Traditional of Autobiography. Boston: Twayne, 1986.

Johnson, Miriam. "Innocence Upstaged". Turbo Chicks: Talking Young

Feminisms. Allyson Mitchell, Lisa Bryn Rundle and Lara Karaian, Eds.

Toronto: Sumach Press, 2001. 252-255.

Johnson, Steven. Interface Culture: How New Technology Transforms the Way We Create and Communicate. San Francisco: Harper Collins Publishers, 1997.

Kaplan, N. and Farrell, E. "Weavers of Webs: A Portrait of Young Women on the Web." The Arachnet Electronic Journal on Virtual Culture. 2.3, 1994. $<$ http://www.monash.edu.au/journals/ejvc/kaplan.v2n3>.

Kennedy, Helen. "Technobiography: Researching Lives, Online and Off." Biography 26.1, Winter, 2003. (120-139).

Kilbourne, Jean. Deadly Persuasion: Why Women and Girls Must Fight the Addictive Power of Advertising. New York, NY : Free Press, 1999.

King, Alyson, and Avi, Hyman. "Women's Studies and the Internet: A Future with a H istory." Resources for Feminist Research. 27.2 (1999). Kitzmann, Andreas. "That Different Place: Documenting The Self Within Online Environments." Biography 26.1, Winter, 2003. (48 - 65).

Koerber, Amy. "Postmodernism, Resistance, and Cyberspace: Making 
Prior 171

Rhetorical Spaces for Feminist Mothers on the Web." Women's Studies in Communication, 24.2. 218-240

Korenman, Joan. "Email Forums and Women's Studies: The example of WMST-L." CyberFeminism: Connectivity, Critique, Creativity, Hawthorne, Susan and Renate Klein, eds. Melbourne: Spinifex Press, 1999, 80-97.

LaFramboise, Donna. The Princess as the Window: A New Gender Morality. Toronto: Penguin Books, 1996.

Lejeune, Philippe. "The 'Journal de jeune fille" in Nineteenth-Century France." Trans. Martine Breillac. In Inscribing the Daily. Ed. Bunkers and Huff. 107-122.

Lensick, Judy Nolte. "Expanding the Boundaries of Criticism: The Diary as Female Autobiography." in Women and Autobiography. Brownley, Martine Watson and Allison B. Kimmich, Eds. Wilmington, Del. : Scholarly Resources, 1999.

Lieberman MA, Golant M, Giese-Davis J, Winzlenberg A, Benjamin H,

Humphreys K, Kronenwetter C, Russo S, and Spiegel D. "Electronic

Support Groups for Breast Carcinoma: a Clinical Trial of Effectiveness."

Cancer. 2003 Feb 15.97(4):920-5.

Long, Judy. Telling women's lives: Subject/narrator/reader/text. New York: New York University Press, 1999.

Looker, Dianne and Thiessen, Victor. The Digital Divide in Canadian Schools:

Factors Affecting Student Access To and Use of Information Technology. 
Ottawa: Statistics Canada, 2003.

Lorde, Audre. The Cancer Journals. Argyle, NY: Spinsters Inc., 1980.

Lotz, Amanda D., "Communicating Third-Wave Feminism and New Social

Movements: Challenges for the Next Century of Feminist Endeavor."

Women and Language. 26.1 2-9.

Lury, Celia. "The Rights and Wrongs of Culture: Issues of Theory and

Methodology." Feminist Cultural Theory: Process and Production.

Skeggs, Beverly. Ed. New York, NY: Manchester University

Press, 1995 33-45.

Marlow, Cameron. "Getting the Scoop: Social Networks for News Dissemination."

Presented at the Sunbelt Social Network Conference XXII, New Orleans,

LA, February 2003. <http://web.media.mit.edu/ cameron/cv/pubs/02-

01.html>.

Martin, Michèle. "An Unsuitable Technology for a Woman? Communication as

Circulation." Sex and Money: Feminism and Political Economy in the

Media. Meehan, Eileen R. and Ellen Riordan, eds. Minneapolis,

MN: University of Minnesota Press, 2001.

Martin, Michèle. Communication and Mass Media: Culture, Domination, and

Opposition. Scarborough, Ontario: Prentice Hall, 1997.

Marshall, Barbara L., "Communication as Politics: Feminist Print Media in English

Canada". Women's Studies International Forum. 18.4 (1995) : 463-474.

Mcdowell, Akkida. "The Art of the Ponytail." Body Outlaws: Young Women Write

About Body Image and Identity. Edut, Ophira and Rebecca Walker, Eds. 
Seattle: Seal Press, 2000.

McNeill, Laurie. "Teaching an Old Genre New Tricks: The Diary on the Internet." Biography 26.1, Winter, 2003. (24-47).

Medhurst, Angela. "Shop 'til you[r connection] drop[s]: Considering the Electronic Supermarket." Digital Desires: Language, Identity and New Technologies. CuttingEdge. The Women's Research Group, eds. New York, NY: I.B. Tauris, 2000.

Meehan, Eileen, and Ellen Riordan, eds. Sex and Money: Feminism and Political Economy in the Media. Minneapolis: University of Minnesota Press, 2001. Meekosha, Helen. "Virtual Activists? Women and the Making of Identities of Disability." Hypatia 17.3, Summer 2002 : 67-88.

Miedema, Baukje, Stoppard, Janet M. and Anderson, Vivienne. Eds.

“Introduction." Women's Bodies Women's Lives: Health, Well-Being and

Body Image. Toronto: Sumach Press, 2000.

Mitchell, Allyson. "The Writing's On The Wall: Feminist and Lesbian Graffiti as Cultural Production." Turbo Chicks: Talking Young Feminisms.

Allyson Mitchell, Lisa Bryn Rundle and Lara Karaian, Eds.

Toronto: Sumach Press, 2001. 221-232.

Mitchell, Allyson and Karalian, Lara. "Third-Wave Feminisms." Feminist Issues: Race, Class, and Sexuality. " 4 "th ed. Mandell, Nancy, Ed. Toronto: Pearson / Prentice Hall, (58-82).

Mortensen, Torill and Walker, Jill. "Blogging Thoughts: Personal Publications as an Online Research Tool." Researching ICTs in Context. Morrison, 
Andrew (Ed.). InterMedia Report, Oslo, 2002.

$<$ http://www.intermedia.uio.no/konferanser/skikt-

02/docs/Researching ICTs in context-Ch11-Mortensen-Walker.pdf>.

Newbold, Chris. "Approaches to Cultural Hegemony Within Cultural Studies".

Approaches to Media : A Reader. Boyd-Barrett, Oliver and Chris Newbold, Eds. New York : St. Martin's Press, (328-337).

Ollivier, Michele and Robbins, Wendy. "Electronic Communications and

Feminist Activism: The Experience of PAR-L." Atlantis, 24.1

(1999) : 39-53.

Oxford English Dictionary, $2^{\text {nd }}$ ed., Oxford : Oxford University Press, 2004.

Pehar, J. "E-Brides: The Mail-Order Bride Industry and the Internet." Canadian Woman Studies 22.3/4 (Spring/Summer 2003) : 171-5.

Penguin Dictionary of Sociology, $4^{\text {th }}$ ed. Abercrombie, Nicholas, Stephen Hill and Bryan S. Turner, Eds. Toronto: Penguin Books, 2000.

Piercy, Marge and Freeman, Jane. Getting Together: How to Start a Consciousness-RaisingGroup. Cape Cod Women's Liberation, 1972, $<$ http://research.umbc.edu/ korenman/wmst/crguide2.html>.

Perkins, Margo V. Autobiography as Activism: Three Black Women of the Sixties. University Press of Mississippi, 2000.

Pinterics, Natasha. "Riding the Feminist Waves: In With The Third?" Canadian Women's Studies. 20/21, 4/1, (2001): 15-21.

Purcell, K. "Towards a Communication Dialectic: Embedded Technology and the Enhancement of Place." Sociological Inquiry. 67.1 (1997): 101-112. 
Rebick, Judy. "We've come part way, baby: A new opportunity has opened for the women's movement." Rabble.ca. March 15, 2004. Rabble.ca: Montreal, PQ. <http://www.rabble.ca/news full story.shtml ?sh itm=9eef7880ce4 b73bc6868da0dd56fa $115 \& r=1>$.

Reddick, A., C. Boucher and M. Groseilliers. The Dual Digital Divide: The information highway in Canada. Public Interest Advocacy Centre, Ottawa. 2000.

Rheingold, Howard and Kimball, Lisa. How Online Social Networks Benefit Organizations. <http://www.rheingold.com/Associates/ onlinenetworks.html>, 2000.

Richards, Amelia (Amy). "Body Image: Third Wave Feminism's Issue?", Body Outlaws: Young Women Write About Body Image and Identity". $2000: 196-199$.

Rideout, V. "Public access to the Internet and the Canadian Digital Divide." The Canadian Journal of Information and Library Science. $25.2 / 3(2000): 1-21$.

Roberts, Lynne D. and Parks, Malcolm R. "The Social Geography of GenderSwitching in Virtual Environments on the Internet." Virtual Gender: Technology, Consumption and Identity Matters. Ed. Eileen Green and Alison Adam. New York : Routledge, 2001. 265-285.

Robinson, Gertrude J. and Saint-Jean, Armande. "Women's Participation in the Canadian News Media: Progress since the 1970s." Summary of Findings. Montreal: McGill University, Department of Communications, 1997. 
Roiphe, Katie. The Morning After: Sex, Fear and Feminism. Boston: Little Brown and Company, 1993.

Rotermann, Michelle. "Wired Young Canadians". Canadian Social Trends, 63 Winter (2001) : 4-8.

Scott, Anne. "(In)formning Politics: Processes of Feminist Activism in the Information Age." Women's Studies International Forum. $24.3 / 4(2001): 409-421$.

Scott-Dixon, Krista. "Ezines and Feminist Activism: Building a Community." Resources for Feminist Research. 27.1/2 (1999) : 127-132, 1999.

- - -, "The All-girl On-line Revolution." Herizons. 15, Summer (2001) : 24.

- - -, “Girls Need Modems!: Cyberculture and Women's Ezines. York University, 1998. <www.stumptuous.com/mrp.html>.

Shade, Leslie Regan. "Net Gains: Does Access Equal Equity?" Journal of Information Technology Impact. 1.1 (1999) : 25-42. $<$ http://www.jiti.com/v1n1/shade.pdf >

- - -, "The Digital Divide: From Definitional Stances to Policy Initiatives." Prepared for Department of Canadian Heritage P3: Policy and Program Forum, Ottawa, April 16, 2002a.

- - -, Gender and Community in the Social Construction of the Internet. New York: Peter Lang Publishing, 2002b.

Shade, Leslie Regan and Barbara Crow. Canadian Feminist Perspectives on Digital Technology." Topia: Canadian Journal of Cultural Studies. 11 Spring $2004: 161-176$. 
Signorielli, Nancy. ed. Role Portrayal and Stereotyping on TV: An Annotated Bibliography of Studies Relating to Women, Minorities, Aging, Sexual Behaviour, Health and Handicaps. Wesport, CN: Greenworld Press, 1998. Silver, Cynthia. "Older surfers". Canadian Social Trends, 63 Winter (2001) : 9-12. Skeggs, Beverly, Ed. Feminist Cultural Theory: Process and Production. New York, NY: Manchester University Press, 1995.

Smith, Sidonie. A poetics of women's autobiography: Marginality and the fictions of self-representation. Bloomington : Indiana University Press, 1987.

Soja, Edward W. Thirdspace: Journeys to Los Angeles and Other Real-andImagined Places. Oxford: Blackwell, 1996.

Sommers, Christina Hoff. Who Stole Feminism? How Women Have Betrayed Women. New York: Simon and Schuster, 1994.

Sorapure, Madeleine. "Screening Moments, Scrolling Lives: Diary Writing on the web." Biography, 26.1 (2003) : 1-23.

Sorgatz, Rex. "Girl, Interrupted" Citypages.com, 25.1230, June 29, 2004 <http://www.citypages.com/databank/25/1230/article12271.asp>.

Spender, Dale. Nattering on the Net: Women, Power and Cyberspace. Toronto: Garamond Press, 1996.

Stanton, Donna C. The Female Autography. Chicago: University of Chicago Press, 1984.

Statistics Canada. "General Social Survey: Internet use 2000." The Daily.

Ottawa: Statistics Canada, Monday, March 26, 2001. <http://www.statcan.ca/Daily/English/010326/d010326a.htm>. 
- - -, "Overview: Access to and Use of Information Communication Technology." Ottawa: Statistics Canada, March 2001. <http://www.statcan.ca/english/freepub/56-505-XIE/free.htm>.

- - -, "2001 Census: Analysis Series, Earnings of Canadians: Making a Living in the New Economy." Ottawa: Statistics Canada, March 112003.

$<$ http://www12.statcan.ca/english/census01/Products/Analytic/companion/ earn/pdf/96F0030XIE2001013.pdf > .

- - -, The Changing Profile of Canada's Labour Force. Ottawa:

Statistics Canada, 2003. <http://www12.statcan.ca/english/census01/ Products/Analytic/ companion/mob/contents.cfm>.

- - -, "Employment in Computer and Telecommunications Industries: A Profile." The Daily, Ottawa: Statistics Canada, March 14, 2003.

- - -, Women in Canada: Work Chapter Updates. Ottawa: Statistics Canada, 2003. <http://www.statcan.ca/english/freepub/89F0133XIE/89F 0133XIE02001.pdf>.

Steenbergen, Candis. "Feminism and Young Women: Alive and Well and Still Kicking." Canadian Women's Studies. 20/21, 4/1, (2001) : 6-14.

- - -, "Talkin' ‘bout Whose Generation?" Turbo Chicks: Talking Young Feminisms. Allyson Mitchell, Lisa Bryn Rundle and Lara Karaian, Eds. Toronto: Sumach Press, 2001. 256-272.

Stern, Susannah R. "Virtually Speaking. Girls' Self-Disclosure on the WWW." 
Women's Studies in Communication. 25.2 (2002) : 223-253.

Sutton, Jo and Pollock, Scarlet. "Online Activism for Women's Rights."

CyberPsychology \& Behavior. 3.5 (2000): 699-706.

Takayoshi, P., Huot, E. and Huto, M. "No Boys Allowed: The World Wide Web as

a Clubhouse for girls." Computers and Consumption. 16 (1999) 89-106.

Thomspson, Leah. "The Silencing of Young Women's Voices." Canadian

Women's Studies. 20/21, 4/1, (2001): 136-138.

Travers, Ann. Writing the Public in Cyberspace: Redefining inclusion on the Net.

New York: Garland Publishing, 2000.

Tuchman, Gaye. "Women's Depiction by the Mass Media." Signs.

$4.3(1979): 530$.

Turkle, Sherry. Life on the Screen: Identity in the Age of the Internet.

New York: Simon and Schuster, 1995.

Vaillancourt, C. A Profile of Employment in Computer and Telecommunications

Industries. Ottawa: Statistics Canada, March 2003.

Valiquette, Michelle. ed. Women and the Media: Resources for Analysis and

Action. Toronto: Media Watch, 1993.

Ward, Katie J. "The Cyber-Ethnographic $(R e)$ Construction of Two Feminist

Online Communities." Sociological Research Online. 4.1 (1999).

$<\underline{\text { www. socresonline.org.uk/socresonline/4/1/ward.html> }}$.

Wertheim, Margaret, "The Pearly Gates of Cyberspace: A history of space from

Dante to the Internet. Cyber Reader : Critical writings for the digital era.

Spiller, Neil, Ed. New York : Phaidon Press, 2002. 
Whittier, Nancy. "Political Generations, Micro-Cohorts, and the Transformation of Social Movements." American Sociological Review 62-5 (1997) : 760-778. Winzelberg, Andrew J., Eppstein, Dori, and Eldredge, Kathleen L. "Effectiveness of an Internet-based program for reducing risk factors for eating disorders." Journal of Consulting and Clinical Psychology 68.2 (April 2000) : 346-50.

Wylie, Betty Jane. Reading Between the Lines: The Diaries of Women. Toronto: Key Porter Books Limited, 1995.

Zalis, Elayne. "At Home in Cyberspace: Staging Autobiographical Scenes." Biography 26.1, Winter, 2003. (84-119). 